\title{
SOBERANIA E SEGURANÇA
}

ALIMENTAR EM TEMPOS DE PANDEMIA DA COVID-19

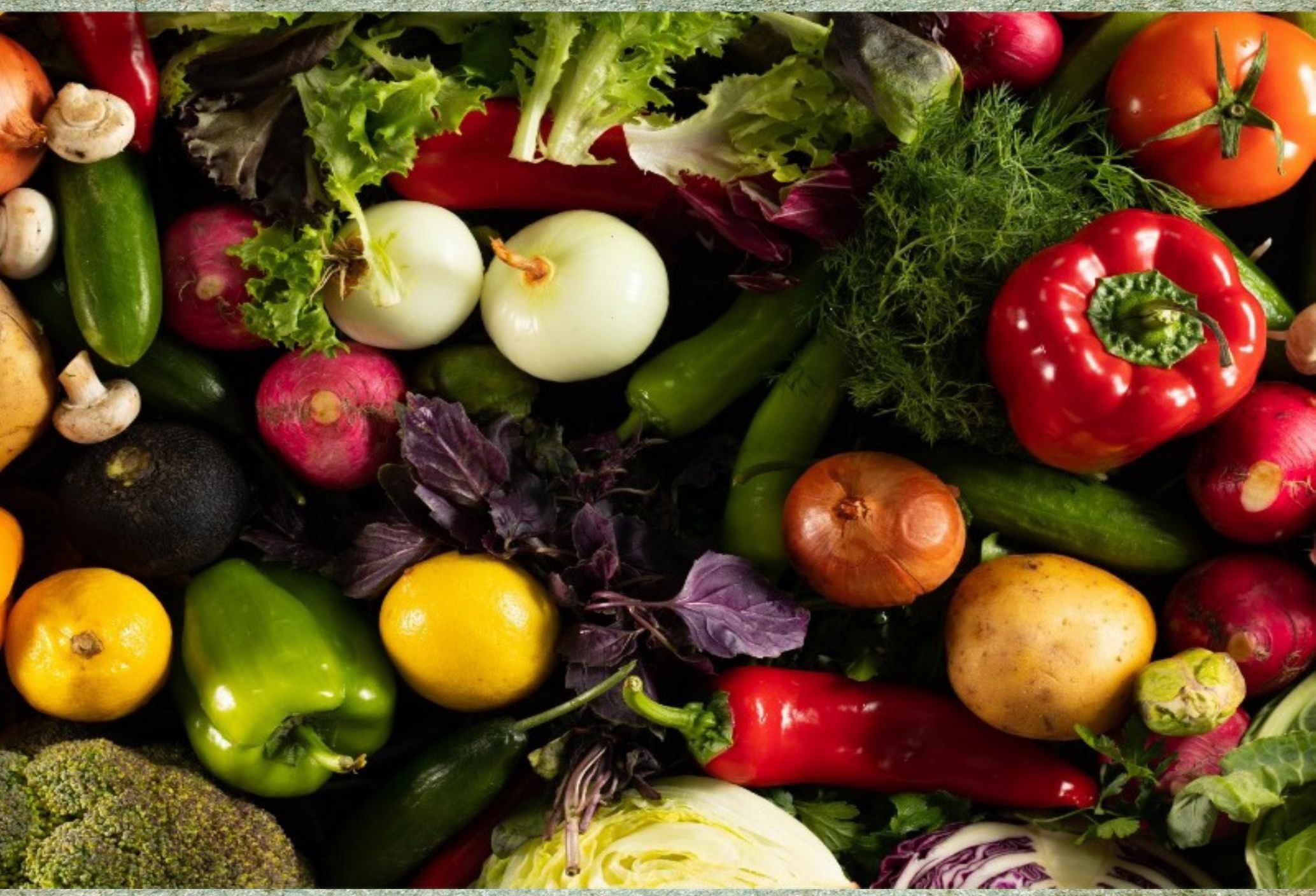

Liziany Müller Alessandra Regina Müller Germani Gisele Martins Guimarães Tatiana Aparecida Balem [Organizadoras]

\section{$A R C O$}




\section{SOBERANIA E SEGURANÇA}

ALIMENTAR EM TEMPOS DE PANDEMIA DA COVID-19

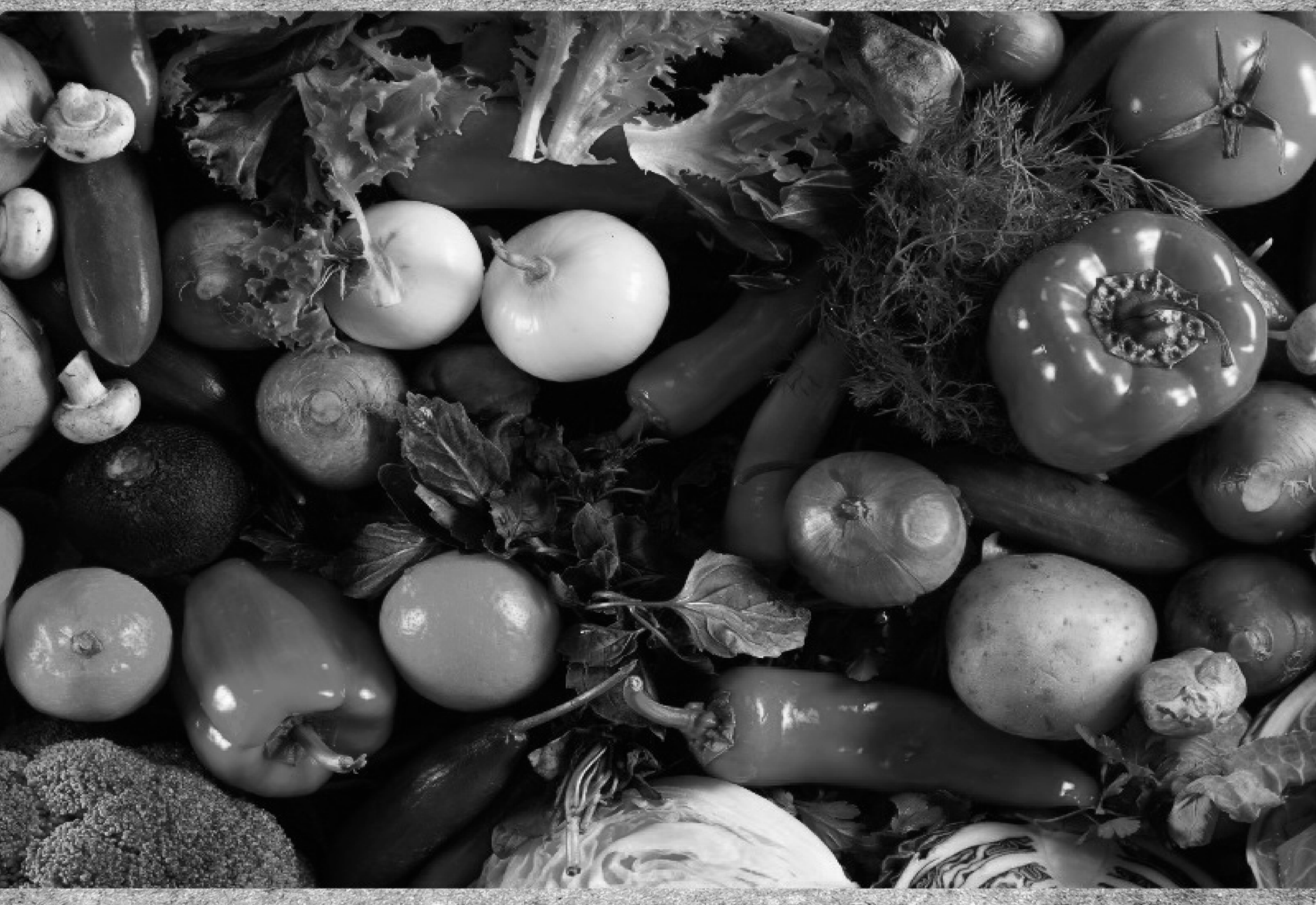

Liziany Müller Alessandra Regina Müller Germani Gisele Martins Guimarães Tatiana Aparecida Balem [Organizadoras] 


\section{CONSELHO EDITORIAL}

Prof. Dr. Adilson Tadeu Basquerot e Silva

UNIDAVI/SC

http://lattes.cnpq.br/8318350738705473

Profa. Msc. Jesica Wendy Beltrán UFCE- Colômbia

http://lattes.cnpq.br/0048679279914457

Profa. Dra Fabiane dos Santos Ramos UFSM- Santa Maria/RS

http://lattes.cnpq.br/0003382878348789

Dr. João Riél Manuel Nunes Vieira de Oliveira Brito

UAL - Lisboa- Portugal.

http://lattes.cnpq.br/1347367542944960

Profa. Dra. Alessandra Regina Müller Germani

UFFS- Passo Fundo/RS

http://lattes.cnpq.br/7956662371295912

Prof. Dr. Everton Bandeira Martins

UFFS - Chapecó/SC

http://lattes.cnpq.br/9818548065077031

Prof. Dr. Erick Kader Callegaro Corrêa UFN- Santa Maria/RS

http://lattes.cnpq.br/2363988112549627

Prof. Dr. Pedro Henrique Witchs UFES - Vitória/ES

http://lattes.cnpq.br/3913436849859138

Prof. Dr.Thiago Ribeiro Rafagnin UFOB

http://lattes.cnpq.br/3377502960363268
Prof. Dr. Mateus Henrique Köhler

UFSM- Santa Maria/RS

http://lattes.cnpq.br/5754140057757003

Profa. Dra. Liziany Müller Medeiros

UFSM- Santa Maria/RS

http://lattes.cnpq.br/1486004582806497

Prof. Dr. Camilo Darsie de Souza

UNISC- Santa Cruz do Sul/RS

http://lattes.cnpq.br/4407126331414

Prof. Dr. Dioni Paulo Pastorio

UFRGS - Porto Alegre/RS

http://lattes.cnpq.br/7823646075456872

Prof. Dr. Leonardo Bigolin Jantsch

UFSM- Palmeira das Missões/RS

http://lattes.cnpq.br/0639803965762459

Prof. Dr. Leandro Antônio dos Santos

UFU- Uberlândia/MG

http://lattes.cnpq.br/4649031713685124

Dr. Rafael Nogueira Furtado

UFJF- Juiz de Fora/MG

http://lattes.cnpq.br/9761786872182217

Profa. Dra. Angelita Zimmermann

UFSM- Santa Maria/RS

http://lattes.cnpq.br/7548796037921237

Profa. Dra. Francielle Benini Agne

Tybusch

UFN - Santa Maria/RS

http://lattes.cnpq.br/4400702817251869

Copyright (c) Arco Editora, alguns direitos reservados.

Copyright do texto (c) 2021 os autores e as autoras.

Copyright da edição (c) 2021 Arco Editora. 
Diagramação e Projeto Gráfico : Gabriel Eldereti Machado imagem capa: $w w w$. pixabay.com

Revisão: dos/as autores/as.

Dados Internacionais de Catalogação na Publicação (CIP) (Câmara Brasileira do Livro, SP, Brasil)

Soberania e segurança alimentar em tempos de pandemia da Covid-19 [1ivro eletrônico] / [organizadoras] Liziany Müller ... [etal.]. -Santa Maria, RS : Arco Editores, 2021. PDF

Outros organizadores: Alessandra Regina Müller Germani, Gisele Martins Guimarães, Tatiana Aparecida Balem

ISBN 978-65-89949-32-9

1. Agricultura e tecnologias relacionadas 2. Agroecologia 3. Alimentação - Imunidade

4. Alimentos 5. Alimentos - Qualidade 6. COVID-19 Pandemia I. Müller, Liziany. II. Germani, Alessandra Regina Müller. III. Guimarães, Gisele Martins.

IV. Balem, Tatiana Aparecida

$21-85613$ CDD-613. 2 Índices para catálogo sistemático:

1. Alimentos - Aspectos da saúde 613.2

Maria Alice Ferreira - Bibliotecária - CRB-8/7964 10.48209/978-65-89949-32-9

O padrão linguístico-gramatical, bem como o sistema de citações e referências bibliográficas são prerrogativas de cada autor. Da mesma maneira, o conteúdo e teor de cada capítulo é de inteira e exclusiva responsabilidade de seu respectivo autor. 


\section{APRESENTAÇÃO}

A obra intitulada: Soberania e segurança alimentar em tempos de pandemia da COVID-19, com organização das professoras e pesquisadoras Liziany Müller, Alessandra Regina Müller Germani, Gisele Martins Guimarães e Tatiana Aparecida Balem. A pandemia da COVID-19 no contexto brasileiro trouxe ainda mais à tona a discrepância de realidades sociais, agravando a situação de acesso a alimentação. Cerca de $55,2 \%^{1}$ dos brasileiros estiveram em situação de insegurança alimentar durante o ano de 2020, onde 116,8 milhões de brasileiros que não tiveram acesso pleno e permanente a alimentos necessários. Desse modo, passamos a apresentação dos capítulos que compõem a obra:

O capítulo: AGRICULTURA FAMILIAR, COVID-19 E NOVAS ESTRATÉGIAS DE COMERCIALIZAÇÃO E CONSUMO NA REGIÃO SUL DO RS de Abel Perinazzo Cassol, Mario Duarte Canever, Letícia Paludo Vargas e Patrícia Martins da Silva, traz a reflexão acerca da centralidade da agricultura familiar em torno do tema da segurança alimentar e produção de alimentos, buscando evidenciar os impactos da pandemia da Covid-19 e as dinâmicas sociais articuladas e fortalecidas na construção de (novas) estratégias de comercialização e consumo.

No capítulo: CONSUMO ALIMENTAR E AQUISIÇÃO DE ALIMENTOS ASSOCIADOS AO ISOLAMENTO SOCIAL NO ENFRENTAMENTO AO COVID-19 de Lya Raquel Mendes da Rocha, Katharina Eduarda Rocha Lima, Letícia Mazza Malta, Suzana Maria Rebêlo Sampaio da Paz, Theonas Gomes Pereira e Carmen Viana Ramos, tratou-se de um estudo do tipo transversal realizado com uma amostra de indivíduos da cidade de Teresina, capital do Piauí. Propôs-se este estudo que teve como objetivo analisar a associação entre o isolamento social, aquisição e processo de higienização dos alimentos e o consumo alimentar.

O capítulo: SEGURANÇA ALIMENTAR E NUTRICIONAL DE AGRICULTORES FAMILIARES NO CONTEXTO DA PANDEMIA DO CORONAVÍRUS, de

1 Disponível em: https://portal.ufpa.br/index.php/ultimas-noticias2/12611-relatorio-aponta-que-52-2-dos-brasileiros-nao-tiveram-acesso-regular-a-alimentos-de-qualidade-durante-a-pandemia-de-covid-19 
Dayane de Castro Morais, Elizangela da Silva Miguel, Sílvia Oliveira Lopes, Jersica Martins Bittencourt, Silvia Eloiza Priore, discute a agricultura familiar é um importante circuito de comercialização, no entanto a pandemia do novo coronavírus (SARS-CoV-2) impôs diversos desafios para os agricultores familiares.

Com o capítulo: SEGURANÇA ALIMENTAR E QUALIDADE AMBIENTAL: UMA PROPOSTA DE UTILIZAÇÃO DA JACA VERDE COMO ALIMENTO de Kathleen Hodgson Weintraub, Camila Gonçalves de Oliveira Rodrigues e Katia Cilene Tabai, o estudo visa explorar um exemplo deste tipo de alimento, a jaca, fruto da árvore jaqueira (Artocarpus heterophyllus Lam.), que cumpre esta função em vários ecossistemas no Brasil.

O capítulo: SEGURANÇA ALIMENTAR E NUTRICIONAL E ALTERAÇÕES NO CONSUMO DE ALIMENTOS DURANTE A PANDEMIA DO CORONAVÍRUS de Dayane de Castro Morais, Elizangela da Silva Miguel, Carina Aparecida Pinto e Silvia Eloiza Priore mostra a discussão da pandemia da Covid-19 e a questão da população que viu sua renda familiar reduzir, em função do crescente desemprego, do isolamento social e do aumento do preço de alimentos e outros serviços essenciais como o gás de cozinha.

No capítulo: CONSUMO DE ARROZ E FEIJÃO POR JOVENS ADULTOS: MUDANÇAS GERADAS PELA PANDEMIA DA COVID-19 de Victória Teixeira Xavier e Cilene da Silva Gomes Ribeiro, o estudo objetivou avaliar possíveis alterações no acesso, preparo e consumo de arroz e feijão entre jovens adultos, durante a pandemia, analisando quais foram as mudanças ocorridas no cotidiano alimentar dos mesmos.

Gabriella Eldereti Machado 


\section{SUMÁRIO}

\section{CAPÍTULO 1}

AGRICULTURA FAMILIAR, COVID-19 E NOVAS ESTRATÉGIAS DE COMERCIALIZAÇÃO E CONSUMO NA REGIÃO SUL DO RS....................

Abel Perinazzo Cassol

Mario Duarte Canever

Letícia Paludo Vargas

Patrícia Martins da Silva

doi: 10.48209/978-65-89949-32-1

\section{CAPÍTULO 2}

CONSUMO ALIMENTAR E AQUISIÇÃO DE ALIMENTOS ASSOCIADOS AO ISOLAMENTO SOCIAL NO ENFRENTAMENTO AO COVID-19

Lya Raquel Mendes da Rocha

Katharina Eduarda Rocha Lima

Letícia Mazza Malta

Suzana Maria Rebêlo Sampaio da Paz

Theonas Gomes Pereira

Carmen Viana Ramos

doi: 10.48209/978-65-89949-32-2

\section{CAPÍTULO 3}

SEGURANÇA ALIMENTAR E NUTRICIONAL DE AGRICULTORES FAMILIARES NO CONTEXTO DA PANDEMIA DO CORONAVÍRUS.........52

Dayane de Castro Morais

Elizangela da Silva Miguel

Sílvia Oliveira Lopes

Jersica Martins Bittencourt

Silvia Eloiza Priore

doi: 10.48209/978-65-89949-32-3 


\section{CAPÍTULO 4}

SEGURANÇA ALIMENTAR E QUALIDADE AMBIENTAL: UMA PROPOSTA DE UTILIZAÇÃO DA JACA VERDE COMO ALIMENTO.......71

Kathleen Hodgson Weintraub

Camila Gonçalves de Oliveira Rodrigues

Katia Cilene Tabai

doi: 10.48209/978-65-89949-32-4

\section{CAPÍTULO 5}

SEGURANÇA ALIMENTAR E NUTRICIONAL E ALTERAÇÕES NO CONSUMO DE ALIMENTOS DURANTE A PANDEMIA DO CORONAVÍRUS

Dayane de Castro Morais

Elizangela da Silva Miguel

Carina Aparecida Pinto

Silvia Eloiza Priore

doi: 10.48209/978-65-89949-32-5

\section{CAPÍTULO 6}

CONSUMO DE ARROZ E FEIJÃO POR JOVENS ADULTOS: MUDANÇAS GERADAS PELA PANDEMIA DA COVID-19.

Victória Teixeira Xavier

Cilene da Silva Gomes Ribeiro

doi: 10.48209/978-65-89949-32-6

SOBRE AS ORGANIZADORAS 


\section{d o $10.48209 / 978-65-89949-32-1$}

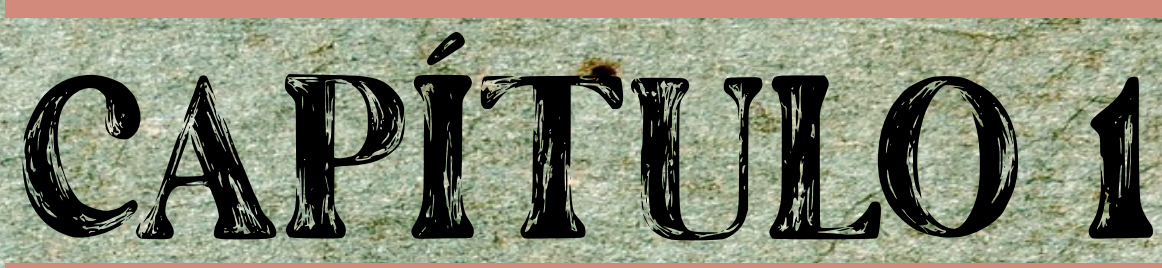

\section{AGRICULTURA \\ $\rightarrow \infty$ FAMILIAR, COVID-19 E NOVAS ESTRATÉGIAS DE COMERCIAHIZAÇÃO E CONSUMO NA REGIÃO SUL DO RS}

Abel Perinazzo Cassol Mario Duarte Canever Letícia Paludo Vargas Patrícia Martins da Silva 


\section{INTRODUÇÃO}

A Covid-19 é a maior pandemia das últimas décadas e trouxe impactos ao sistema agroalimentar pelo fechamento de estabelecimentos, confinamento das pessoas, redução do transporte de pessoas e mercadorias, interrupções do fornecimento de matérias primas para o funcionamento de cadeias produtivas, aumento de desemprego, entre outros (UNITED NATIONS, 2020; NICOLA et al., 2020). Há também evidências que a pandemia aconteceu lado a lado com um período em que a economia mundial já estava em crise (GUNTHER, 2020; FAO et al. 2020), adicionando em mais de 100 milhões os quase 700 milhões de pessoas subnutridas no mundo e interrompendo o ciclo de redução de pobreza global desde 1990 (SUMNER, A.; HOY, C.; ORTIZ-JUAREZ, 2020). Os impactos são sentidos globalmente, mas desproporcionalmente nas localidades, e, em virtude da ampliação das desigualdades sociais, especialmente pelas populações/ países mais vulneráveis.

A Covid-19 é uma zoonose (doença) que é transmitida de outros animais vertebrados para os humanos (PLATTO et al., 2020), possivelmente de morcegos, primeiramente identificados no mercado de perecíveis (wet market) de Wuhan na China. Assim, desde o aparecimento da doença o sistema alimentar tem sido relacionado diretamente com a pandemia (RIVERA-FERRE et al., 2021).

A emergência de uma zoonose é um evento raro que para acontecer requer a facilitação dos mecanismos de transmissão de uma espécie para outra. A degradação ambiental, a aceleração das perdas de biodiversidade, a migração de espécies selvagens de animais e microorganismos são consequências diretas do modelo industrial de alimentação que fragilizam as barreiras que inibem estas transmissões (RIVERA-FERRE et al., 2021). Assim, a produção, o processamento e o consumo de alimentos (o sistema agroalimentar) está intimamente ligado com a crescente emergência de patógenos causadores de doenças nos humanos nas últimas décadas (RIVERA-FERRE, 2021; WALLACE, 2020).

Se o sistema agroalimentar está na origem do aparecimento da Covid-19, ele também tem sido severamente impactado pelo seu surgimento. Os impactos 
ocorreram em nível das cadeias de suprimentos e também na segurança alimentar, especialmente dos grupos populacionais mais vulneráveis. As cadeias de suprimento, especialmente as cadeias longas e globais tiveram impactos maiores pelas restrições no transporte e logística internacional, pelo fechamento de estabelecimentos, principalmente hotéis e restaurantes e por vários impactos diretos ocasionados pelo adoecimento de trabalhadores das empresas agroindustriais (SCHNEIDER et al., 2020; HECK et al., 2020). De outro lado, o acesso, a disponibilidade e o uso de alimentos mundo afora, principalmente em países de baixa e média rendas foi profundamente afetado.

Frente a este contexto, torna-se evidente que o sistema agroalimentar predominante, baseado na produção de commodities, e cuja funcionalidade remete às cadeias longas e globais, alta escala de produção e minimização de custos, demonstrou-se vulnerável frente à magnitude dos desafios alimentares que circundam os dias de hoje. Outrossim, a pandemia da Covid-19 externou a necessidade e a emergência da construção de outros caminhos para a produção e reprodução da vida, incluindo as relações de produção e consumo.

As cadeias agroalimentares curtas e baseadas na produção local (agricultura familiar), embora também tenham sofrido, especialmente pela ruptura dos canais de comercialização como feiras livres e compras governamentais, como o Programa de Aquisição de Alimentos (PAA) e o Programa Nacional de Alimentação Escolar (PNAE), foram muito mais resilientes e responderam melhor à crise da Covid-19. Isto foi observado na Áustria (DARNHOFER, 2020), no Brasil (PREISS et al., 2020), no Canadá (HOBBS, 2020), entre outros países (FAO, 2020).

O objetivo deste capítulo direciona-se à reflexão acerca da centralidade da agricultura familiar em torno do tema da segurança alimentar e produção de alimentos, buscando evidenciar os impactos da pandemia da Covid-19 e as dinâmicas sociais articuladas e fortalecidas na construção de (novas) estratégias de comercialização e consumo. Neste marco, buscar-se-á considerar a abordagem proposta para reflexão, partindo do território da agricultura familiar zona sul do estado do RS. 
Em uma breve caracterização da agricultura familiar no território mencionado, registra-se a diversidade e complexidade em sua constituição e abrangência, incluindo diversas etnias resultantes dos processos de imigração e descendência, assentamentos de reforma agrária, comunidades quilombolas, povos indígenas, pescadores artesanais, dentre outros. Em consequência, a diversidade aparece também como elemento transversal às formas de organização dos processos de trabalho, sistemas de produção, geração de renda e comercialização, destacando-se a presença de um conjunto diversificado de formas de cooperação tais como associações, cooperativas, redes sociotécnicas e outras iniciativas correlacionadas.

Assim sendo, as reflexões propostas para o presente capítulo pretendem expressar os impactos relatados através do diálogo estabelecido com atores sociais relacionados ao público e território ora mencionado, bem como refletir sobre as dinâmicas sociais que se tornaram perceptíveis, relacionadas ao tema da segurança e soberania alimentar. A base desta análise está centrada nos resultados do projeto "Observatório da Problemática da Seca e do Covid-19 na Agricultura Familiar da Região Sul do Rio Grande do Sul", coordenado por docentes e discentes do Departamento de Ciências Sociais Agrárias da Universidade Federal de Pelotas - UFPel.

\section{SEÇÃO 02: A SITUAÇÃO ATUAL DA (IN)SEGURANÇA ALIMENTAR NO PAís, A AGRICULTURA FAMILIAR E A NECESSIDADE DE OUTROS SISTEMAS ALIMENTARES}

A segurança alimentar é certamente uma das dimensões mais relevantes neste novo contexto transformado pela Covid-19. Entender os fatores estressantes que afetam não só a produção, mas também a distribuição de alimentos é agora particularmente crucial. Observa-se que o advento da pandemia desestruturou a oferta de alimentos em todo o mundo, dificultando o acesso a tais produtos por parte das populações. Ainda que esse processo tenha sido heterogêneo e acompanhado por inúmeras estratégias e alternativas que o amenizaram, o fato é que a questão da segurança alimentar e do combate à fome retornaram com força ao debate público, especialmente no Brasil. 
Em termos gerais, segundo a Organização das Nações Unidas para a Alimentação e a Agricultura (FAO et al., 2021), a pandemia levou a aumentos da fome e prejudicou o desenvolvimento para redução de todas as formas de desnutrição no mundo. A nutrição inadequada e a desnutrição foram sentidas mais fortemente entre crianças e adolescentes ao não terem mais a opção da alimentação escolar (UNICEF, 2020).

Especificamente no caso brasileiro, a peculiaridade reside no fato de que o país já experimentava gradual aumento dos índices de insegurança alimentar nos últimos anos, e a pandemia foi um evento que veio a agravar uma situação que já se encontrava ruim (REDE PENSAN, 2021). A desestruturação e o desmantelamento de diversas políticas públicas de desenvolvimento rural, especialmente aquelas voltadas ao abastecimento e à oferta de alimentos ao mercado interno e às compras da agricultura familiar, é um dos principais motivos da piora dos índices alimentares nacionais (PIRAUX; CANIELLO, 2019)1.

Há dois processos concomitantes gerados pela pandemia e que vem afetando o contexto da alimentação e da agricultura no Brasil pandêmico, ambos com efeitos importantes para a segurança e soberania alimentar. O primeiro deles refere-se à diminuição do acesso aos alimentos. Nos últimos anos, o país tem apresentado taxas constantes de desemprego, precarização das relações de trabalho e endividamento crescente de uma parcela significativa de sua população (BRIDI, 2020). Em relação ao emprego, são cerca de 14,8 milhões de brasileiros desempregados e 33 milhões de subocupados. Dentre aqueles com emprego, o número de informais (sem registro em carteira) chega a 34,2 milhões de pessoas, o que representa $39 \%$ dos trabalhadores empregados no país (PNAD, 2021). Esse contexto, que já era grave e se aprofunda com a pandemia², tem impactos

1 Desde 2016 o Brasil tem experimentado a conjugação de crise política e econômica, as quais tiveram como resultado o enfraquecimento de políticas e programas voltados à diminuição das desigualdades sociais, sob a justificativa da austeridade fiscal (SILVA, 2018); e o enfraquecimento institucional dos programas e conselhos voltados à alimentação (extinção do Ministério do Desenvolvimento Agrário; diminuição drástica de recursos do PAA e do PNAE; extinção do Conselho Nacional de Segurança Alimentar e Nutricional). Esse processo tem dificultado o acesso alimentar da população pobre brasileira (ALPINO et al., 2020).

2 Apenas para citar o impacto da pandemia nas taxas de desemprego, no início de 2020 era $11,2 \%$ da população economicamente ativa desempregada. Os dados de julho de 2021 apontam para um total de $14,7 \%$ de desempregados (PNAD, 2021). 
diretos nos índices de segurança alimentar dos brasileiros, uma vez que a perda ou a instabilidade na renda das famílias repercute na quantidade e na qualidade de sua alimentação (REDE PENSAN, 2021).

Concomitante a perda de renda das famílias, o aumento dos preços dos alimentos é outro fator relacionado e que tem impactado diretamente na alimentação. O sistema agroalimentar predominante no território brasileiro, conhecido como agronegócio, caracteriza-se pela produção em larga escala de commodities agrícolas voltadas à exportação, o que tem gradualmente diminuído o acesso diversificado aos alimentos no país (BELIK, 2020). As dificuldades logísticas das cadeias de valor durante a pandemia - tais como as de produção animal - aliada a desvalorização cambial da moeda nacional e ao crescimento da área produzida de commodities, tem levado ao aumento dos preços de itens básicos da alimentação brasileira. O tradicional "prato feito" (carne, feijão, arroz, ovo, batata frita e salada) teve aumento de $23 \%$ no último ano, com destaque para os aumentos de $61 \%$ nos preços do arroz, $69 \%$ do feijão preto e $27,2 \%$ da carne bovina (CNN BRASIL, 2021).

Esse processo, aliado ao desemprego, tem levado a população em geral a modificar seus hábitos alimentares, substituindo o consumo de alimentos saudáveis e frescos por dietas mais processadas e convenientes, o que resulta em efeitos concretos sobre a (in)segurança alimentar (HOBBS, 2020; NICOLA et al., 2020).

Dados recentemente publicados pela Rede Brasileira de Pesquisa em Soberania e Segurança Alimentar e Nutricional (REDE PENSAN, 2021) confirmam tais constatações. De acordo com o estudo, o Brasil tem experimentado nos últimos seis anos um aumento gradual e constante nos índices de insegurança alimentar. Somente no período entre 2018-2020, a insegurança alimentar grave cresceu em torno de $27,6 \%$ ao ano, o que fez com que seus índices retornassem aos patamares de 2004 (REDE PENSAN, 2021; SALLES COSTA et al., 2020). 3 Os níveis de (In)segurança alimentar no país são medidos através da Escala Brasileira de Insegurança Alimentar (EBIA), que classifica essa situação, a partir de diferentes indicadores: Segurança Alimentar: não há problema de acesso aos alimentos em termos qualitativos ou quantitativos, nem preocupação que venham a faltar; Insegurança Alimentar (IA) Leve: preocupação com falta de alimentos no futuro próximo e arranjos domésticos para que os alimentos durem mais; IA Moderada: comprometimento da qualidade da alimentação para manter a quantidade necessária; IA Grave (fome): restrição da quantidade de alimentos, levando à situação de fome (adultos e crianças). 
Pode-se afirmar que o país retrocedeu 15 anos em 5, voltando a ter a fome como um problema estrutural a partir de 2016, já que havia saído do mapa da fome da ONU em 2014 (REDE PENSAN, 2021).

Atualmente, estima-se que o número de domicílios brasileiros em situação de fome é de $9 \%$, o que representa em torno de 19 milhões de pessoas. Se somados àqueles com insegurança alimentar moderada, o total de domicílios alcança $20,5 \%$ do total (quase 44 milhões de brasileiros) (REDE PENSAN, 2021, p. 37). Entre a população rural, esses números são ainda mais graves. De acordo com o mesmo estudo, $26,9 \%$ dos domicílios rurais experimentam situação de insegurança alimentar moderada ou grave. Aqueles em situação de fome (IA grave) representam $12 \%$ do total. Dentre aqueles estabelecimentos rurais que tem como principal atividade econômica a agricultura familiar, 35,7\% estão em situação de insegurança alimentar moderada ou grave (IBIDEM, 2021). Já entre os domicílios rurais com dificuldades de acesso à água, esses índices quase dobram (IBIDEM, 2021).

O segundo processo relacionado à pandemia e com importantes efeitos sobre a segurança alimentar e nutricional dos brasileiros refere-se às dificuldades de oferta e redução dos preços pagos aos agricultores por alguns alimentos. Se o desemprego e os preços inflacionados dos alimentos têm afetado os consumidores, as dificuldades de acesso aos mercados e a diminuição dos preços recebidos por alguns produtos tem impactado na segurança alimentar dos agricultores.

Uma das principais consequências da pandemia foi a interrupção ou alteração no funcionamento de diversos mercados alimentares locais, especialmente aqueles mais acessados pela população de baixa renda, tais como as feiras livres e feiras do produtor (SCHNEIDER et al., 2020). Juntamente com a suspensão das aulas e da oferta de merenda aos escolares em algumas cidades, evidenciou-se uma redução da oferta de alimentos frescos e saudáveis no decorrer da pandemia. Além de impactar na qualidade dos alimentos consumidos, essa restrição de acesso aos mercados teve efeitos importantes na renda dos agricultores familiares (SCHNEIDER et al., 2020; BID, 2020). 
Em relação aos preços pagos pelos produtos, há pesquisas apontando para uma diminuição dos valores recebidos pelos produtores, os quais têm relatado dificuldades de manutenção dos preços frente à pandemia (BID, 2020). Esse processo tem levado a perda significativa de receita entre os agricultores familiares. Estudo de Del Grossi (2020) para o ano passado estimou uma perda média de $35 \%$ da renda bruta familiar tradicionalmente auferida pelos agricultores familiares brasileiros, e metade deles relatou alguma diminuição de renda em julho de 2020. Essa conjugação entre dificuldades de oferta e acesso aos mercados e problemas de manutenção das rendas agrícolas, tem reverberado na piora dos índices de segurança alimentar e nutricional e no aumento da população em situação de fome.

Conforme dito acima, a grande constatação da situação atual de insegurança alimentar no país decorre do fato de que a volta da fome não é resultante exclusivo do surto pandêmico, mas de uma série de crises e problemas estruturais que já atravessavam o país antes da pandemia. A esses problemas veio a se somar a pandemia, agravando ainda mais a situação de acesso e distribuição dos alimentos.

O peso da pandemia, contudo, também tem sido estimado sobre a situação de segurança alimentar dos brasileiros. Pesquisa do Grupo Justiça por Comida estimou em $59 \%$ o total de domicílios em situação de insegurança alimentar atualmente (GALINDO et al., 2021). Ou seja, de cada dez domicílios, seis encontram-se com alguma dificuldade em acessar e consumir alimentos tradicionalmente acessados. Dentre as principais transformações na alimentação decorrentes da pandemia, o estudo cita a diminuição do consumo regular de carnes e de frutas e verduras, os quais tiveram uma diminuição para $44 \%$ e $41 \%$ dos domicílios entrevistados, respectivamente (GALINDO et al., 2021).

Esses dados deixam claras as relações entre os sistemas alimentares, a segurança alimentar e a pandemia da Covid-19. Se, por um lado, os sistemas industriais de produção, distribuição e consumo são personagens principais da 
disseminação de vírus e patógenos globais e da situação atual de acesso aos alimentos no Brasil, por outro a sua necessária transformação poderá resultar em uma série de benefícios em distintas dimensões (sociais; ambientais; econômicas; sanitárias).

Há na literatura nacional e internacional uma série de estudos e pesquisas reivindicativos da necessidade de outros sistemas alimentares que superem o modelo industrial e sua padronização alimentar. Baseados em escalas territoriais, na diversificação da base produtiva por meio da adoção de práticas ecológicas e no encurtamento das distâncias entre produtores e consumidores, esses estudos têm compilado uma série de evidências que demonstram a viabilidade de sistemas alimentares sustentáveis (GAZOLLA; SCHNEIDER, 2017; MALUF; LUZ, 2018; NIEDERLE; WESZ Jr., 2018; BERDEGUÉ; FAVARETO, 2019; MORAGUES-FAUS et al., 2020). Nesse contexto, o papel e o potencial da agricultura familiar são vistos como essenciais, seja na oferta de alimentos locais e saudáveis, seja na sua capacidade de adotar práticas e sistemas produtivos sustentáveis, contribuindo para a segurança alimentar e para o meio ambiente (PERAFÁN; SCHNEIDER, 2019; CASSOL; VARGAS; CANEVER, 2020).

Esse potencial tornou-se evidente com o advento da pandemia, na medida em que diversos agricultores familiares e suas organizações construíram novas estratégias de comercialização dos seus produtos, resultando em uma "reinvenção" dos seus mercados a partir da novidade do uso de sites e plataformas digitais de oferta de alimentos (GAZOLLA; AQUINO, 2021). Apesar de recente, essas novas dinâmicas de distribuição e acesso aos alimentos têm contribuído para amenizar as dificuldades apresentadas pelo contexto atual, reverberando a potencialidade e a viabilidade de sistemas alimentares sustentáveis.

Conforme apresentamos a seguir, no território da zona sul do Rio Grande do Sul, os atores da agricultura familiar também têm se mobilizado para construir alternativas de comercialização e consumo dos seus produtos no contexto da pandemia. Tais ações têm gerado novas práticas e processos em torno dos sistemas alimentares territoriais e da segurança alimentar e nutricional da população 
local.

\section{SEÇÃO O3: COMERCIALIZAÇÃO E CONSUMO NA AGRICULTURA FAMILIAR DA REGIÃO SUL DO RIO GRANDE DO SUL}

Existe cerca de 17,5 mil propriedades agrícolas na microrregião de Pelotas - RS, $83,7 \%$ das quais classificadas como pertencentes a agricultores familiares com área média de 18 hectares, ocupando cerca de 2,7 pessoas por propriedade (IBGE 2017). Estes agricultores familiares produzem uma ampla diversidade de alimentos, como raízes e tubérculos (batatas, mandioca), cereais (arroz, milho), leguminosas (feijões), folhosas, frutas, mel, leite, carne, entre outros, que atinge o mercado através de feiras, cooperativas e agroindústrias, programas governamentais, varejo alimentar e vendas diretas. Em março de 2020 , por ocasião do aparecimento da Covid-19, estes produtores já vinham sofrendo os impactos de uma seca que perdurava por vários meses, e a chegada da pandemia veio agravar a situação. Especialmente, esse agravamento deu-se pela desestruturação dos canais de comercialização, principalmente àqueles vinculados aos programas governamentais (PNAE e PAA), mas também com a redução/eliminação das vendas para canais tradicionais da agricultura familiar, como minimercados, hotéis, restaurantes e padarias, assim como a interrupção temporária das feiras agroecológicas na região (UFPEL, 2020).

A despeito da importância dos impactos ao nível da produção, especialmente sobre os agricultores familiares, o foco do presente artigo é a comercialização e o consumo de alimentos. Serão analisadas e descritas as mudanças protagonizadas por produtores e consumidores para garantirem o alimento a partir da emergência da Covid-19 na zona sul do Rio Grande do Sul. O ponto de partida da reflexão está centrado nos resultados do projeto "Observatório da Problemática da Seca e do Covid-19 na Agricultura Familiar da Região Sul do Rio Grande do Sul", coordenado por docentes e discentes do Departamento de Ciências Sociais Agrárias da UFPel. Um dos objetivos do projeto foi construir um observatório da produção e do consumo de alimentos frente à pandemia, o qual evidenciou a 
rápida transformação da realidade social por ela imposta, principalmente a partir de abril até agosto de $2020^{4}$.

Como mencionado anteriormente, imediatamente após a chegada do novo coronavírus, mercados e feiras locais de abastecimento foram suspensos ou tiveram seu funcionamento reduzido. Observou-se também a ruptura de canais de comercialização para restaurantes e outros estabelecimentos tradicionais demandantes da agricultura familiar, o que impactou no acesso dos alimentos aos consumidores urbanos e também na garantia da sustentação econômica das famílias de agricultores familiares, produzindo efeitos significativos na segurança alimentar e nutricional do território. Adicionalmente, a suspensão do calendário de aulas (escolas municipais, estaduais e na UFPel), interrompendo a execução do PAA e PNAE contribuiu para que as vendas da agricultura familiar no território reduzissem em cerca de cinquenta por cento, conforme dados coletados no observatório (CASSOL; VARGAS; CANEVER, 2020).

Com o passar do tempo houve a retomada dos mercados locais, especialmente as feiras da agricultura familiar e agroecológicas, mas também o retorno do funcionamento dos restaurantes, padarias e bares. Obviamente, o número de consumidores destes canais de acesso à alimentação se mantinha abaixo do normal. A preocupação com a saúde principalmente no início da pandemia e o receio de ser contaminado pelo novo coronavírus diminuíram as compras presenciais de alimentos, exceto nos supermercados e hipermercados. Esse foi um fenômeno observado mundialmente (RIVERA-FERRE et al., 2021) e também na Zona Sul do Estado RS.

Ainda em abril de 2020, o MEC através da Resolução 02/2020 autorizou excepcionalmente a distribuição de gêneros alimentícios às famílias dos estudantes. Isto foi feito via PNAE, mas seus efeitos foram discretos. O governo do estado do RS na esteira da crise de alimentação optou por adquirir tais produtos de grandes redes atacadistas, não cumprindo a lei que determina a compra

$4 \quad$ Ao longo do projeto foram realizadas 21 entrevistas com agricultores familiares, extensionistas rurais, movimentos sociais, secretários de agricultura e prefeitos dos municípios, consumidores e outros atores envolvidos com a agricultura familiar da Região Sul do Rio Grande do Sul. 
de pelo menos $30 \%$ da alimentação escolar da agricultura familiar local, o que manteve esse mercado restrito no território da zona sul ${ }^{5}$. Por outro lado, a UFPel articulou com a Emater/RS o reinício das compras da agricultura familiar para o fornecimento de alguns kits de alimentos a serem distribuídos aos alunos bolsistas de baixa renda.

Com o impacto inicial da crise gerada pelo fechamento dos canais tradicionais, agentes, como gestores de agroindústrias familiares e coloniais, e jovens agricultores familiares iniciaram um movimento em direção a oferta de alimentos via plataformas digitais. Com o uso de ferramentas como Facebook, Instagram e grupos de WhatsApp, iniciando entregas diretas nos domicílios dos consumidores. Primeiramente estes agentes coletavam os alimentos (frutas, verduras, embutidos, etc), que tanto podiam ser produzidos por eles próprios ou por outros agricultores participantes do projeto, para depois compor as cestas e distribuírem entre os clientes cadastrados na plataforma. Este foi o caso observado na Associação dos Produtores Agroecológicos da Região Sul (Arpa-Sul). De acordo com uma das agricultoras entrevistadas,

A Associação está comercializando também via entrega domiciliar. Encomendas são realizadas diretamente por WhatsApp e distribuídas para os grupos dos associados. Entregas realizadas no sábado em horário simultâneo à feira da Dom Joaquim. Esta via de comercialização tem sido relevante em volume e valor comercializado, levando ao debate em torná-lo permanente em período posterior. (...) [apesar de] uma pequena queda nas compras na feira (...) [houve] aumento nas entregas à domicílio. (Agricultora agroecológica, integrante da Arpa-Sul. Entrevista realizada em 14/05/20).

Outras iniciativas de comércio online foram aparecendo, como: (01) a Feira Virtual da Agricultura Familiar criada pela EMATER/RS, a qual visava conectar consumidores aos agricultores da região que realizam entregas domiciliares; (02) a Cooperativa Sul Ecológica, que contava com agricultores agroecológicos, e criou um sistema de pedidos via WhatsApp, estabelecendo parceria com a 220 Bike, para entrega dos seus produtos diretamente aos clientes; (03) a agroindús-

$5 \quad$ Diversas matérias e movimentos sociais denunciaram à época o uso da referida resolução por parte do governo gaúcho, estimando um gasto de cerca de $\mathrm{R} \$ 23$ milhões na compra de alimentos ultraprocessados e com baixo valor nutricional, destinados aos escolares (CONTRAF, 2020). 
tria familiar Aura Verde Alimentos que juntamente com a Cooperativa dos Produtores Agrícolas do Monte Bonito (Coopamb), a Cooperativa Agropecuária de Arroio do Padre (Coopap) e a Cooperativa Sul Ecológica, criou a Feira em Casa, que funciona através da oferta de uma "caixa de assinatura" de cestas de produtos da agricultura familiar convencionais e/ou orgânicos.

Sumariamente, a oferta de alimentos durante este período de pandemia passou por pelos menos três diferentes fases (Quadro 1). A primeira fase foi de "Fechamento", onde houve dificuldades para os agricultores colocarem seus produtos no mercado, redução de contratos públicos (devido, por exemplo, ao fechamento de escolas) ou o encerramento de canais de comercialização de restaurantes, padarias, hotéis, entre outros. Embora as interrupções e rupturas nas cadeias alimentares pudessem resultar em produtos agrícolas não vendidos e em perdas de alimentos - principalmente produtos perecíveis (hortaliças, frutas, leite, frango), na região não houve relatos de que tenha havido desperdícios de alimentos. A segunda fase foi de "Retomada", onde as feiras voltaram a funcionar e as compras públicas sinalizaram que poderiam permanecer ativas. Neste momento foi quando surgiram as iniciativas de venda online. A terceira fase, a qual denominamos de "Reacomodação", pode ser descrita como a nova realidade atualmente vivenciada. Essa fase tem sido caracterizada por um processo concomitante de diminuição da demanda "presencial" de produtos da agricultura familiar nos mercados tradicionais (feiras, mercados institucionais e programas governamentais principalmente), do menor poder de compra dos consumidores e do aumento dos custos de produção; mas também de alguma estabilidade - e em alguns casos crescimento - da demanda por produtos através de mercados digitais tais como os descritos acima. Ou seja, a situação atual da oferta e do consumo de alimentos da agricultura familiar no território da região sul apresenta-se como um momento de transição na qual as incipientes estratégias de comercialização surgidas na pandemia estão tentando se consolidar e reproduzir simultaneamente à retomada dos canais tradicionalmente acessados. 
Quadro 1 - As diferentes fases da oferta de alimentos da agricultura familiar no Sul do Rio Grande do Sul

\begin{tabular}{|c|c|c|}
\hline $\begin{array}{c}1^{\mathrm{a}} \text { Fase } \\
\text { Fechamento }\end{array}$ & $\begin{array}{c}2^{\mathrm{a}} \text { Fase } \\
\text { Retomada }\end{array}$ & $\begin{array}{c}3^{a} \text { Fase } \\
\text { Reacomodação }\end{array}$ \\
\hline $\begin{array}{l}\text { - Desabastecimento } \\
\text { - Bloqueios } \\
\text { - Redução de } \\
\text { demanda }\end{array}$ & $\begin{array}{l}\text { - Volta das feiras } \\
\text { - Retorno lento das } \\
\text { compras públicas } \\
\text { - Venda online }\end{array}$ & $\begin{array}{l}\text { - } \text { Menor demanda } \\
\text { mercados/projetos } \\
\text { institucionais } \\
\text { - } \\
\text { Adaptação aos novos } \\
\text { canais } \\
\text { - }\end{array}$ \\
\hline
\end{tabular}

Fonte: Elaborado pelos autores (2021) a partir de dados do Observatório (2020).

Do mesmo modo, a segurança alimentar também foi impactada pelo lado da demanda. Em relação aos hábitos de consumo alimentar, são visíveis algumas transformações geradas no período analisado, notadamente em virtude do distanciamento social e das restrições impostas pelo novo coronavírus. Inicialmente, observou-se um momento de "pânico", onde muitos fizeram estoques de alimentos em casa. Nesta fase, houve crescimento do consumo de alimentos preparados em casa (Quadro 2).

O momento de pânico na região sul foi relativamente curto e a segunda fase surgiu após algumas semanas com o aumento da confiança e com "transformações nos hábitos de consumo". Essas transformações diferiram de acordo com a renda auferida pelas famílias. Consumidoras de classe média entrevistadas relataram aumentos do consumo de produtos frescos, pois passaram a ter maior tempo em casa, o que possibilitava a preparação (cocção) do alimento e maior preocupação com a saúde. Para estes consumidores verificou-se diminuição da frequência de compras em feiras em favor da aquisição de alimentos em pequenos mercados de bairro (fruteiras e mercearias), e um crescimento do aumento do consumo de produtos não perecíveis adquiridos em supermercados. Foi neste estrato da população que se observou maior aderência às compras virtuais, tanto da agricultura familiar, quanto de outros serviços. 
Uma consumidora entrevistada, quando indagada sobre as mudanças nos seus hábitos de consumo em virtude da pandemia, destacou que

Sim [modifiquei meus hábitos]. Até por que a gente acaba comendo só em casa, comemos melhor...e sabendo o que está comendo. Em termos de variedade houve um prejuízo...mas no saldo, estamos comendo de forma mais saudável. (Consumidora, servidora pública. Entrevista realizada em 29/04/20).

Diferentemente, entre as famílias com menor poder aquisitivo, os dados demonstraram aumentos do consumo de produtos ultraprocessados e não perecíveis, adquiridos principalmente em grandes mercados atacadistas. Essas escoIhas decorrem da brusca diminuição da renda nesse estrato da população, que encontrava nos grandes supermercados a oferta de promoções e preços baixos. Igualmente, houve relatos de diminuição da frequência de compra em feiras locais por parte desse grupo. Entrevistados afirmaram dificuldades em manter o consumo de quantidades adequadas de alimentos, especialmente feijão e arroz, mas também frutas, legumes, verduras e carnes, em razão de preços crescentes.

Conforme consumidora entrevistada,

Diminui (o acesso aos alimentos) por que subiu o preço. Não estamos encontrando mais alguns produtos, tipo arroz, feijão, lentilha... parece que está diminuindo. Eu achei que subiu bastante [os preços]. Por isso só vou comprar uma vez a cada semana/quinze dias. Compro bastante. Aumentou bastante, principalmente aqui na volta...nos minimercadinhos aqui da volta está tudo caro. (Consumidora, diarista. Entrevista realizada em 05/05/20).

Esses fatos demonstrados na pesquisa evidenciam o crescimento da insegurança alimentar no Brasil durante a pandemia da Covid-19. As razões para os aumentos de preços foram obviamente conectados com a pandemia. Ainda que, deve-se registrar o surgimento do auxílio emergencial do governo federal, o qual injetou na economia $\mathrm{R} \$ 322$ bilhões ao longo dos meses restantes de $2020^{6}$. Os aumentos de preços foram mais sentidos nos supermercados e menos nas feiras livres. Ou seja, esse processo atingiu mais profundamente a população pobre. Neste momento da crise, ainda perdurou a diminuição expressiva das refeições 6 Informação obtida em https://www.tesourotransparente.gov.br/visualizacao/painel-de-monitoram entos-dos-gastos-com-covid-19. Acesso em 06/09/2021. 
fora do lar, em restaurantes e padarias, por exemplo. Portanto, verifica-se como o consumo das famílias tem se transformado em decorrência dos efeitos gerados pela pandemia.

Quadro 2 - As diferentes fases da demanda de alimentos pela população do Sul do Rio Grande do Sul

\begin{tabular}{|c|c|c|}
\hline $\begin{array}{l}1^{\text {a }} \text { Fase } \\
\text { Pânico }\end{array}$ & $\begin{array}{c}2^{\mathrm{a}} \text { Fase } \\
\text { Mudança de hábitos }\end{array}$ & $\begin{array}{c}3^{\mathrm{a}} \text { Fase } \\
\text { Reacomodação } \\
\text { parcial }\end{array}$ \\
\hline $\begin{array}{l}\text { - Estoques de não } \\
\text { perecíveis } \\
\text { - Preparo dos } \\
\text { alimentos em casa } \\
\text { - Redução drástica } \\
\text { do consumo fora } \\
\text { do lar }\end{array}$ & $\begin{array}{l}\text { - Preocupação com saúde } \\
\text { (alimentos frescos) } \\
\text { - Redução da frequência de } \\
\text { compras } \\
\text { - Compras virtuais } \\
\text { - Aumento de ultraprocessa- } \\
\text { dos } \\
\text { - Compras em supermerca- } \\
\text { dos e atacadistas }\end{array}$ & $\begin{array}{l}\text { - Aprofundamento da } \\
\text { crise } \\
\text { - Insegurança alimentar } \\
\text { - Fim do auxílio } \\
\text { emergencial } \\
\text { - Diminuição da renda }\end{array}$ \\
\hline
\end{tabular}

Fonte: Elaborado pelos autores (2021) a partir de dados do Observatório (2020).

O terceiro momento é uma continuidade do segundo estágio, mas com o aprofundamento da crise alimentar provocada pela perda do poder de compra de alimentos. Nominamos esta fase de "Reacomodação parcial" em razão das dificuldades de garantir um padrão alimentar para a população no presente e no futuro próximo, similar àquele observado anteriormente à pandemia. Esta etapa está só no começo e deve se aprofundar com o término do auxílio emergencial em fins de 2021 e com as projeções de manutenção da inflação dos preços dos alimentos. Portanto, especialmente entre a população de baixa renda, a tendência futura é um agravamento da perda da renda familiar que resultarão em maiores dificuldades de acesso aos alimentos, o que deve aumentar os índices de insegurança alimentar no território da zona sul e no país como um todo. 


\section{CONSIDERAÇÕES FINAIS}

A discussão acima evidencia a gravidade do contexto atual de acesso e consumo de alimentos enfrentados pela população brasileira nos últimos anos. Às recorrentes crises econômicas e à instabilidade política somou-se a emergência da pandemia, com efeitos catastróficos nos índices de segurança alimentar e nutricional do país.

Contudo, apesar da gravidade do momento, é possível identificar o surgimento de inúmeras iniciativas e experiências coletivas de construção de novas estratégias e dinâmicas de oferta de alimentos. Especialmente, esses processos são evidentes nos sistemas alimentares locais, baseados na agricultura familiar e seus diferentes atores, conforme apresentamos no decorrer do artigo. A emergência da Covid-19 trouxe graves consequências para o sistema alimentar convencional e a segurança alimentar, mas, por outro lado, tem ajudado a reposicionar a centralidade do papel da alimentação e dos sistemas alimentares locais na agenda nacional.

O surto da Covid-19 evidenciou a necessidade de se estabelecer novos mecanismos de governança envolvendo as autoridades públicas, os cidadãos, os canais tradicionais de comercialização de alimentos, as cooperativas e os agricultores para a conceituação e desenho de novos modelos de suprimento de alimentos que gerem mais benefícios sociais, econômicos e ambientais. Nesta perspectiva é preconizada a importância do relacionamento entre produtores e consumidores (a exemplo do que ocorreu nas iniciativas construídas durante a pandemia na zona Sul do Rio Grande do Sul), a promoção da solidariedade e de ações coletivas para a consolidação de sistemas alimentares mais resilientes.

No caso da zona sul do Rio Grande do Sul, muitos consumidores mudaram seus hábitos. Dentre as classes mais favorecidas, houve uma melhora da qualidade da dieta alimentar a partir da preparação das refeições em casa e da escoIha por alimentos mais frescos e saudáveis. Por outro lado, a pandemia atingiu de maneira mais expressiva a população vulnerável, determinando um incremento 
às compras em hipermercados e o consumo de alimentos ultraprocessados, e diminuindo, para além do acesso, também a qualidade nutricional da sua alimentação.

Contudo, apesar da desigualdade evidente no acesso aos alimentos e suas implicações em termos da garantia da segurança alimentar e nutricional, a pandemia pode constituir-se em uma alavanca para um sistema alimentar mais seguro e sustentável que possa estar mais preparado para situações de crise. Para tanto, os desafios do porvir requererão que os aprendizados da Covid-19 não sejam esquecidos.

\section{REFERÊNCIAS}

BANCO INTERAMERICANO DE DESARROLLO - BID. Retos para la agricultura familiar en el contexto del Covid-19: evidencia de productores en ALC. Washington: BID, 2020.

BELIK, W. Estudo sobre a cadeia de alimentos. Imaflora, Outubro de 2020.

BERDEGUÉ, J; FAVARETO, A. Desarrollo Territorial Rural en América Latina y el Caribe. 2030 - Alimentación, agricultura y desarrollo rural en América Latina y el Caribe, No. 32. Santiago de Chile. FAO. 18 p. 2019.

BRIDI, M.A. A pandemia Covid-19: crise e deterioração do mercado de trabalho no Brasil. Estudos Avançados, São Paulo, v. 34, n. 100, p. 141-165, 2020.

CASSOL, A.; VARGAS, L.; CANEVER, M. Desenvolvimento territorial, Covid-19 e as novas estratégias de produção, comercialização e consumo de alimentos da agricultura familiar da região sul do Rio Grande do Sul. Revista Brasileira de Gestão e Desenvolvimento Regional. G\&DR. V. 16, N. 4, P. 388-401, dez/2020 (Ed. Especial).

CNN BRASIL. Arroz e feijão sobem $60 \%$ em um ano e prato feito fica $23 \%$ mais caro, diz FGV. 2021. Disponível em: <https://www.cnnbrasil.com.br/business/arroz-e-feijao-sobem-60-em-um-ano-e-prato-feito-fica-23-mais-caro-diz-fgv/>. Acesso em 20 ago 2021. 
CONTRAF BRASIL. Em plena pandemia, Governo desconsidera produção da Agricultura Familiar e faz compras de alimentos de atacadistas. 2020. Disponível em: <https://contrafbrasil.org.br/noticias/em-plena-pandemia-governo-desconsidera-producao-da-agricultura-familiar-e-faz-co-0e1e/>. Acesso em 05 jul 2021.

DARNHOFER, I. Farm resilience in the face of the unexpected: lessons from the COVID-19 pandemic. 2020.Agric. Hum. Values. https://doi.org/10.1007/ s10460-020- 10053-5.

DEL GROSSI, M. Efeitos crise Covid: análise nacional e agricultura familiar. Centro de Gestão da Agricultura Familiar e Inovação, CEGAFI/UnB. Informativo julho 2020

FAO, COVID-19 and the role of local food production in building more resilient local food systems. 2020. (Police Brief). FAO, Rome. https://doi.org/10.4060/ cb1020en

FAO. Cities and local governments at the forefront in building inlusive and resilient food systems: key results from the FAO survey "Urban food systems and Covid-19". Roma: FAO, 2020b.

FAO, IFAD, UNICEF, WFP and WHO. The State of Food Security and Nutrition in the World 2021. Transforming food systems for food security, improved nutrition and affordable healthy diets for all. Rome, 2021.FAO. https://doi. org/10.4060/cb4474en

GALINDO, E; TEIXEIRA, M.A; De ARAÚJO, M; MOTTA, R; PESSOA, M; MENDES, L; RENNÓ, L. Efeitos da pandemia na alimentação e na situação da segurança alimentar no Brasil. Food for Justice Working Paper Series, no. 4. Berlin: Food for Justice: Power, Politics, and Food Inequalities in a Bioeconomy, 2021. DOI 10.17169/refubium-29554

GAZZOLA, M; SCHNEIDER, S (Orgs). Cadeias curtas e redes agroalimentares alternativas: negócios e mercados da agricultura familiar. Porto Alegre, Ed. UFRGS, 2017.

GAZOLLA, M; AQUINO, J.R. Reinvenção dos mercados da agricultura familiar no Brasil: a novidade dos sites e plataformas digitais de comercialização em tempos de Covid-19. Estudos Sociedade e Agricultura. 29 (2) • 427-460 - jun. a set. 2021. https://doi.org/10.36920/esa-v29n2-8 
GUNTHER, A., COVID-19: fight or flight. Agric. Hum. Values 37, 591-592. 2020. https:// doi.org/10.1007/s10460-02010101-0.

HECK, F.; JÚNIOR, L.; RUIZ, R.; MENEGON, F. Os territórios da degradação do trabalho na região Sul e o arranjo organizado a partir da Covid-19: a centralidade dos frigoríficos na difusão espacial da doença. Metodologias e Aprendizado, v.3, 2020.

HOBBS, J. E. Food supply chains during the COVID-19 pandemic. Can. J. Agric. Econ./Revue canadienne d'agroeconomie 68, 171-176. 2020.https://doi. org/10.1111/ cjag.12237.

NIEDERLE, P., WESZ JR., V. As novas ordens alimentares. Porto Alegre, Ed. da UFRGS. 2018.

NICOLA, M., ALSAFI, Z., SOHRABI, C., KERWAN, A., AL-JABIR, A., IOSIFIDIS, C., AGHA, M., AGHA, R. The socio-economic implications of the coronavirus pandemic (COVID-19): A review. Int. J. Surg. 78, 185-193. 2020 https://doi.org/10.1016/j. ijsu.2020.04.018.

NONNENBERG, M.J; MARTINS, M.M.V; CECHIN, A. O que está acontecendo com os preços do arroz no Brasil? Instituto de Pesquisa Estatística Aplicada (IPEA). Carta de Conjuntura $n^{\circ} 49$ (4º trimestre), 2020.

MALUF, R. S.; LUZ, L. F. Sistemas alimentares descentralizados: um enfoque de abastecimento na perspectiva da soberania e segurança alimentar e nutricional. In: Maluf, Renato S.; Flexor, Georges. (Org.). Questões agrárias, agrícolas e rurais: conjunturas e políticas públicas. 1ed.Rio de Janeiro: E-papers, 2018 , v. 1, p. 214-224.

PERAFÁN, M; SCHNEIDER, S. Que desenvolvimento dos territórios rurais em América Latina e no Caribe? In: GUIBERT, M; SABOURIN, E (coord.). Ressources, inégalités et développement des territoires ruraux en Amérique latine, dans la Caraïbe et en Europe, Paris, Institut des Amériques/Agence française de développement/Fondation EU-LAC, 2020.

PIRAUX, M; CANIELLO, M. Reflexões retrospectivas e prospectivas sobre a governança territorial para o desenvolvimento rural no Brasil. Raízes: Revista De Ciências Sociais E Econômicas, vol. 39, n. 2, 359-379, 2019. https://doi. org/10.37370/raizes.2019.v39.115. 
PLATTO, S., XUE, T., CARAFOLI, E. COVID19: an announced pandemic. Cell Death Dis. 11, 1-13. 2020. https://doi.org/10.1038/s41419-020-02995-9.

PREISS, P.V., NAVARRO, R.S., SILVA, G.P.D., WEBER, J., VOGT, H.D.M., FACCIN. C. Relatório de resultados preliminares da pesquisa "o impacto da covid-19 na comercialização direta da agricultura familiar no RS": Regiões Metropolitana do Delta do Jacuí e Vale do Rio Pardo. Santa Cruz do Sul: OBSERVA-DR, 2020.

REDE BRASILEIRA DE PESQUISA EM SOBERANIA E SEGURANÇA ALIMENTAR E NUTRICIONAL. Insegurança alimentar e Covid-19 no Brasil. Rio de Janeiro, 2021.

RIVERA-FERRE, M. G., GELATS, F. L., RAVERA, F., OTEROS-ROZAS, E., DI MASSO, M., BINIMELIS, R., EL BILALI, H. The two-way relationship between food systems and the COVID19 pandemic: causes and consequences. Agricultural systems, June 2021, Vol.191. https://doi.org/10.1016/j.agsy.2021.103134

SCHNEIDER, S; CASSOL, A; LEONARDI, A; MARINHO, M. Os efeitos da pandemia da Covid-19 sobre o agronegócio e a alimentação. Estudos Avançados, São Paulo, v. 34, n. 100, p. 167-188, 2020.

SILVA, M. L. L. Contrarreforma da Previdência Social sob o comando do capital financeiro. Serviço Social \& Sociedade (131): 130-154, 2018.

SPERANDIO, N; MORAIS, D. C. Alimentação escolar no contexto da pandemia: a ressignificação e o protagonismo do Programa Nacional de Alimentação Escolar. Segur. Aliment. Nutr., Campinas, v. 28, p. 1-11, 2021. DOI: http:// dx.doi.org/10.20396/san.v28i00.8661396

SUMNER, A., HOY, C., \& ORTIZ-JUAREZ, E. Estimates of the impact of COVID-19 on global poverty. (April), 1-9. 2020. https://doi.org/10.35188/ UNU-WIDER/2020/800-9

UNITED NATIONS. A UN framework for the immediate socio-economic response to COVID-19. 2020. NY, New York.

UNICEF. Impactos primários e secundários da Covid-19 em crianças e adolescentes. 25 de agosto de 2020. Disponível em: https://www.unicef.org/bra zil/ media/9966/file/impactos-covid-criancas-adolescentes-ibope-unicef-2020.pdf. Acesso em: 27 ago. 2020. 
UNIVERSIDADE FEDERAL DE PELOTAS (UFPEL). Observatório da Problemática da Seca e da Covid-19 na Agricultura Familiar da Região Sul do Rio Grande do Sul. Informe No 01. 2021. Disponível em: <https://w p.ufpel.edu.br/ dcsa/observatorio-do-dcsa/informes/informe-no-01/>. Acesso em 30 ago 2021.

WALLACE, R. Pandemia e agronegócio: doenças infecciosas, capitalismo e ciência. São Paulo, Editora Elefante, 2020. 
d $10.48209 / 978-65-89949-32-2$

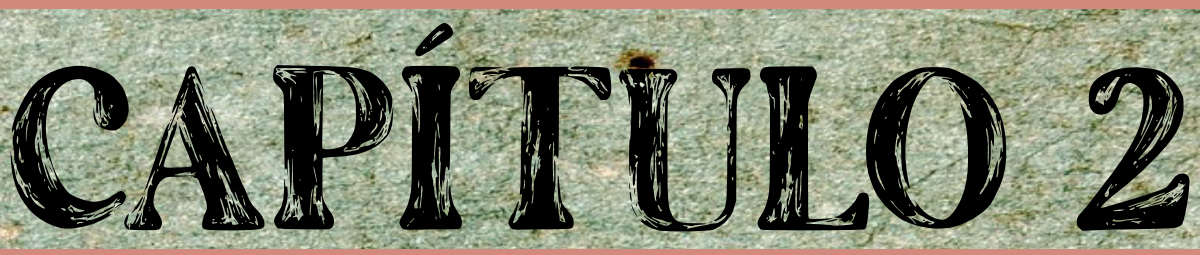

CONSUMO ALIMENTAR $\rightarrow-\infty$

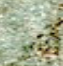
E AQUISIÇÃO DE ALIMENTOS ASSOCIADOS AO ISOLAMENTO SOCLAL. NO ENFRENTAMENTO AO COVID-19

Lya Raquel Mendes da Rocha Katharina Eduarda Rocha Lima Letícia Mazza Malta Suzana Maria Rebêlo Sampaio da Paz Theonas Gomes Pereira Carmen Viana Ramos 


\section{INTRODUÇÃO}

A COVID-19 é uma doença causada pelo coronavírus, denominado SARS-CoV-2, que apresenta um espectro clínico que varia de infecções assintomáticas a quadros graves. Segundo a Organização Mundial de Saúde (OMS), cerca de $80 \%$ dos pacientes com COVID-19 podem ser assintomáticos ou oligossintomáticos e, aproximadamente, $20 \%$ dos casos detectados requer atendimento hospitalar por apresentarem dificuldade respiratória, dos quais aproximadamente $5 \%$ podem necessitar de suporte ventilatório. O vírus SARS-CoV-2 é transmitido de pessoa a pessoa, por meio de gotículas de saliva ou secreção nasal quando uma pessoa infectada tosse ou espirra.(BRASIL, 2020).

Dados do Ministério da Saúde do Brasil referem que até maio de 2021, haviam 169.597 .415 casos de pessoas infectadas pelo vírus e 3.530 .582 casos de óbitos no mundo. No Brasil ocorreram 16.515.120 casos e 461.931 óbitos. No estado do Piauí registrou-se 294.288 casos e 6.511 óbitos (PIAUÍ, 2021). E para a cidade de Teresina, capital do Piauí, contabilizava 100.956 casos de covid-19 e 2.554 óbitos (TERESINA,2021).

Diante da gravidade da situação epidemiológica, a Organização Mundial de Saúde (OMS) publicou a declaração pública de pandemia em relação ao novo Coronavírus - Covid-19, em março de 2020, assim como, a Declaração de Emergência em Saúde Pública de Importância Internacional da OMS, em janeiro de 2020 (WHO, 2020). No Brasil, a declaração de emergência em Saúde pública foi publicada em fevereiro de 2020 e em março a portaria que trata da medida de isolamento objetivando a separação de pessoas sintomáticas ou assintomáticas, em investigação clínica e laboratorial, de maneira a evitar a propagação da infecção e transmissão local (BRASIL, 2020c; BRASIL, 2020d).

Conforme a OMS, o novo coronavírus pode sobreviver por horas e até dias dependendo da superficie, da temperatura e da umidade do ambiente. Diante disso, é importante ficar atento para que não ocorra contaminação no momento da compra e da manipulação dos alimentos. A transmissão de pessoa para pes- 
soa tem sido descrita tanto em ambientes hospitalares quanto familiares. Portanto, é de extrema importância evitar mais propagação no público e na área da saúde (KAMPF et al, 2020).

Como tentativa de frear a propagação do vírus, a OMS e as principais autarquias de saúde no Brasil divulgaram como cuidados: higienizar as mãos com álcool $70 \%$, cobrir a boca com o antebraço ou lenço descartável ao tossir e espirrar, uso de máscaras, evitar aglomerações e manter-se em isolamento domiciliar, por até 14 dias, em caso de sintomas da doença. Também é incentivada a manutenção das pessoas em ambientes bem ventilados e que as empresas e instituições públicas considerem a realização de trabalho remoto (home office), reuniões virtuais e cancelamento de viagens. As normativas publicadas até março de 2020 catalisaram o fechamento de muitos estabelecimentos de refeições coletivas e a migração de outros tantos para os serviços de take out/away e delivery (OLIVEIRA, ABRANCHES, LANA, 2020).

Dentre os desafios impostos pela realidade de isolamento social, estão as práticas relacionadas ao consumo alimentar, em que as pessoas estão confinadas nos domicílios, em provável situação de stress e ansiedade que podem influenciar no tipo de alimento consumido, horários de realização das refeições, dentre outros. Esses fatores podem resultar em desvios nutricionais, como o ganho de peso, podendo levar ao sobrepeso e obesidade. A obesidade é um importante fator de risco modificável para as doenças crônicas não transmissíveis (WHO, 2014; EPPING-JORDAN et al, 2005; WHO, 2009). O excesso de peso e a obesidade são globalmente responsáveis por $44 \%$ da carga global de diabetes, $23 \%$ de doença isquêmica do coração e entre $7 \%$ e $41 \%$ para alguns tipos de câncer (WHO, 2014).

As primeiras análises de um dos maiores estudos em alimentação e saúde do país mostraram um aumento generalizado na frequência de consumo de frutas, hortaliças e feijão (de 40,2\% para 44,6\%) durante a pandemia da covid19. Ao mesmo tempo, indicou que nas regiões Norte e Nordeste e entre pessoas de escolaridade mais baixa houve aumento no consumo de alimentos ultrapro- 
cessados, produtos industrializados que contêm adição de muitos ingredientes, como açúcares, sais, adoçantes, corantes, aromatizantes e conservantes (ALBURQUERQUE, 2020).

Pesquisas divulgadas em 2020 concluem que o consumo de ultraprocessados aumenta em $26 \%$ o risco de obesidade. Além disso, aumenta o risco de sobrepeso, obesidade e circunferência abdominal elevada em 23-34\%, de síndrome metabólica em $79 \%$, de dislipidemia em 102\%, de doenças cardiovasculares em $29-34 \%$ e da mortalidade por todas as causas em $25 \%$ (IDEC, 2020).

Para essa nova realidade de isolamento social também está imposto à produção, distribuição, comercialização e entrega, realizadas presencialmente ou por meio do comércio eletrônico, de produtos como os alimentos e bebidas, considerada como atividade essencial, conforme prescreve o inciso XII, art. $3^{\circ}$, do Decreto $n^{0}$ 10.282/20 (BRASIL, 2020). Apesar dos alimentos não serem considerados prováveis veículos de transmissão do COVID-19, considera-se fundamental o atendimento fiel às Boas Práticas de Fabricação e de Manipulação de Alimentos nesse momento, com o intuito de contribuir para diminuir a transmissão direta do COVID-19 pessoa a pessoa no ambiente de produção, devido ao rigor com as práticas de higiene adotadas (BRASIL, 2020f).

Muito se tem falado dos cuidados de higiene que devem ser adotados para se prevenir da Covid-19. Porém, divulgar os cuidados que se deve ter com as compras de supermercado e entregas de alimentos por delivery, utilizando a técnica estéril que envolve condutas que reduzem ao máximo a carga microbiana pode ser importante para evitar a propagação do vírus. No caso das compras de supermercado e compras de alimentos delivery, a técnica estéril pode ser adaptada para diminuir o risco de se contrair o vírus (CASTRO, 2020).

Apesar do cenário promovido pela Covid-19, com grande parte da população em distanciamento social, há a necessidade de adquirir alimentos para suprir sua demanda fisiológica. Desse modo, torna-se importante a adoção de todas as medidas de prevenção possíveis, tendo em vista a potencial facilidade da transmissão quando se trata de objetos compartilhados e manuseio de embalagens. 
A adaptação a essa nova rotina de cuidados tem se tornado difícil para muitos, gerando dúvidas quando se refere, principalmente, a aquisição de hábitos para a adequada higienização (DE SOUZA ,2020).

Diante deste cenário propôs-se este estudo que teve como objetivo analisar a associação entre o isolamento social, aquisição e processo de higienização dos alimentos e o consumo alimentar.

\section{METODOS}

Tratou-se de um estudo do tipo transversal realizado com uma amostra de indivíduos da cidade de Teresina, capital do Piauí. A população de Teresina considerando os maiores de 19 anos é de 548.919, conforme o Censo Demográfico realizado em 2010 (BRASIL, 2020). Os dados foram coletados no período de setembro a novembro de 2020.

A amostra do estudo foi composta pelos residentes de Teresina, com 18 anos ou mais e com acesso à redes sociais (facebook, instagran, whatsapp) disponibilizadas em aplicativos com acesso em smartsfones, notebooks, etc.. Para o cálculo amostral levou-se em consideração uma margem de erro de 5\%, com nível de significância de 95\%, obtendo-se 400 participantes. O cálculo da amostra foi feito segundo a fórmula que segue (CALLEGARI-JACQUES, 2003):

\section{$\mathrm{n}=\mathrm{N} \times \mathrm{no} / \mathrm{N}+\mathrm{no}$}

onde:

$\mathrm{n}=$ tamanho da amostra

$\mathrm{N}=$ tamanho da população

no=primeira aproximação ao tamanho da amostra $\left(n o=1 / E^{2}\right)$

$\mathrm{E}=$ erro tolerável.

Com o objetivo de garantir a representatividade de toda a população, procedeu-se a estratificação proporcional da amostra, tomando por base a porcentagem populacional de cada estado conforme tabela abaixo: 
Tabela 1: População maiores de 10 anos de idade da cidade de Teresina por zona de residência, 2010.

\begin{tabular}{|c|c|c|c|}
\hline Zona de residência & População* & Percentual & Amostra \\
\hline Centro & 105602 & 14,0 & 56 \\
\hline Leste & 142987 & 19,0 & 76 \\
\hline Norte & 248589 & 33,0 & 132 \\
\hline Sudeste & 113504 & 15,1 & 60 \\
\hline Sul & 142039 & 18,9 & 76 \\
\hline Total & $\mathbf{7 5 2 . 7 2 1}$ & $\mathbf{1 0 0 , 0}$ & $\mathbf{4 0 0}$ \\
\hline
\end{tabular}

Fonte: IBGE - Censo Demográfico 2010. *Dados utilizados para cálculo da proporcionalidade da população em cada zona de residência.

A coleta de dados foi realizada a partir de um recrutamento online em que foi empregado um formulário online desenvolvido especialmente para a pesquisa. Os critérios de inclusão adotados foram: todos os usuários das redes sociais, como o facebook, whatsapp e instagram que sejam maiores de 18 anos e aceitem participar da pesquisa. Foram excluídos todos indivíduos menores de 18 aos e que não eram residentes em Teresina.

O instrumento utilizado foi um questionário estruturado contendo questões relacionadas a: dados sócio-demográficos, processo de aquisição e higienização dos alimentos, mudanças corporais e consumo alimentar. Os dados sócio demográficos continham questões relacionados a: idade, sexo, zona da cidade em que reside, escolaridade, estado civil, trabalho, renda familiar atual, número de pessoas no domicílio, teve covid-19, fez isolamento social e por quanto tempo. Quanto aos dados relacionados ao consumo alimentar foi utilizado o questionário dos marcadores de consumo alimentar destinado a crianças acima de dois anos, adolescentes, adultos, gestantes e idosos, conforme é recomendação do (BRASIL, 2015). Quanto as questões relacionadas ao processo de aquisição de higienização de alimentos foram elaboradas com base na nota técnica № 18/2020 da 
ANVISA intitulado Covid-19 e as Boas Práticas de Fabricação e Manipulação de Alimentos (BRASIL, 2020). As questões versavam sobre: costuma pedir alimentação pronta em casa; joga no lixo todas as embalagens recebidas; lava as mãos com água e sabão antes de consumir os alimentos por 20 segundos; higieniza as superfícies que tiveram contato com as embalagens; lava as frutas e verduras com agua corrente quando chegam do supermercado; coloca as frutas e verduram em solução de hipoclorito por 15 minutos; lava as embalagens de vidro, tetra pak, latas e plásticos com água e sabão; nas embalagens não laváveis aplica solução de hipoclorito ou álcool a $70 \%$.

O referido questionário ficou disponível e hospedado no Google Forms, ferramenta gratuita pertencente ao pacote de aplicativos Google Docs, que permite criar questionário e disponibilizá-los on-line para serem respondidos. Para cada questionário criado, o aplicativo produz uma tabela contendo todas as informações coletadas, incluindo um resumo das respostas. $O$ referido instrumento foi disponibilizado através de um link, para isso utilizou-se as mídias sociais como o Facebook, Instragram e Whatsapp para divulgação da pesquisa permitindo chegar a uma maior quantidade de pessoas. A divulgação do link foi realizada pelos pequisadores responsáveis pela pesquisa.

Para a avaliação do consumo alimentar foram utilizados os indicadores de consumo conforme é proposto no Manual de Orientações para avaliação de marcadores de consumo alimentar na atenção básica do Sistema de Vigilância Alimentar e Nutricional (SISVAN) do Ministério da Saúde (BRASIL, 2015). Quais sejam: Realiza refeições assistindo TV, no computador e/ou celular; Realiza pelo menos 3 refeições ao longo do dia; Ontem você consumiu: feijão, frutas frescas, verduras e/ou legumes, Hambúrguer/embutidos (presunto, mortadela, salame, linguiça, salsicha), Bebidas adoçadas, Macarrão instantâneo, salgadinhos de pacote ou biscoitos salgados, Biscoito recheado, doces/guloseimas (balas, pirulitos, chiclete, caramelo, gelatina). Para análise das respostas relacionadas ao processo de higienização dos alimentos foi utilizado as orientações contidas na NOTA TÉCNICA No 18/2020 da ANVISA intitulado Covid-19 e as Boas Práticas de Fabricação e Manipulação de Alimentos (BRASIL, 2020). 
Para a análise dos dados foi elaborado um banco de dados no Excel mediante dupla entrada. Em seguida, os dados foram exportados para o programa STATA Versão 14. As variáveis foram apresentadas por meio de estatística descritiva por meio de proporção absoluta e relativa. Para verificar a associação entre a adoção do isolamento social e as práticas de aquisição, higienização dos alimentos, consumo alimentar e os fatores sócio-demográficos dos participantes foi realizado o teste de qui-quadrado de Pearson e a força da associação foi observada a partir do calculo da razão de prevalência (RP) e intervalo de confiança (IC 95\%) a partir da regressão de Poisson. Foi fixado o nível de significância de 0,05 para rejeição da hipótese nula.

O conceito de isolamento social utilizado foi o definido pelo inquérito telefônico VIGITEL (Vigilância de Fatores de Risco e Proteção para Doenças Crônicas por Inquérito Telefônico) como: ter evitado sair de casa a menos que necessário, ter evitado aglomerações de pessoas ou lugares muito cheios e ter evitado contato próximo com outras pessoas, como cumprimentos ou abraços ( BRASIL, 2020).

A pesquisa foi aprovada pelo Comitê de Ėtica e Pesquisa (CEP) do Centro Universitário Uninovafapi, parecer № 4.167.330, datado de 20 de julho de 2020. Todos os participantes assinaram o TCLE. Não houve recusas para participar da pesquisa. Esta pesquisa aprovada pelo Edital de Pesquisa PIBIC/ PIVIC № 015/ 2020-2021 do Centro Universitário Uninovafapi.

\section{RESULTADOS}

Participaram do estudo 394 pessoas. A amostra calculada inicialmente foi de 400 participantes, o que resultou numa perda de 1,5\%. As características sóciodemográficas, conforme a adoção do isolamento social ou não, estão descritos na Tabela 1. Quanto a faixa de idade dos participantes, 59,4\% estavam na faixa de idade de 18 a 39 anos; 77,7\% eram do sexo feminino; 46,7\% residiam na zona leste da cidade; $98 \%$ possuíam acima do nível médio; $64,5 \%$ não tinham companheiro; $72,6 \%$ não trabalhavam; $53 \%$ possuíam uma renda familiar até 
cinco salários mínimos, contudo, 27,7\% recebiam mais de 8 salários mínimos; $75,1 \%$ moravam no domicílio com 2 a 4 pessoas. Quanto a associação entre as variáveis, os resultados mostram que o trabalho e a renda tiveram associação estatisticamente significativa com o isolamento social. A chance de quem não trabalha fazer isolamento social foi $17 \%$ inferior, quando comparado com quem trabalha. Já em relação a renda familiar, quem tem renda superior a 8 salários mínimos tem 1,2 vezes mais chances de fazer isolamento social quando comparados a quem tem renda até 2 SM (TABELA 1).

Quanto a ocorrência da COVID-19 entre os participantes do estudo, os resultados mostraram que $15,5 \%$ relataram ter tido a doença, contudo, não houve associação estatística com a prática do isolamento social (TABELA 2).

No que se refere às práticas relacionadas a aquisição de alimentos e higienização das embalagens conforme o isolamento social estão apresentados descritos na tabela 3. A retirada da embalagem e colocação em outros utensílios da casa, a desinfecção dos alimentos utilizando a solução de hipoclorito por 15 minutos e a lavagem com água e sabão das embalagens (vidro, tetra pak, latas e plásticos) mostrou associação estatisticamente significativa com aqueles que praticavam o isolamento social. Aquelas pessoas que tem o hábito de após lavar frutas e verduras e colocar em solução com água e hipoclorito por 15 minutos tiveram 1,12 vezes mais chances de fazer isolamento social quando comparado a quem não tem este hábito. Já quanto ao hábito de lavar com água e sabão embalagens de vidro, tetra pak, latas e plásticos, observou-se que quem as pratica tem $10 \%$ menos chance de isolamento social quando comparado a quem tem este hábito (TABELA 3).

Quanto ao consumo alimentar do dia anterior e sua associação com a ocorrência do isolamento social, o consumo de feijão mostrou associação estatisticamente significativa, ou seja, quem não consumiu feijão no dia anterior teve $13 \%(p=0,017)$ menos chances de fazer isolamento social quando comparado com quem consumiu (TABELA 4). 
Tabela 1: Características sociodemográficas dos participantes e sua associação com a ocorrência do isolamento social. Teresina, 2021

\begin{tabular}{|c|c|c|c|c|c|c|}
\hline \multirow{3}{*}{ Variáveis } & \multicolumn{5}{|c|}{ Isolamento social } & \multirow{3}{*}{ Valor de $p$} \\
\hline & \multicolumn{2}{|c|}{ Total } & \multicolumn{2}{|c|}{ Sim } & \multirow{2}{*}{ RP (IC 95\%) } & \\
\hline & $\mathbf{N}$ & $\%$ & $\mathbf{N}$ & $\%$ & & \\
\hline \multicolumn{7}{|l|}{ Idade (anos) } \\
\hline 18 a 39 & 234 & 59,4 & 178 & 76,1 & 1,0 & - \\
\hline 40 a 59 & 135 & 34,3 & 105 & 77,8 & $1,02(0,91-1,15)$ & 0,706 \\
\hline 60 e mais & 25 & 6,3 & 20 & 80,0 & $1,05(0,85-1,30)$ & 0,637 \\
\hline \multicolumn{7}{|l|}{ Sexo } \\
\hline Feminino & 306 & 77,7 & 245 & 80,1 & $1,21(0,91-1,62)$ & 0,183 \\
\hline Masculino & 88 & 22,3 & 58 & 65,9 & 1,0 & - \\
\hline \multicolumn{7}{|l|}{$\begin{array}{l}\text { Zona da } \\
\text { cidade }\end{array}$} \\
\hline Centro & 30 & 7,6 & 26 & 86,7 & $1,22(0,98-1,52)$ & 0,074 \\
\hline Leste & 184 & 46,7 & 146 & 79,4 & $1,12(0,93-1,35)$ & 0,233 \\
\hline Norte & 55 & 14,0 & 39 & 70,9 & 1,0 & - \\
\hline Sudeste & 28 & 7,1 & 20 & 71,4 & $1,01(0,75-1,34)$ & 0,961 \\
\hline Sul & 97 & 24,6 & 72 & 74,2 & $1,05(0,85-1,29)$ & 0,664 \\
\hline \multicolumn{7}{|l|}{ Escolaridade } \\
\hline $\begin{array}{l}\text { Até Ens } \\
\text { Fun comp }\end{array}$ & 8 & 2,0 & 7 & 87,5 & 1,0 & - \\
\hline $\begin{array}{c}\text { Ens méd } \\
\text { inc e + }\end{array}$ & 386 & 98,0 & 296 & 76,7 & $0,88(0,67-1,14)$ & 0,335 \\
\hline \multicolumn{7}{|l|}{ Estado civil } \\
\hline $\begin{array}{c}\text { Sem } \\
\text { companheiro }\end{array}$ & 254 & 64,5 & 198 & 78,0 & 1,0 & - \\
\hline $\begin{array}{c}\text { Com } \\
\text { companheiro }\end{array}$ & 140 & 35,5 & 105 & 75,0 & $0,96(0,86-1,08)$ & 0,514 \\
\hline \multicolumn{7}{|l|}{ Trabalha } \\
\hline Sim & 108 & 27,4 & 95 & 88,0 & 1,0 & - \\
\hline Não & 286 & 72,6 & 208 & 72,7 & $0,83(0,75-0,91)$ & $<0,001$ \\
\hline \multicolumn{7}{|l|}{$\begin{array}{c}\text { Renda familiar } \\
\text { atual }\end{array}$} \\
\hline até $2 \mathrm{SM}$ & 89 & 22,6 & 62 & 69,7 & 1,0 & - \\
\hline Entre 2 e $5 \mathrm{SM}$ & 120 & 30,4 & 88 & 73,3 & $1,05(0,88-1,25)$ & 0,565 \\
\hline Entre 5 e $8 \mathrm{SM}$ & 76 & 19,3 & 62 & 81,6 & $1,17(0,98-1,39)$ & 0,075 \\
\hline$>8 \mathrm{SM}$ & 109 & 27,7 & 91 & 83,5 & $1,20(1,02-1,41)$ & 0,027 \\
\hline
\end{tabular}




\section{Número}

pessoas

no domicilio

\begin{tabular}{ccccccc}
\hline 1 & 25 & 6,4 & 21 & 84,0 & $1,96(0,82-4,69)$ & 0,131 \\
\hline 2 a 4 & 296 & 75,1 & 228 & 77,0 & $1,80(0,76-4,24)$ & 0,181 \\
\hline 5 a 8 & 66 & 16,8 & 51 & 77,3 & $1,80(0,76-4,29)$ & 0,182 \\
\hline Mais de 9 & 7 & 1,8 & 3 & 42,9 & 1,0 & - \\
\hline
\end{tabular}

Tabela 2: Proporção dos participantes que tiveram covid19 segundo isolamento social. Teresina, 2021

\begin{tabular}{|c|c|c|c|c|c|c|}
\hline \multirow{3}{*}{ Teve covid19 } & \multicolumn{5}{|c|}{ Isolamento Social } & \multirow{3}{*}{$\begin{array}{l}\text { Valor } \\
\text { de } p\end{array}$} \\
\hline & \multicolumn{2}{|c|}{ Total } & \multicolumn{2}{|c|}{ Sim } & \multirow{2}{*}{ RP (IC 95\%) } & \\
\hline & $\mathbf{N}$ & $\%$ & $\mathbf{N}$ & $\%$ & & \\
\hline Não & 333 & 84,5 & 257 & 77,2 & 1,0 & - \\
\hline Sim & 61 & 15,5 & 46 & 75,4 & $\begin{array}{c}0,98 \\
(0,84-1,14) \\
\end{array}$ & 0,769 \\
\hline Total & 394 & 100,0 & 91 & 23,1 & & \\
\hline
\end{tabular}

Tabela 3: Características relativas a aquisição de alimentos e práticas higiênico- sanitárias dos alimentos pedidos por delivery associados a ocorrência do isolamento social. Teresina, 2021

\begin{tabular}{c|c|c|c|c|c|c}
\multirow{2}{*}{ Variáveis } & \multicolumn{5}{c|}{ Isolamento Social } & \multirow{2}{*}{ Valor } \\
\cline { 2 - 5 } & \multicolumn{2}{|c|}{ Total } & \multicolumn{2}{c|}{ Sim } & RP (IC 95\%) & \multirow{2}{*}{ de p } \\
\hline \multirow{7}{*}{} & N & $\%$ & N & $\%$ & & \\
\hline Não & 98 & 24,9 & 76 & 77,6 & 1,0 & - \\
\hline Sim & 296 & 75,1 & 227 & 76,7 & $0,99(0,87-1,12)$ & 0,860 \\
\hline Ao receber alimentação retira embalagem e coloca em utensílio decasa? \\
\hline Não & 72 & 22,6 & 48 & 66,7 & 1,0 & - \\
\hline Sim & 247 & 77,4 & 194 & 78,5 & $1,18(0,99-1,40)$ & 0,068 \\
\hline \multicolumn{7}{|c|}{ Após receber a alimentação, você joga no lixo todas as embalagens } \\
\hline Não & 25 & 7,5 & 16 & 64,0 & 1,0 & - \\
\hline Sim & 309 & 92,5 & 240 & 77,7 & $1,21(0,89-1,64)$ & 0,207 \\
\hline
\end{tabular}


Antes alimentação, lava as mãos (água/sabão) por pelo menos 20 segundos

\begin{tabular}{c|c|c|c|c|c|c}
\hline Não & 33 & 9,2 & 20 & 60,6 & 1,0 & - \\
\hline Sim & 324 & 90,8 & 258 & 79,6 & $1,31(0,99-1,74)$ & 0,057 \\
\hline
\end{tabular}

Higieniza as superfícies que tiveram contato com as embalagens?

\begin{tabular}{c|c|c|c|c|c|c}
\hline Não & 94 & 27,1 & 78 & 83,0 & 1,0 & - \\
\hline $\operatorname{Sim}$ & 253 & 72,9 & 190 & 75,1 & $0,90(0,80-1,02)$ & 0,092 \\
\hline
\end{tabular}

Ao fazer as compras de frutas e verduras, lava com água corrente

\begin{tabular}{c|c|c|c|c|c|c}
\hline Não & 17 & 4,3 & 12 & 70,6 & 1,0 & \\
\hline $\operatorname{Sim}$ & 377 & 95,7 & 291 & 77,2 & $1,09(0,80-1,49)$ & 0,575 \\
\hline
\end{tabular}

Após lavar frutas/verduras, coloca em solução com água e hipoclorito por 15 minutos

\begin{tabular}{c|c|c|c|c|c|c}
\hline Não & 154 & 39,1 & 110 & 71,4 & 1,0 & - \\
\hline Sim & 240 & 60,9 & 193 & 80,4 & $1,12(1,00-1,27)$ & 0,049 \\
\hline
\end{tabular}

Lava com água e sabão embalagens de vidro, tetra pak, latas e plásticos

\begin{tabular}{c|c|c|c|c|c|c}
\hline Não & 77 & 19,5 & 65 & 84,4 & 1,0 & - \\
\hline Sim & 317 & 80,5 & 238 & 75,1 & $0,90(0,93-1,18)$ & 0,046 \\
\hline
\end{tabular}

Embalagens que não podem ser lavadas, aplica solução de água com hipoclorito ou álcool a $70 \%$ ?

\begin{tabular}{c|c|c|c|c|c|c}
\hline Não & 126 & 32,0 & 94 & 74,6 & 1,0 & - \\
\hline Sim & 268 & 68,0 & 209 & 78,0 & $1,04(1,00-1,27)$ & 0,470
\end{tabular}

O modelo final, que mostra o resultado da regressão de Poisson multivariada, evidenciou que dentre as variáveis estudadas houve associação estatisticamente significativa com a prática do isolamento social: o sexo, ter trabalho, ter uma renda acima de 8 salários mínimos, colocar as frutas e verduras em solução de hipoclorito após as lavagens, lavar com água e sabão as embalagens tetra pak, latas e plásticos e consumir feijão no dia anterior. Quanto ao sexo, os homens tiveram $20 \%$ menos chance de fazer o isolamento social quando comparado as mulheres. Relativo ao trabalho, quem não trabalha tem $17 \%$ menos chance de fazer isolamento social em relação a quem trabalha. No que diz respeito a renda familiar, aqueles que tem renda >8 SM tem 1,2 vezes (ou $20 \%$ mais chances de fazer isolamento social quando comparado com quem 
tem renda de até 2 SM. Quanto as questões higiênico-sanitárias dos alimentos, aqueles que após lavar frutas/verduras, coloca em solução com água e hipoclorito por 15 minutos tem 1,12 vezes (ou 12\%) mais chance de isolamento social quando comparado a quem não o faz. Relacionado ao consumo de alimentos, quem não consome feijão tem $12 \%$ menos chances de isolamento social quando comparado a quem consome feijão (TABELA 5).

Tabela 4: Consumo alimentar dos participantes conforme o isolamento social. Teresina, 2021

\begin{tabular}{|c|c|c|c|c|c|c|}
\hline \multirow{3}{*}{ Variáveis } & \multicolumn{5}{|c|}{ Isolamento social } & \multirow{3}{*}{$\begin{array}{l}\text { Valor } \\
\text { de } p\end{array}$} \\
\hline & \multicolumn{2}{|c|}{ Total } & \multicolumn{2}{|c|}{ Sim } & \multirow{2}{*}{ RP (IC 95\%) } & \\
\hline & $\mathbf{N}$ & $\%$ & $\mathbf{N}$ & $\%$ & & \\
\hline \multicolumn{7}{|c|}{ Realiza refeições assistindo TV, no computador e/ou celular? } \\
\hline Não & 130 & 33,0 & 107 & 82,3 & 1,0 & - \\
\hline Sim & 263 & 66,8 & 195 & 74,1 & $\begin{array}{c}0,90 \\
(0,81-1,00)\end{array}$ & 0,056 \\
\hline \multicolumn{7}{|c|}{ Realiza pelo menos 3 refeições você faz ao longo do dia } \\
\hline Não & 70 & 17,8 & 56 & 80,0 & $\begin{array}{c}1,05 \\
(0,92-1,20)\end{array}$ & 0,475 \\
\hline Sim & 324 & 82,2 & 247 & 76,2 & 1,0 & - \\
\hline \multicolumn{7}{|c|}{ Ontem você consumiu: Feijão } \\
\hline Não & 173 & 44,2 & 123 & 71,1 & $\begin{array}{c}0,87 \\
(0,78-0,98)\end{array}$ & 0,017 \\
\hline Sim & 218 & 55,8 & 178 & 81,6 & 1,0 & - \\
\hline \multicolumn{7}{|c|}{ Frutas frescas } \\
\hline Não & 136 & 34,6 & 104 & 76,5 & $\begin{array}{c}0,99 \\
(0,88-1,11)\end{array}$ & 0,899 \\
\hline $\operatorname{Sim}$ & 257 & 65,4 & 198 & 77,0 & 1,0 & - \\
\hline \multicolumn{7}{|c|}{ Verduras elou legumes } \\
\hline Não & 125 & 31,8 & 97 & 77,6 & $\begin{array}{c}1,01 \\
(0,90-1,14)\end{array}$ & 0,807 \\
\hline
\end{tabular}


Sim 268

68,2

205

76,5

1,0

Hambúrguer/embutidos (presunto, mortadela, salame, linguiça, salsicha)

Não

272

69,0

$208 \quad 74,5$

1,0

Sim

122

31,0

95

77,9

$1,02(0,91-$
$1,14)$

0,758

\section{Bebidas adoçadas}

Não

230

58,8

182

79,1

1,0

Sim

161

41,2

121

75,2

$0,95(0,85-$
$1,06)$

0,363

Macarrão instantâneo, salgadinhos de pacote ou biscoitos salgados

$\begin{array}{ccccccc}\text { Não } & 343 & 87,7 & 262 & 76,4 & 1,0 & - \\ \text { Sim } & 48 & 12,3 & 41 & 85,4 & \begin{array}{c}1,12(0,98- \\ 1,27)\end{array} & 0,095\end{array}$

Biscoito recheado, doces/guloseimas (balas, pirulitos, chiclete, caramelo, gelatina)

\begin{tabular}{ccccccc} 
Não & 284 & 72,3 & 221 & 77,8 & 1,0 & - \\
$\operatorname{Sim}$ & 109 & 27,7 & 81 & 74,3 & $\begin{array}{c}0,95(0,84- \\
1,08)\end{array}$ & 0,476 \\
\hline
\end{tabular}

Tabela 5: Modelo final regressão de Poisson multivariado.

\begin{tabular}{ccc}
\hline Variáveis & RP (IC 95\%) & Valor de $\mathbf{p}$ \\
\hline Sexo & 1,0 & - \\
\hline Feminino & $0,80(0,69-0,92)$ & 0,003 \\
\hline Masculino & & \\
\hline Trabalha & $1,26(1,13-1,39)$ & $<0,001$ \\
\hline Sim & 1,0 & - \\
\hline Não & 1,0 & - \\
\hline Renda familiar atual & $1,05(0,89-1,24)$ & 0,563 \\
\hline Até 2 SM & & \\
\hline Entre 2 e 5 SM & & \\
\hline
\end{tabular}




\begin{tabular}{ccc}
\hline Entre 5 e 8 SM & $1,20(1,00-1,43)$ & 0,039 \\
\hline > 8 SM & $1,26(1,07-1,49)$ & 0,005 \\
\hline Após lavar frutas/verduras, coloca em solução com água e hipoclorito \\
\hline Não & 1,0 & - \\
\hline Sim & $1,16(1,03-1,30)$ & 0,014 \\
\hline Lava com água e sabão embalagens de vidro, tetra pak, latas e plásticos \\
\hline Não & 1,0 & - \\
\hline Sim & $0,77(0,68-0,86)$ & $<0,001$ \\
\hline & Consumiu ontem feijão & 0,020 \\
\hline Não & $0,88(0,78-0,98)$ & - \\
\hline Sim & 1,0 & \\
\hline
\end{tabular}

\section{DISCUSSÃO}

Os resultados do estudo permitiram revelar que a adoção do isolamento social pelos participantes se mostrou associado a indicadores sócios demográficos como sexo, trabalho e renda, bem como, algumas práticas de higienização e aquisição dos alimentos e o consumo de feijão durante a pandemia.

No que diz respeito aos indicadores sócio-demográficos ter trabalho aumentou a chance de realizar o isolamento social. Gandra (2020) comparando dados da Pesquisa Nacional por Amostra de Domicílios Contínua (PNADC) e da Pesquisa Nacional por Amostra de Domicílios COVID (PNAD-Covid) entre famílias de diferentes classes sociais e renda familiar, mostrou que pessoas que trabalham e tem uma estabilidade financeira tem mais chances de realizar o isolamento social.

Quanto a renda familiar, o presente estudo mostrou que pessoas que possuem maior renda, conseguem fazer o isolamento social com mais facilidade, provavelmente porque a garantia de ter uma renda fixa e um trabalho permitiu 
que houvesse maior possibilidade da realização das atividades no domicílio, sem precisar sair de casa. Outros estudos convergem com esses resultados, como é o caso da pesquisa realizada no Brasil por Bezzera et al (2020), em que a parcela da população brasileira com menor renda está praticando menos o isolamento social, uma vez que está vinculada à atividades essenciais e precisam se locomover ao local de trabalho, ao contrário disso, tem-se a parcela com maior renda, que de forma geral, são vinculadas às atividades que pararam e/ou estabeleceram o trabalho remoto. Siqueira et al, (2020) mostrou no seu estudo realizado na região metropolitana de Belo Horizonte e em na própria cidade, que quanto mais alta a classe social, maior o nível de adesão ao isolamento social.

No que tange ao sexo dos pesquisados, percebeu-se que o número de pessoas do sexo feminino que participaram da pesquisa é três vezes maior que do sexo masculino, além disso, o fato de ser do sexo masculino reduziu as chances de fazer o isolamento social. Como mostra no estudo feito por (BEZERRA, 2020) quando inquiridos se o isolamento estava gerando algum estresse no ambiente doméstico, $27 \%$ dos homens disseram que não estavam sentindo nenhum estresse em função do isolamento, $56 \%$ relataram estar sentindo um pouco de estresse e $17 \%$ afirmaram que o isolamento tem gerado muito estresse no ambiente doméstico. Os homens tendem a sair de casa com mais frequência que as mulheres, com a chegada da pandemia consequentemente veio uma série de mudanças na rotina, como o isolamento social que gerou um estresse na vida de muitos homens, os quais estavam acostumados a sair para trabalhar, fazer exercícios e até mesmo o futebol e o bar com os amigos no final de semana. Esse estresse acaba gerando ansiedade, o que gera a necessidade de fazer alguma atividade fora de casa. Com isso os homens tendem a fazer menos o isolamento social. Corroborando com os dados da presente pesquisa, Lima-Costa et al. (2020), em uma coorte realizada com idosos brasileiros encontrou que as saídas de casa para as atividades essenciais foram informadas com mais frequência pelos homens $(\mathrm{OR}=1,84)$ para trabalhar e fazer exercícios. 
No que diz respeito a higienização dos alimentos verificou-se que houve associação estatisticamente significativa entre a adoção do isolamento social com a prática de colocar as frutas e verduras em solução de hipoclorito após as lavagens, lavar com água e sabão as embalagens tetra pak, latas e plásticos. Em pesquisa realizada em Joinville, Santa Catarina (SC), por GONÇALVES (2021), verificou que $68,3 \%$ dos estudantes do sexo masculino e feminino não realizavam higienização de alimentos e embalagens antes do início da pandemia, 74,2\% dos estudantes do sexo feminino afirmou ter começado a higienizar alimentos e embalagens após a pandemia, destes 53,9\% continuaram higienizando mesmo após mais de 3 meses do início da pandemia, 23,6\% dos estudantes do sexo masculino relatou higienizar apenas quando lembra e 22,5\% informou que após este período de mais de três meses após a pandemia parou de higienizar alimentos e embalagens. $O$ aumento dos cuidados de higiene por parte da população torna-se um momento oportuno para enfatizar a importância das boas práticas de higiene voltadas à alimentação, enfatizando que estas são orientadas não somente em um momento de pandemia como o que têm-se vivido nos últimos meses, mas que podem se manter presentes contribuindo para a proteção contra as DTA ( GONÇALVES, 2021).

Observou-se também que não houve associação significativa entre o consumo da maioria dos alimentos e o adoção da prática do isolamento social, exceto em relação ao feijão, em que observou-se um maior consumo de feijão em quem fez o isolamento social, provavelmente pelo fato de ficar mais tempo em casa para poder preparar alimentos como esse que demandam mais tempo de cozimento. Em estudo realizado por Malta et al, (2020) que pesquisou a regularidade do consumo de feijão antes e durante a pandemia relatou não haver diferença significativa.

A presente pesquisa trouxe como vantagem a possibilidade de obter informações sobre comportamentos de adultos em relação à pandemia e o isolamento social, sem expô-los ao risco de infecção, inerente à entrevista presencial. Outra vantagen foi o número de participantes residentes em Teresina situados 
em todas as grandes regiões da cidade. As limitações do estudo são aquelas relativas às pesquisas por meio de entrevistas on line como a recusa em prestar informações por essa via. Outra limitação deste estudo para avaliar os padrões de is olamento social é que a pandemia evolui rapidamente, e as análises com base nos resultados são limitadas ao período nos quais as informações foram coletadas.

\section{CONCLUSÃO}

A pandemia da covid-19 trouxe ao mundo uma nova rotina, que foi a adoção do isolamento social como uma das principais medidas de controle para o avanço dos casos. Os resultados deste estudo mostraram que a adoção deste comportamento esteve ligado a condição de ter um vínculo trabalhista, uma melhor renda, e ser do sexo feminino. Na aquisição e higienização de alimentos, o sexo feminino se mostrou mais eficaz e preocupado com a higienização de superficies e alimentos utilizando hipoclorito de sódio e água corrente. Quanto ao consumo de alimentos, somente o consumo do feijão mostrou associação. Nessa perspectiva, medidas protetivas que assegurem o emprego e renda se mostraram como necessárias para o assegurar o isolamento social de forma a reduzir o número de casos e, consequentemente, os óbitos por essa doença.

\section{REFERENCIAS}

ALBURQUERQUE, F. Estudo mostra mudança de hábitos alimentares durante a pandemia. São Paulo - SP, 2020. Disponível em <https://agenciabrasil. ebc.com.br/saude/noticia/2020-10/estudo-mostra-mudanca-de-habitos-alimentares-durante-pandemia> Acesso em: 29 jun. 2021.

BRASIL. MINISTÉRIO DA SAÚDE. Sobre a doença. 2020 Disponível em < https://www.gov.br/saude/pt-br/vacinacao >Acesso em: 28 de jun. 2021.

BRASIL. Presidência da República. Secretaria Geral. Subchefia para Assuntos Jurídicos. Lei $\mathrm{N}^{\circ}$ 13.979, 6 de Fevereiro de 2020. Dispõe sobre as medidas para enfrentamento da emergência de saúde pública de importância internacional decorrente do coronavírus responsável pelo surto de 2019. Brasília: Presidência da República, 2020. Disponível em < https://www.planalto.gov.br/ccivil_03/_ Ato2019-2022/2020/Lei/L13979.htm. Acesso em: 22 mai.2021 
BRASIL. Ministério da Saúde. Agencia Nacional de Vigilância Sanitária - ANVISA. NOTA TÉCNICA N 18/2020 - Covid-19 e as Boas Práticas de Fabricação e Manipulação de Alimentos. Brasília: Ministério da Saúde, 2020. http://www.vigilanciasanitaria.sc.gov.br/index.php/sample-sites-2/149-noticias/noticias-2020/ 1152-anvisa-publica-nota-tecnica-n-18-2020-sobre-adocao-de-boas-praticas-de-fabricacao-e-manipulacao-de-alimentos-durante-a-pandemia-de-covid-19 Acesso em: 20 abr 2021

BRASIL. Instituto Brasileiro de Geografia e Estatística - IBGE. Censo Demográfico de 2010.Brasília: IBGE, 2020.Disponível em http://sidra.ibge.gov.br/home/ cnt/brasil. Acesso em: 21 de abr 2020.

BRASIL. Secretaria de Vigilância em Saúde, Departamento de Análise em Saúde e Vigilância de Doenças não Transmissíveis. Vigitel Brasil 2019 : vigilância de fatores de risco e proteção para doenças crônicas por inquérito telefônico : estimativas sobre frequência e distribuição sociodemográfica de fatores de risco e proteção para doenças crônicas nas capitais dos 26 estados brasileiros e no Distrito Federal , 2019. Disponível em : https://portalarquivos.saude.gov.br/images/ pdf/2020/April/27/vigitel-brasil-2019-vigilancia-fatores-risco.pdf . Acesso 23 jun 2021

BRASIL.Ministério da Saúde. Secretaria de Atenção à Saúde. Departamento deAtençãoBásica. Orientações para avaliação de marcadores de consumo alimentar na atenção básica [recurso eletrônico]. Brasília: Ministério da Saúde, 2015. Disponível em: < https://bvsms.saude.gov.br/bvs/publicacoes/marcadores_consumo_alimentar_atencao_basica.pdf. Acesso em 23 de jun 2021.

BEZERRA, Anselmo César Vasconcelos et al. Fatores associados ao comportamento da população durante o isolamento social na pandemia de COVID-19. Ciência \& Saúde Coletiva, v. 25, p. 2411-2421, 2020. Disponível em: <https://doi. org/10.1590/1413-81232020256.1.10792020>.Acesso em 23 mar 2021

CALLEGARI-JACQUES, S.M. Bioestatística: princípios e aplicações. 1.ed. PortoAlegre:EditoraArtmed, 2003.255p

CASTRO, M. T. Comprando alimentos durante a pandemia de Covid-19. Food Safety Brazil, 2020. Disponível em: https://foodsafetybrazil.org/comprando-alimentos-durante-pandemia-de-covid-19/ Acesso em: 25 de janeiro de 2021

EPPING-JORDAN, J.E.; GALEA, G.; TUKUITONGA, C.; BEAGLEHOLE,R.Preventingchronicdiseases:takingstepwiseaction.Lancet;366:1667-71,2005. Disponível em https://www.sciencedirect.com/science/article/pii/S0140673605673424 Acesso em 27 mai 2021 
GANDRA, JULIANA. Covid-19, Diversidade das Famílias e Desigualdades. 2020. Associação Brasileira de Estudos Populacionais,Abep,Dezembro de 2020. Acessado em 25/06/2021 ás 18:30 horas. Disponível em: http://abep-covid19.com.br/ arquivos/Juliana_Gandra.pdf . Acesso 26 mai 2020

GONÇALVES, Bruna Maria; DOS SANTOS TORIANI, Sônia. Hábitos relacionados à higiene alimentar em tempos de COVID-19: uma pesquisa com estudantes de uma instituição de ensino superior privada de Joinville (SC). Brazilian Journal of Development, v. 7, n. 2, p. 18799-18811, 2021. Disponível em: https://www. brazilianjournals.com/index.php/BRJD/article/view/25172 Acesso 23032021

INSTITUTOBRASILEIRODEDEFESAAOCONSUMIDOR.Pandemia:aumentodeconsumodeultraprocessadospeloBrasil.2020Disponívelem:

https://idec.org.br/noticia/pandemia-aumento-de-consumo-de-ultraprocessados-pelo-brasil Acesso em: 03de jun.2021

KAMPF, G.; TODT, D.; PFAENDER, S.; STEINMANN, E. Persistência de coronavírus em superfícies inanimadas e sua inativação com agentes biocidas. Journal of Hospital Infecção. Volume 104, Edição 3, Março 2020 , Páginas 246-251. Acesso em: < https://www.3tres3.com.br/abstracts/persistencia-de-coronavirus-nas-superficies-e-inativac\%C3\%A3o-com-biocidas_302/> Acesso em 21 mai. 2021

LIMA-COSTA, Maria Fernanda et al. Distanciamento social, uso de máscaras e higienização das mãos entre participantes do Estudo Longitudinal da Saúde dos Idosos Brasileiros: iniciativa ELSI-COVID-19. Cadernos de Saúde Pública [online]. 2020, v. 36, n. Suppl 3 . Disponível em: https://www.scielo.br/j/csp/a/q4Zn6d6RtBMWR78fntMMJxj/ . Acesso em 06/07/2021.

MALTA, D. C; et al. A pandemia da COVID-19 e as mudanças no estilo de vida dosbrasileiros adultos: um estudo transversal, 2020. Epidemiol. Serv. Saúde, Brasília v.29,n.4,e2020407,2020.Disponível em

https://www.scielo.br/j/ress/a/VkvxmKYhw9djmrNBzHsvxrx/?format=html Acessoem:28jun. 2021.

OLIVEIRA, Tatiana Coura; ABRANCHES, Monise Viana; LANA, Raquel Martins. (In) Segurança alimentar no contexto da pandemia por SARS-CoV-2. Cadernos de Saúde Pública, v. 36, p. e00055220, 2020. https://www.researchgate.net/publication/340465835_InSeguranca_alimentar_no_contexto_da_pandemia_por_ SARS-CoV-2/citation/download. <Acesso em: 26/06/2021. 
PIAUÍ. Secretaria Estadual de Saúde. Gerência de Vigilância a Saúde. Coordenação de Epidemiologia. Dados sobre Covid19: SemanaEpidemiológica, Piauí, SESAPI. 2021. Disponível em https://datastudio.google.com/reporting/ a6dc07e9-4161-4b5a-9f2a-6f9be486e8f9/page/2itOB>Acessoem: 27dejun.2021

SIQUEIRA, M.R; MARTINS et al. Isolamento Social e Mudanças de Hábitos Alimentares dos cidadãos de BH e RMBH. Belo Horizonte - MG, 2020. Disponível em: https://scielosp.org/j/rbepid/i/2020.v23/ > Acessado em: 29 de jun. de 2021.

SOUZA, A. N. M. et al. Higienização das embalagens em tempo de covid-19: Um relato de experiência. Revista Extensão \& Sociedade, v. 12, n. 1, 2020. Disponível em: https://periodicos.ufrn.br/extensaoesociedade/article/view/20806. Acesso em: 25/01/2021.

WORLD HEALTH ORGANIZATION. Statement on the second meeting of the International Health Regulations (2005) Emergency Committee regarding the outbreak of novel coronavirus (2019-nCoV) . Geneva: World Health Organization ; 2020 Acesso em Mar 202. Disponíevl em:» https://www.who.int/news-room/ detail/30-01-2020-statement-on-the-second-meeting-of-the-international-healthregulations-(2005)-emergency-committee-regarding-the-outbreak-of-novelcoronavirus-(2019-ncov)

. Global status report on noncommunicable diseases 2014. Geneva: World Health Organization; 2014. Disponível em : https://apps.who.int/iris/ handle/10665/148114. Acesso em 05 mar 2021

Global health risks: mortality and burden of disease attributable to selected major risks. Geneva: World Health Organization; 2009. Disponível em: https://apps.who.int/iris/handle/10665/44203. Acesso em 04 fev 2021 


\section{d o $10.48209 / 978-65-89949-32-3$}

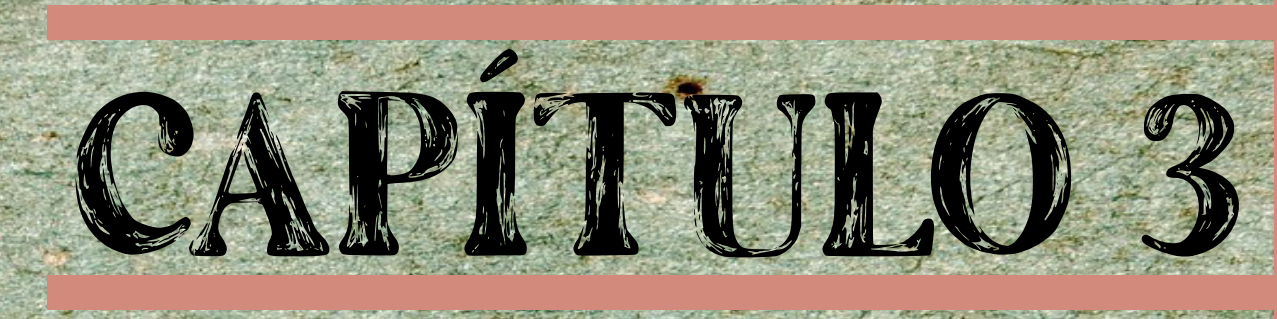

\section{SEGURANÇA ALIMENTAR}

E NUTRICIONAL DE

AGRICULTORES FAMILIARES

NO CONTEXTO DA PANDEMIA DO CORONAVÍRUS

Dayane de Castro Morais Elizangela da Silva Miguel Sílvia Oliveira Lopes Jersica Martins Bittencourt Silvia Eloiza Priore 


\section{INTRODUÇÃO}

O conceito de Segurança Alimentar e Nutricional (SAN) foi determinado pela Lei Orgânica de Segurança Alimentar e Nutricional (LOSAN), compreendendo a:

realização do direito de todos ao acesso regular e permanente a alimentos de qualidade, em quantidade suficiente, sem comprometer o acesso a outras necessidades essenciais, tendo como base práticas alimentares promotoras da saúde que respeitem a diversidade cultural e que sejam ambiental, cultural, econômica e socialmente sustentáveis (BRAZIL, 2006a).

Determinantes demográficos, socioeconômicos, de estado nutricional, disponibilidade de alimentos e consumo alimentar influenciam o alcance da SAN (PEREIRA et al., 2006; KEPPLE, SEGALL- CORRÊA, 2011; MALUF, REIS, 2013).

Considerando que a alimentação apresenta uma relação direta com estes determinantes, uma vez que é influenciada por fatores sociais, nutricionais, econômicos e culturais (CARVALHO et al., 2011; SILVA et al., 2012), destacamos que a forma de produção de alimentos é um dos pilares para a garantia da SAN. Assim, a produção oriunda da agricultura familiar, responsável pela maior parte dos alimentos consumidos no país, bem como seus agricultores merecem ser considerados. Destaca-se que a agricultura familiar consiste na:

prática de atividades no meio rural que utilize mão de obra familiar e tenha percentual mínimo da renda originada de atividades econômicas do estabelecimento ou empreendimento. Tem como característica a diversificação da produção (BRAZIL, 2006b).

Desse modo, de acordo com a Lei $\mathrm{n}^{\circ} 11.326 / 2006$, art. $3^{\circ}$, pode ser considerado agricultor e empreendedor familiar todo aquele que exerce atividades no meio rural, contanto que atenda às seguintes formalidades: não detenção de nenhum título de terra maior do que quatro módulos fiscais; utilização de mão de obra de sua própria família nos trabalhos e atividades de cunho econômico; renda familiar advinda de atividades relacionadas ao próprio estabelecimento e que administre o empreendimento juntamente da família (BRASIL, 2006b). 
Considerando a forma de produção, a agricultura familiar tem como características, além da diversificação da produção, cultivos de alimentos que são destinados basicamente para o mercado interno e produção para o autoconsumo, contribuindo para a garantia da SAN de famílias rurais (FONTOURA, 2012).

A produção para autoconsumo é vista então como uma forma de garantir a autonomia em relação às escolhas alimentares das famílias, além de possibilitar o acesso direto aos alimentos. Ou seja, os alimentos seguem direto do local de produção para a unidade de consumo (domicílio), sem passar por processo intermediário que o torne valor de troca (GRISA, GAZOLLA, SCHNEIDER, 2010).

A agricultura familiar é um importante circuito de comercialização, no entanto a pandemia do novo coronavírus (SARS-CoV-2) impôs diversos desafios para os agricultores familiares. No Brasil, estes agricultores foram surpreendidos com as limitações resultantes dessa crise sanitária e econômica. O avanço do novo coronavírus gerou a interrupção das atividades cotidianas da população, devido à necessidade de isolamento social para evitar a disseminação da doença. Nesse sentido, a redução do escoamento da produção, devido às medidas de distanciamento social, em decorrência do fechamento de escolas, feiras e demais comércios, implicou na perda parcial ou total de suas rendas, e consequentemente no aumento da insegurança alimentar e nutricional (FUTEMMA et al., 2021).

\section{INSEGURANÇA ALIMENTAR E NUTRICIONAL E PANDEMIA (SARS-CoV-2)}

A Covid-19 é uma doença infecciosa causada pelo novo coronavírus (SARS-CoV-2), identificado pela primeira vez em dezembro de 2019, em Wuhan, na China. Desde então, os casos começaram a se espalhar rapidamente pelo mundo, primeiramente na Ásia e depois por outros continentes. Em fevereiro de 2020 foi identificado o primeiro caso no Brasil. Já em março, a Organização Mundial da Saúde (OMS) definiu o surto da doença como pandemia (OPAS, 2021). 
O surgimento da Covid-19 no Brasil explicitou ainda mais a enorme vulnerabilidade social existente no país, impactando na SAN, à semelhança do que vem acontecendo em outros países. A situação de insegurança alimentar e nutricional (InSAN) e a fome já vinha crescendo no Brasil desde 2016, contudo foi aprofundada pela pandemia (RIBEIRO-SILVA et al., 2020).

A OMS estima que em 2013, 867 milhões de pessoas no mundo estiveram subnutridas de forma crônica e que $70 \%$ das pessoas que estavam em situação de insegurança alimentar e nutricional eram residentes de zonas rurais (ALMEIDA et al., 2017).

Dados da Pesquisa de Orçamentos Familiares (POF) trouxe que no Brasil, em 2017-2018, dos 68,9 milhões de domicílios, 36,7\% apresentaram algum grau de insegurança alimentar. Dos domicílios localizados no meio urbano, 35,1\% apresentaram insegurança alimentar. No entanto, no meio rural essa prevalência foi superior, chegando a 46,4\% dos domicílios (IBGE, 2020).

Desse modo, a insegurança alimentar que já estava se agravando no Brasil, alcançou índices ainda mais altos com a pandemia de Covid-19. A Rede Brasileira de Pesquisa em Soberania e Segurança Alimentar (Rede PENSSAN) realizou o Inquérito Nacional sobre Insegurança Alimentar no Contexto da Pandemia da Covid-19, com 2.180 domicílios, em áreas urbanas e rurais das cinco grandes regiões brasileiras, entre os meses de novembro e dezembro de 2020 , e detectou $55,2 \%$ dos domicílios em situação de insegurança alimentar, sendo $34,7 \%$, $11,5 \%$ e $9,0 \%$ insegurança alimentar leve, moderada e grave, respectivamente. Ainda, enquanto no meio urbano a prevalência de insegurança alimentar foi de $54,4 \%$, sendo $10,8 \%$ moderada e $8,5 \%$ grave; no meio rural esta mostrou-se ainda mais acentuada chegando a $60,0 \%$ de insegurança alimentar, sendo $14,9 \%$ moderada e $12,0 \%$ grave (REDE PENSSAN, 2021).

Destaca-se que nas macrorregiões Norte e Nordeste a insegurança alimentar moderada e grave no meio rural é ainda mais alarmada que nas outras macrorregiões do país com prevalências de 38,0\% e 34,9\%, respectivamente (REDE PENSSAN, 2021). 
Ao considerar a ocupação da pessoa de referência do domicílio verificou-se que aqueles domicílios chefiados por agricultor familiar ou produtor rural apresentaram 34,8\% de segurança alimentar, contrapondo a 29,5\%, 21,4\% e $14,3 \%$ de insegurança alimentar leve, moderada e grave, respectivamente. Ressalta-se que esta prevalência de insegurança alimentar moderada e grave $(35,7 \%)$ foi superior a encontrada em domicílios cujo morador de referência apresentava trabalho informal (29,9\%) (REDE PENSSAN, 2021).

É válido ressaltar que agricultores familiares são dependentes de água para a produção de alimentos, tanto para comercialização quanto para autoconsumo. Desta forma, observou-se que domicílios sem acesso a água para produção de alimentos apresentaram prevalências de insegurança alimentar moderada e grave duas vezes maior do que aqueles que tinham esse bem essencial. Ou seja, enquanto domicílios com acesso a água apresentaram $54,8 \%$ de insegurança alimentar, sendo $21,8 \%$ moderada e grave, aqueles sem acesso hídrico para produção de alimentos apresentaram $77,7 \%$ e $44,2 \%$, respectivamente (REDE PENSSAN, 2021).

Ainda sobre a produção de alimentos, tal pesquisa apontou que entre aqueles domicílios que tiveram redução nos preços ou na produção de alimentos a insegurança alimentar foi de $71,7 \%$, sendo $47,6 \%$ grave, enquanto naqueles que não tiveram alteração foi de $58,7 \%$, com $25,3 \%$ de presença de fome (REDE PENSSAN, 2021).

A pandemia ressalta os retrocessos ocorridos no Brasil nos últimos anos, como, por exemplo, a extinção da Secretaria Nacional de Segurança Alimentar e Nutricional (SESAN) pela Medida Provisória 870, assinada em $1^{\circ}$ de janeiro de 2019 pelo presidente da república e os cortes orçamentários para os programas governamentais como Programa de Aquisição de Alimentos (PAA), que geram impactos negativos para a SAN e, consequentemente, afetam os agricultores familiares (BRASIL, 2019; SANTARELLI et al., 2019). 


\section{FATORES RELACIONADOS À INSEGURANÇA ALIMENTAR NO MEIO RURAL}

A insegurança alimentar e nutricional, como o próprio conceito menciona, tem diversas vertentes para o seu atendimento. Esta exige ações múltiplas e transdisciplinares. Historicamente a SAN era tratada considerando somente questões de suficiência na disponibilidade alimentar. Porém, hoje compreende-se a necessidade de abarcar outras vertentes, como acesso e qualidade na oferta (LOPES, PAIXÃO, SANTOS, 2020). Desta forma, ressalta-se a importância em se discutir a SAN abordando conceitos como o de Direito Humano a Alimentação Adequada (DHAA) e Soberania Alimentar.

Tendo em vista a inter-relação da SAN, DHAA e soberania, a compreensão da alimentação adequada é incorporada. Esta considera algumas dimensões, como apresentado na Figura 1 (MACHADO; SPERANDIO, 2020).

Figura 1 - Dimensões da alimentação adequada.
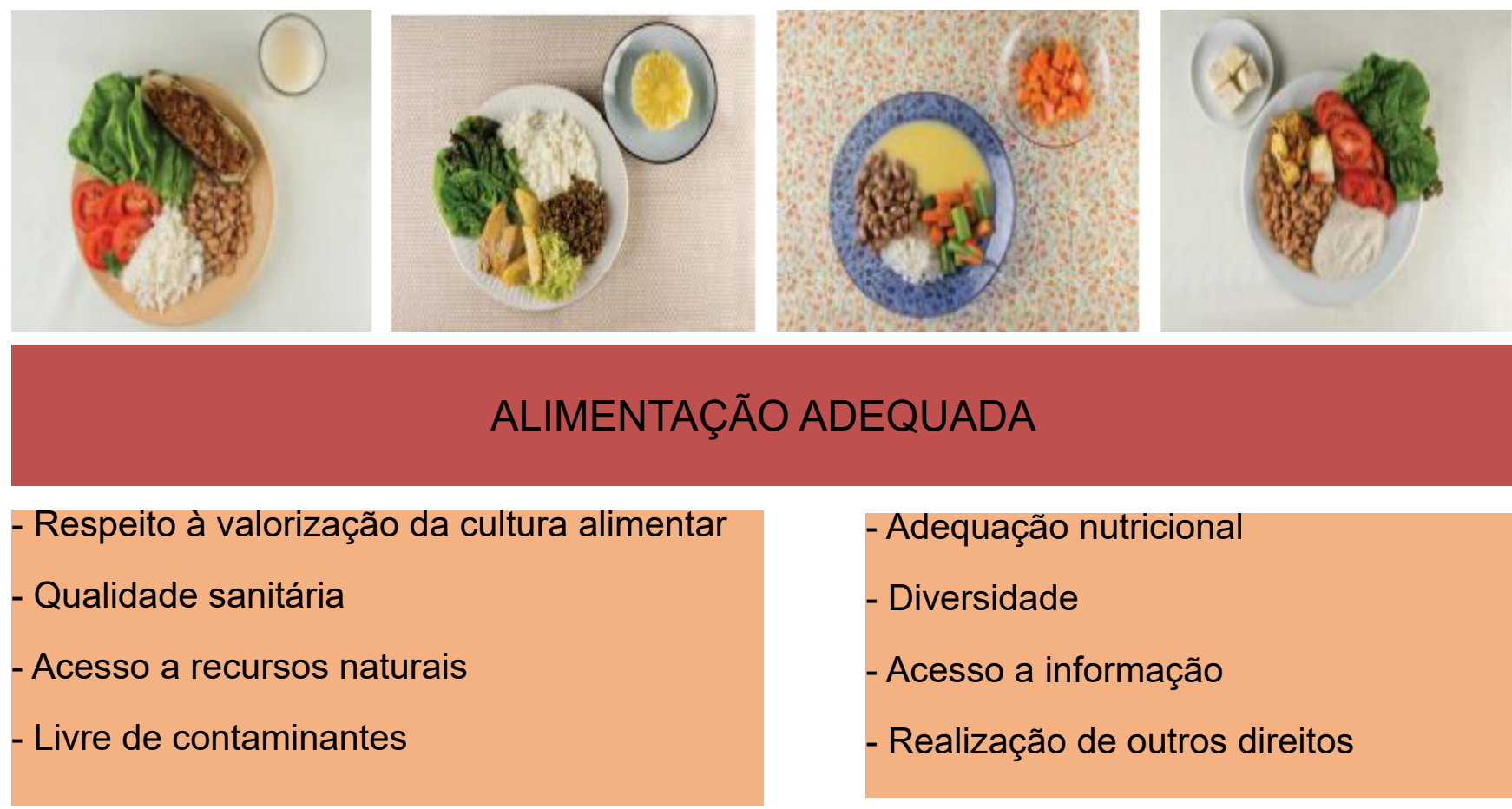

\section{ALIMENTAÇÃO ADEQUADA}

Fonte: Elaborado pelas autoras a partir de BRASIL, 2014; MACHADO; SPERANDIO, 2020. 
A inserção da compreensão de alimentação adequada no contexto da SAN demonstra ainda mais o processo de vulnerabilidade gerado pela pandemia. Isso externalizou a fragilidade das ações públicas em especial a da população rural, uma vez que, já ocorria desarticulação de programas e políticas públicas também no campo. A exemplo, a destinação de incentivo financeiro a programas como: Programa "Água para todos" (cisternas), Programa de Aquisição de Alimentos (PAA), incentivo a Assistência Técnica e Extensão Rural que tiveram reduções bruscas de $94 \%, 67 \%$ e 94\%, respectivamente, comparando os anos de 2014 e 2018 (VASCONCELOS et al., 2019).

Portanto, a população rural já sofria um processo de desorganização das ações, o que com a pandemia repercutiu em aumento nas prevalências de insegurança alimentar na população rural, aumento no desemprego, redução do poder de compra e dificuldades em acessar uma alimentação mais saudável e adequada (IBGE, 2020; MAAS et al., 2020).

A vulnerabilidade no campo tem origem em perda de ações que são protetivas para esta população, como a produção para autoconsumo. Este molde agrícola auxilia as famílias a ficarem menos susceptíveis a variações de mercado, que pode repercutir em dificuldades de acesso aos alimentos (LOPES, 2017). A pobreza rural é uma realidade, e este acesso limitado ao alimento é uma contraposição, já que a produção de alimentos ocorre no campo. Segundo Maas et al. (2020)

Um dos motivos da pobreza seria a troca de atividades agrícolas por atividades não agrícolas, devido à crise na agricultura e à mecanização da produção, o que tornou áreas rurais em áreas com aspectos tipicamente urbanos, em que a população passa a não depender da renda de atividades agrícolas (MAAS et al., 2020).

Estudo realizado em um município do Sul do Brasil com famílias rurais foi observado que $69,8 \%$ não plantam nenhum tipo de alimento e $60,1 \%$ não criam animais (MAAS et al., 2020). Diante desse contexto é apontada a necessidade de promoção de ações para favorecer estratégias de incentivo à produção para autoconsumo. 
As modificações no perfil da população rural, como o envelhecimento e êxodo rural, têm contribuído para fragilizar ainda mais este grupo (LUZ et al., 2020). As projeções de emprego e renda no campo não favorecem a permanência das famílias, e com a pandemia e a desorganização de programas como o Programa Nacional de Alimentação Escolar (PNAE) e o Programa de Aquisição de Alimentos (PAA), muitas famílias ficaram sem local de comercialização da sua produção. Em estudo realizado no Amazonas é destacado a importância da articulação de políticas para venda dos alimentos de origem da agricultura familiar, em especial, com a mediação do PNAE. Neste trabalhado é enfatizado as dificuldades destes agricultores em acessar os mercados e a importância da organização política para favorecer esta mediação e consequentemente a promoção da SAN (SILVA et al., 2020).

Outra dificuldade apresentada pelos agricultores, que se destacou durante a pandemia e isolamento social, é a dificuldade de acesso à internet e serviços bancários. Nesse contexto, a participação dos agricultores em chamadas públicas para oferta de alimentos às instituições públicas como escolas, e acesso ao auxílio emergencial do governo ficaram comprometidos, intensificando assim a vulnerabilidade no meio rural.

As diferenças sociais entre os agricultores também ficou ainda maior com a pandemia, isso se deve aos canais de comercialização. Os agricultores que forneciam para supermercados de forma direta ou indireta conseguiram escoar a sua produção, porque estes estabelecimentos permaneceram funcionando seguindo critérios de saúde para controle da pandemia. Já os restaurantes, feiras e escolas foram fechados, o que vulnerabilizou os agricultores que comercializavam para estes locais, contribuindo para insegurança alimentar e nutricional desta população (PEDROSO, CORCIOLI, FOGUESATTO, 2020).

A menor renda, presente no meio rural, ficou ainda mais evidente durante a pandemia em função do aumento da inflação no país que culminou em aumento do preço dos alimentos e comprometimento de quitação de contas fixas (como energia, medicamentos). Assim, a população, inclusive de agricultores familiares, 
passa a priorizar as outras despesas em detrimento da alimentação. Com isso, há modificações no perfil alimentar das famílias, com redução da qualidade e variedade de alimentos, e posteriormente da quantidade, conforme a situação de insegurança alimentar e nutricional vai se agravando.

A figura 2 sintetiza estes fatores relacionados ao aumento da insegurança alimentar e nutricional de agricultores familiares durante a pandemia.

Figura 2 - Fatores relacionados à insegurança alimentar e nutricional de agricultores durante a pandemia do coronavírus.

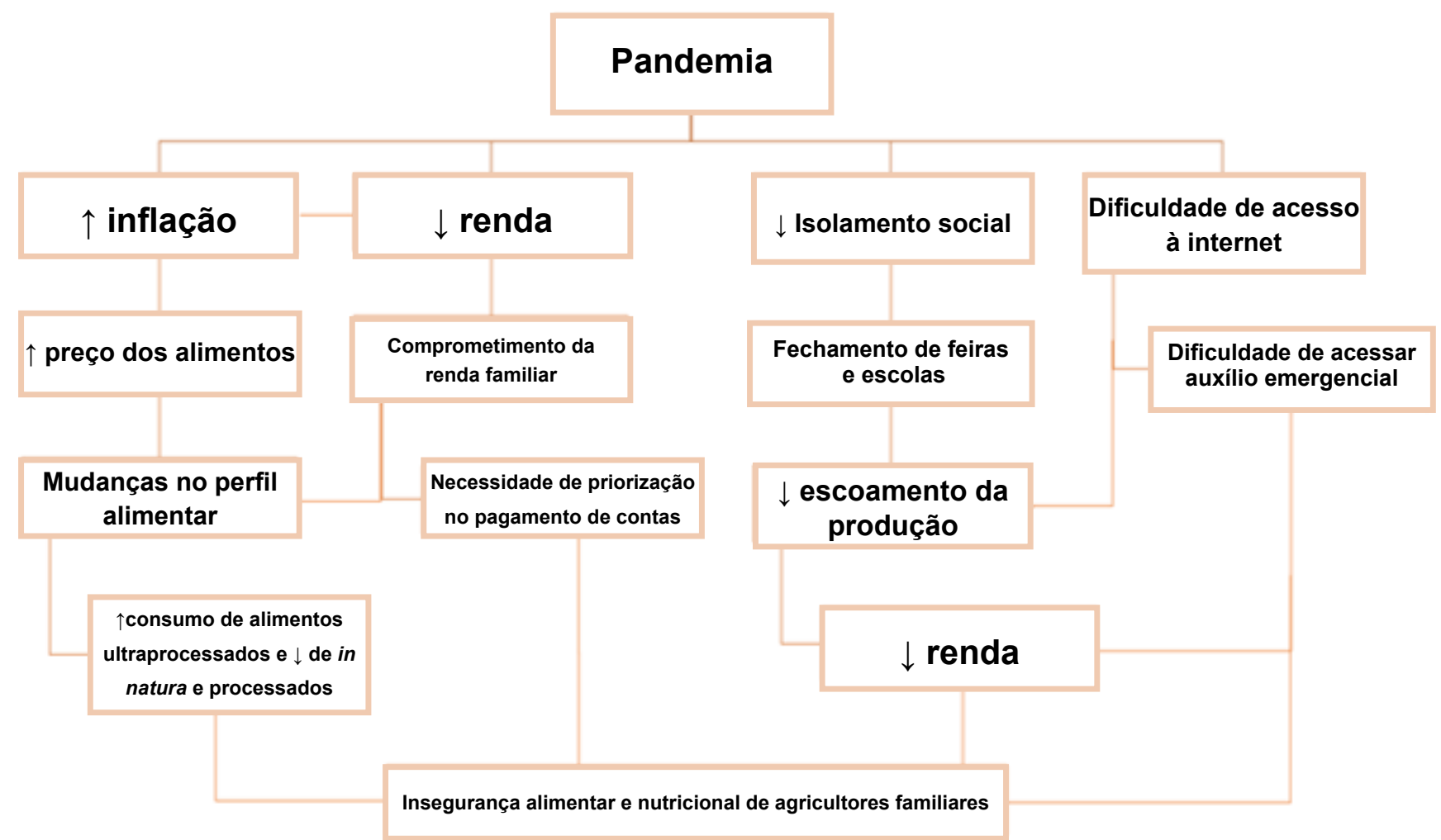

Fonte: Elaborado pelas autoras.

\section{ESTUDOS REALIZADOS COM AGRICULTORES FAMILIARES}

Pesquisas realizadas na zona rural do país, envolvendo agricultores familiares, demonstram altas prevalências de insegurança alimentar, avaliada por diferentes indicadores como Escala Brasileira de Insegurança Alimentar (EBIA), disponibilidade calórica e presença de desnutrição, no período anterior à pandemia (TRIVELLATO et al., 2019; CALIXTO et al., 2021). 
Assim, vista a importância de se trabalhar com este público e a necessidade de conhecer a realidade dos agricultores familiares de municípios da Zona da Mata Mineira, os Programas de Pós-graduação em Agroecologia e Ciência da Nutrição da Universidade Federal de Viçosa, Minas Gerais, tem desenvolvido pesquisas com agricultores familiares. O Quadro 1 traz resultados de pesquisas desenvolvidas, abordando a situação de insegurança alimentar no meio rural, no período anterior à pandemia. Ressalta-se que não encontramos publicações sobre essa temática desenvolvidas durante a pandemia, até o momento.

Quadro 1 - Pesquisas realizadas com agricultores familiares abordando a insegurança alimentar no meio rural, em período anterior a pandemia.

\begin{tabular}{|c|c|c|}
\hline Autores & Título da Dissertação & Resultados principais \\
\hline $\begin{array}{l}\text { Dutra } \\
(2013)\end{array}$ & $\begin{array}{c}\text { Insegurança Alimentar e } \\
\text { Nutricional e produção para } \\
\text { o autoconsumo na zona rural } \\
\text { de São Miguel do Anta, Minas } \\
\text { Gerais }\end{array}$ & $\begin{array}{l}\text { Verificou-se } 49,5 \% \text { ( } n=39) \text { dos domicílios em } \\
\text { situação de insegurança alimentar segundo } \\
\text { avaliação pela EBIA e 12,7\% ( } n=10) \text { pela } \\
\text { deficiência de energia alimentar. Em todos os } \\
\text { domicílios, do total de calorias disponíveis, } \\
22,7 \% \text { provinham da produção familiar. }\end{array}$ \\
\hline $\begin{array}{l}\text { Morais } \\
(2014)\end{array}$ & $\begin{array}{l}\text { (In)Segurança Alimentar e } \\
\text { Nutricional e relação com } \\
\text { indicadores sociais, econômi- } \\
\text { cos e nutricionais de famílias } \\
\text { residentes em zona rural }\end{array}$ & $\begin{array}{l}\text { Das famílias avaliadas } 49,4 \%(n=79) \\
\text { encontravam-se em situação de insegurança } \\
\text { alimentar, segundo avaliação pela EBIA. }\end{array}$ \\
\hline $\begin{array}{c}\text { Medeiros } \\
(2015)\end{array}$ & $\begin{array}{l}\text { Quintais urbanos e a situação } \\
\text { de (In)Segurança Alimentar de } \\
\text { famílias beneficiárias do } \\
\text { programa bolsa família, no } \\
\text { município de Viçosa, } \\
\text { Minas Gerais }\end{array}$ & $\begin{array}{l}\text { Encontrou-se prevalência de } 80,8 \% \text { ( } n=211 \text { ) } \\
\text { de insegurança alimentar, avaliada pela EBIA, } \\
\text { estando esta associada ao perfil sociodemo- } \\
\text { gráfico da população estudada: domicílios } \\
\text { com presença de menores de } 18 \text { anos e ado- } \\
\text { lescentes, número de moradores por domicí- } \\
\text { lio, situação do imóvel, tratamento da água e } \\
\text { trabalho do chefe da família. }\end{array}$ \\
\hline
\end{tabular}




\begin{tabular}{|c|c|c|}
\hline $\begin{array}{l}\text { Assis } \\
(2016)\end{array}$ & $\begin{array}{c}\text { Implementação do Programa } \\
\text { de Aquisição de Alimentos, } \\
\text { modalidade compra institucio- } \\
\text { nal, na Universidade Federal de } \\
\text { Viçosa, Minas Gerais e } \\
\text { situação de (In)Segurança } \\
\text { Alimentar e Nutricional dos } \\
\text { agricultores familiares benefi- } \\
\text { ciários fornecedores }\end{array}$ & $\begin{array}{l}\text { Observou-se, que todas as famílias dos } \\
\text { agricultores que participaram da pesquisa } \\
\text { encontravam-se em situação de segurança } \\
\text { alimentar, segundo a EBIA; todavia existia a } \\
\text { carência em relação a alguns indicadores } \\
\text { socioeconômicos e famílias com alterações } \\
\text { no estado nutricional. } \\
\text { Pela avaliação da disponibilidade domiciliar } \\
\text { de alimentos, todas as famílias também } \\
\text { estavam seguras, contudo ressalta-se que a } \\
\text { disponibilidade calórica per capita/dia ( } \geq 3.000 \\
\text { na maioria dos domicílios) também pode com- } \\
\text { prometer o estado de segurança alimentar. }\end{array}$ \\
\hline $\begin{array}{l}\text { Lopes } \\
(2017)\end{array}$ & $\begin{array}{l}\text { Impacto de ações de nutrição e } \\
\text { saúde no incentivo à produção } \\
\text { para o autoconsumo na } \\
\text { situação de (In)Segurança } \\
\text { Alimentar e Nutricional em } \\
\text { agricultores familiares no } \\
\text { Município de Viçosa-MG }\end{array}$ & $\begin{array}{l}\text { Segundo classificação da EBIA, foram encon- } \\
\text { trados 38,71\% ( } n=34) \text { domicílios em situação } \\
\text { de insegurança alimentar e a contribuição } \\
\text { monetária da produção para autoconsumo } \\
\text { correspondeu a } 20,5 \% \text { da renda total. }\end{array}$ \\
\hline $\begin{array}{l}\text { Miguel } \\
(2018)\end{array}$ & $\begin{array}{l}\text { Uso de agrotóxicos na produ- } \\
\text { ção de alimentos e condições } \\
\text { de saúde e nutrição de } \\
\text { agricultores familiares }\end{array}$ & $\begin{array}{l}\text { Pela disponibilidade domiciliar de alimentos } \\
\text { 10,4\% }(n=5) \text { dos agricultores familiares se } \\
\text { encontravam em situação de insegurança } \\
\text { alimentar e pela avaliação da deficiência de } \\
\text { energia alimentar, estavam inseguros } 64,6 \% \\
\text { (n=31). }\end{array}$ \\
\hline $\begin{array}{c}\text { Trivellato } \\
(2018)\end{array}$ & $\begin{array}{c}\text { Programa Nacional de Alimen- } \\
\text { tação Escolar (PNAE): partici- } \\
\text { pação da agricultura familiar em } \\
\text { Viçosa-MG e a situação de (In) } \\
\text { Segurança Alimentar e Nutricio- } \\
\text { nal de famílias de agricultores } \\
\text { fornecedores }\end{array}$ & $\begin{array}{l}\text { Verificou-se que } 26 \%(n=7) \text { dos domicílios se } \\
\text { encontravam em situação de insegurança } \\
\text { alimentar segundo avaliação da EBIA. }\end{array}$ \\
\hline
\end{tabular}




\begin{tabular}{|c|c|c|}
\hline $\begin{array}{c}\text { Silva } \\
(2019)\end{array}$ & $\begin{array}{l}\text { Feira de agricultura familiar e } \\
\text { economia solidária: implemen- } \\
\text { tação, desenvolvimento e } \\
\text { situação de (In)Segurança } \\
\text { Alimentar e Nutricional das } \\
\text { famílias expositoras }\end{array}$ & $\begin{array}{c}\text { Observou-se que } 90 \% \text { ( } \mathrm{n}=9 \text { ) das famílias } \\
\text { apresentaram pelo menos um indicador de } \\
\text { InSAN (distrofia nutricional e/ou classificação } \\
\text { de pobreza), contudo } 100 \% \text { das famílias es- } \\
\text { tavam seguras segundo avaliação pela EBIA } \\
\text { e pela disponibilidade domiciliar de alimentos. } \\
\text { Além disso, destaca-se a geração de renda e } \\
\text { criação de rede de apoio por meio do } \\
\text { ambiente da feira. }\end{array}$ \\
\hline
\end{tabular}

$\mathrm{EBIA}=$ Escala Brasileira de Insegurança Alimentar; InSAN= Insegurança Alimentar e Nutricional.

\section{AÇÕES DE ENFRENTAMENTO DA INSEGURANÇA ALIMEN- TAR E NUTRICIONAL RURAL DURANTE A PANDEMIA}

Fica evidente que a pandemia trouxe diversas consequências para população brasileira, aumentado as desigualdades sociais, raciais e de gênero já existentes, além de comprometer ainda mais a garantia do DHAA e a SAN. Diante desse cenário, o governo buscou alternativas para reverter essa situação, criando o auxílio emergencial, com o repasse de um pequeno valor financeiro aos indivíduos desempregados, além da distribuição de gêneros alimentícios adquiridos com recursos do PNAE para alunos matriculados na rede pública de ensino no período (ALPINO et al., 2020; BITTENCOURT et al., 2020).

Ressalta-se que o auxílio financeiro não chegou a todas as famílias que precisavam, inclusive no meio rural onde o acesso à internet para cadastro e às agências bancárias é dificultado. Além disso, o repasse não foi constante, culminando em receio e instabilidade financeira para as famílias. Dados demonstram que, no meio rural, das famílias que solicitaram e receberam o auxílio 35,9\% apresentavam insegurança alimentar leve e $33,2 \%$ moderada e grave, enquanto aquelas famílias que não receberam tal benefício apresentavam 25,1\% e 18,1\%, respectivamente (Rede PENSSAN, 2021).

Além disso, os gêneros alimentícios oferecidos pelo PNAE não cumpriram, em grande parte, as diretrizes do Programa de acesso universal a alimentos de 
qualidade, segundo necessidades nutricionais, durante 200 dias letivos. Muitas unidades executoras não conseguiram oferecer os kits de alimentos de forma periódica e adequada (SPERANDIO; MORAIS, 2021). Pensando na logística de entrega destes kits, acredita-se que muitas famílias de agricultores, com filhos matriculados na rede pública de ensino, não tiveram acesso a esta alimentação ofertada, uma vez que o transporte é dificultado e muitas vezes a informação não chega aquelas regiões mais distantes do centro.

Visando reduzir os impactos socioeconômicos e o aumento da vulnerabilidade e insegurança alimentar e nutricional em agricultores familiares em função da pandemia, foi aprovada a Lei $n^{\circ} 14.048$, de 24 de agosto de 2020. Esta dispõe sobre medidas emergenciais para amparo aos agricultores familiares, alterando as leis $\mathrm{n}^{\circ}$ 13.340, de 28 de setembro de 2016, e 13.606, de 9 de janeiro de 2018, vigentes até então. No seu texto, apenas dois artigos com ações específicas a este público não foram vetados. Estes trazem os dizeres de que o recebimento de auxílio emergencial por agricultores familiares não descaracteriza a condição de segurado especial dos mesmos (Artigo $3^{\circ}$ ); e de que parcelas vencidas emitidas em favor da Companhia Nacional de Abastecimento (Conab) por organizações de agricultores familiares cuja comercialização da produção tenha sido prejudicada pela pandemia da Covid-19, no âmbito do PAA, podem ser quitadas em produtos.

Estas regulamentações foram superficiais e consequentemente tendem a ser ineficazes no combate à crise instalada, inclusive no meio rural. Ressalta-se que tramita no Senado Federal o projeto de Lei $n^{\circ} 823 / 2021$ com o intuito de retomar regulamentações vetadas na lei supracitada, que teriam vigência até 2022. Este PL visa criar o Fomento Emergencial de Inclusão Produtiva Rural, destinado a agricultores familiares em situação de pobreza e de extrema pobreza; concessão automática do Benefício Garantia-Safra; criação de linhas de crédito rural no âmbito do Programa Nacional de Fortalecimento da Agricultura Familiar (Pronaf) para o custeio e investimento na produção de alimentos básicos; instituir o Programa de Atendimento Emergencial à Agricultura Familiar (PAE-AF), visando 
a compra de alimentos oriundos da agricultura familiar e doação a pessoas em insegurança alimentar e nutricional; e prorrogação das dívidas rurais da agricultura familiar para um ano após a última prestação (AGÊNCIA CÂMARA DE NOTíCIAS, 2021).

Assim, ressalta-se que a criação de programas de transferência de renda e seguridade de emprego criados durante a pandemia foram medidas emergenciais necessárias para garantir o acesso ao alimento aos grupos mais vulneráveis. Contudo é importante destacar a importância da continuidade destes programas, visando amenizar a grave situação ainda vivenciada no país, uma vez que nota-se omissão do governo frente a muitos agravos da pandemia da COVID-19 (SANTOS et al., 2021).

Como afirmava Herbert de Souza, o Betinho, "quem tem fome, tem pressa". Logo, estratégias para implementação de políticas de acesso à alimentação adequada e saudável, ou seja, advinda de sistemas sustentáveis, promotores de saúde e que valorizem a cultura e hábitos alimentares fazem se extremamente necessárias também no período pós-pandemia.

\section{CONCLUSÃO}

O cenário atual da pandemia exige compreensão da magnitude dos problemas futuros. Desta forma, medidas governamentais se fazem necessárias para assegurar o acesso à alimentação adequada e saudável, com vistas a reduzir os impactos negativos da pandemia para os mais vulneráveis, como os agricultores familiares.

Políticas específicas a serem adotadas pelos governos para promover e garantir a segurança alimentar e nutricional e impedir a expansão da insegurança alimentar e da fome durante e após esta crise social e sanitária gerada pela pandemia são extremamente urgentes e necessárias, visando reduzir/amenizar as repercussões desta situação para os próximos anos. 


\section{REFERENCIAS}

AGÊNCIA CÂMARA DE NOTÍlCAS. Projeto institui medidas de amparo a agricultores familiares durante e após a pandemia, 2021. Disponível em https:// www.camara.leg.br/noticias/736986-projeto-institui-medidas-de-amparo-a-agricultores-familiares-durante-e-apos-a-pandemia/. Acesso em: 06 set. 2021.

ALMEIDA, J. A. et al. Fatores associados ao risco de insegurança alimentar e nutricional em famílias de assentamentos rurais. Ciência e Saúde Coletiva, Rio de Janeiro, v. 22, n. 2, p. 479-478, 2017.

ALPINO, T. M. A. et al. COVID-19 e (in) segurança alimentar e nutricional: ações do Governo Federal brasileiro na pandemia frente aos desmontes orçamentários e institucionais. Cadernos de Saúde Pública, Rio de Janeiro, v. 36, n. 8, p. 1-17, 2020.

ASSIS, S. C. R. Implementação do Programa de Aquisição de Alimentos, modalidade compra institucional, na Universidade Federal de Viçosa, Minas Gerais e situação de (In)Segurança Alimentar e Nutricional dos agricultores familiares beneficiários fornecedores. Orientadora: Silvia Eloiza Priore. 2016. 319f. Dissertação (Mestrado em Agroecologia). Universidade Federal de Viçosa, Viçosa, 2016.

BITTENCOURT, M. J. et al. O papel do Café com Agroecologia na discussão do Programa Nacional de Alimentação Escolar (PNAE), em tempo de pandemia: Relato de Experiência. ANAIS: Simpósio de Pós-graduação em Agroecologia (SIMPA-UFV), Viçosa-MG, p. 69-72, 2020.

BRASIL. Lei $n^{\circ}$ 11.346, de 15 de setembro de 2006. Cria o Sistema Nacional de Segurança Alimentar e Nutricional - SISAN com vistas em assegurar o direito humano à alimentação adequada e dá outras providências. Diário Oficial [da] República Federativa do Brasil, Brasília, DF, set. 2006a.

BRASIL. Casa Civil. Lei no. 11.326 de 24 de julho de 2006. Estabelece as diretrizes para a formulação da Política Nacional da Agricultura Familiar e Empreendimentos Familiares Rurais. Diário Oficial [da] República Federativa do Brasil, Brasília, DF, jul. 2006b. 
BRASIL. Ministério da Saúde. Guia alimentar para a população brasileira. Brasília: Ministério da Saúde, $2^{\mathrm{a}}$ ed., 2014. 156p.

BRASIL. Medida Provisória $n^{\circ} 870$, de $1^{\circ}$ de janeiro de 2019. Estabelece a organização básica dos órgãos da Presidência da República e dos Ministérios. Diário Oficial [da] República Federativa do Brasil, Poder Executivo, Brasília, DF, $1^{\circ}$ jan. 2019.

CALIXTO, F. A. M. et al. Food availability and food and nutrition (in)security of families providing for the National School Feeding Program. Revista de Nutrição, Campinas, v. 34, p. 1-11, 2021.

CARVALHO, E. O.; ROCHA, E. F. Consumo alimentar de população adulta residente em área rural da cidade de lbatiba (ES, Brasil). Ciência e Saúde Coletiva, Rio de Janeiro, v. 16, n. 1, p. 179-185, 2011.

DUTRA, L. V. Insegurança Alimentar e Nutricional e produção para o autoconsumo na zona rural de São Miguel do Anta, Minas Gerais. Orientadora: Silvia Eloiza Priore. 2013. 118f. Dissertação (Mestrado em Agroecologia). Universidade Federal de Viçosa, Viçosa, 2013.

FONTOURA, A. F. A produção para autoconsumo: características e importância para os sistemas de produção de pecuária familiar da fronteira oeste do RS. Orientador: Pedro Selvino Neumann. 2012. 152 f. Dissertação (Mestrado em Extensão Rural). Universidade Federal de Santa Maria, Santa Maria, 2012.

FUTEMMA, C. et al. A pandemia da Covid-19 e os pequenos produtores rurais: superar ou sucumbir?. Boletim Museu Paraense Emílio Goeldi, Belém, v. 16, n. 1, p. 2-10, 2021.

GRISA, C.; GAZOLLA, M.; SCHNEIDER S. A "produção invisível” na agricultura familiar: autoconsumo, segurança alimentar e políticas públicas de desenvolvimento rural. Agroalimentaria, Mérida, v. 16, n. 31, p. 65-79, 2010.

INSTITUTO BRASILEIRO DE GEOGRAFIA E ESTATÍSTICA-IBGE. POF 20172018: proporção de domicílios com segurança alimentar fica abaixo do resultado de 2004. 2020. Disponível em: https://agenciadenoticias.ibge.gov.br/agencia-sala-de-imprensa/2013-agencia-de-noticias/releases/28896-pof-2017-2018-proporcao-de-domicilios-com-seguranca-alimentar-fica-abaixo-do-resultado-de-2004. Acesso em: 31 ago. 2021. 
KEPPLE, A. W.; SEGALL-CORREAA, A. M. Conceituando e medindo segurança alimentar e nutricional. Ciência e Saúde Coletiva, Rio de Janeiro, v. 21, p.111122, 2011.

LOPES, S. O. Impacto de ações de nutrição e saúde no incentivo à produção para o autoconsumo na situação de (in)segurança alimentar e nutricional em agricultores familiares no Município de Viçosa-MG. Orientadora: Silvia Eloiza Priore. 2017. 277 f. Dissertação (Mestrado em Agroecologia), Universidade Federal de Viçosa, Viçosa, 2017.

LOPES, S.O.; PAIXÃO, M.Q.; SANTOS, R.H.S. A (in) sustentabilidade produtiva e a (in) Segurança Alimentar e Nutricional. In: MORAIS, D.C.; SPERANDIO, N.; PRIORE, S.E. Atualizações e debates sobre segurança alimentar e nutricional. FACEV. 2020.

LUZ, T, C. et al. Fatores de risco cardiovascular em uma população rural Brasileira. Ciência e Saúde Coletiva, Rio de Janeiro, v. 25, p. 3921-3932, 2020.

MAAS, N. M. et al. Insegurança Alimentar em famílias de área rural do extremo sul do Brasil. Ciência e Saúde Coletiva, Rio de Janeiro, v. 25, p. 2605-2614, 2020.

MACHADO, J.C.; SPERANDIO, N. Introdução à Segurança Alimentar e Nutricional. In: MORAIS, D.C.; SPERANDIO, N.; PRIORE, S.E. Atualizações e debates sobre segurança alimentar e nutricional. FACEV. 2020.

MALUF, R. S; REIS, M. C. Conceitos e Princípios de Segurança Alimentar e Nutricional. In: Segurança Alimentar e Nutricional: perspectivas, aprendizados e desafios para as políticas públicas. Rio de Janeiro: Editora Fiocruz. 2013.

MEDEIROS, N. S. Quintais urbanos e a situação de (In)Segurança Alimentar de famílias beneficiárias do programa bolsa família, no município de Viçosa, Minas Gerais. Orientadora: Silvia Eloiza Priore. 2015. 147f. Dissertação (Mestrado em Agroecologia). Universidade Federal de Viçosa, Viçosa, 2015.

MIGUEL, E. S. Uso de agrotóxicos na produção de alimentos e condições de saúde e nutrição de agricultores familiares. Orientadora: Silvia Eloiza Priore. 2018. 161 f. Dissertação (Mestrado em Agroecologia). Universidade Federal de Viçosa, Viçosa, 2018. 
MORAIS. D. C. (In)Segurança Alimentar e Nutricional e relação com indicadores sociais, econômicos e nutricionais de famílias residentes de zona rural. Orientadora: Silvia Eloiza Priore. 2014. 158 f. Dissertação (Mestrado em Ciência da Nutrição). Universidade Federal de Viçosa, Viçosa, 2014.

ORGANIZAÇÃO PAN-AMERICANA DA SAÚDE - OPAS. Folha informativa sobre COVID-19. 2021. Disponível em: https://www.paho.org/pt/covid19. Acesso em: 31 ago. 2021.

PEDROSO, M. T. M.; CORCIOLI , G. .; FOGUESATTO, C. A crise do Coronavírus e o agricultor familiar produtor de hortaliças. Gestão e Sociedade, Belo Horizonte, v. 14, n. 39, p. 3740-3749, 2020.

PEREIRA, D. A. et al. Insegurança Alimentar em Região de Alta Vulnerabilidade Social da Cidade de São Paulo. Revista Segurança Alimentar e Nutricional, Campinas, v.13, n. 2, p.34-42, 2006.

REDE BRASILEIRA DE PESQUISA EM SOBERANIA E SEGURANÇA ALIMENTAR - Rede PENSSAN. Inquérito Nacional sobre Insegurança Alimentar no Contexto da Pandemia da Covid-19 no Brasil (VIGISAN). 2021. Disponível em: http://olheparaafome.com.br/VIGISAN_Inseguranca_alimentar.pdf. Acesso em: 31 ago. 2021.

RIBEIRO-SILVA, R. C. et al. Implicações da pandemia COVID-19 para a segurança alimentar e nutricional no Brasil. Ciência e Saúde Coletiva, Rio de Janeiro, v. 25, n. 9, p. 3421-3430, 2020.

SANTARELLI, M. et al. Autoritarismo, negação de direitos e fome. Brasília: FIAN Brasil, 2019.

SANTOS, M. V. A. et al. Insegurança alimentar e nutricional: uma análise sobre as políticas públicas de interface com alimentação e nutrição em meio a pandemia por Sars-CoV-2. Segurança Alimentar e Nutricional, Campinas, v. 28, p. 1-17, 2021.

SILVA, C. C. S. et al. Associação entre consumo alimentar e (in)segurança alimentar e nutricional em São José dos Ramos - PB. Brazilian Journal of Food Technology, Campinas, v. 15, p. 23-30, 2012. 
SILVA, L. H. et al. PNAE em tempos de pandemia: desafios e potencialidades para sua operacionalização no contexto amazônico. Mundo Amazónico, v. 11, n. 2, p. 1-20, 2020.

SILVA, R. N. Feira de Agricultura Familiar e Economia Solidária: implementação, desenvolvimento e situação de (In)Segurança Alimentar e Nutricional das famílias expositoras. Orientadora: Silvia Eloiza Priore. 2019. 177f. Dissertação (Mestrado em Agroecologia). Universidade Federal de Viçosa, Viçosa, 2019.

SPERANDIO, N.; MORAIS, D. C. Alimentação escolar no contexto de pandemia: a ressignificação e o protagonismo do Programa Nacional de Alimentação Escolar. Segurança Alimentar e Nutricional, Campinas, v. 28, p. 1-11. 2021.

TRIVELLATO, P. T. Programa Nacional de Alimentação Escolar (PNAE): participação da agricultura familiar em Viçosa-MG e a situação de (In)Segurança Alimentar e Nutricional de famílias de agricultores fornecedores. Orientadora: Silvia Eloiza Priore. 2018. 192f. Dissertação (Mestrado em Agroecologia). Universidade Federal de Viçosa, Viçosa, 2018.

TRIVELLATO, P.T. et al. Insegurança alimentar e nutricional em famílias do meio rural brasileiro: revisão sistemática. Ciência e Saúde Coletiva, Rio de Janeiro, v.24, n.3, p.865-874, 2019.

VASCONCELOS, F.A.G. et al. Public policies of food and nutrition in Brazil: From Lula to Temer. Revista de Nutrição, Campinas, v. 32, 2019. 
d $10.48209 / 978-65-89949-32-4$
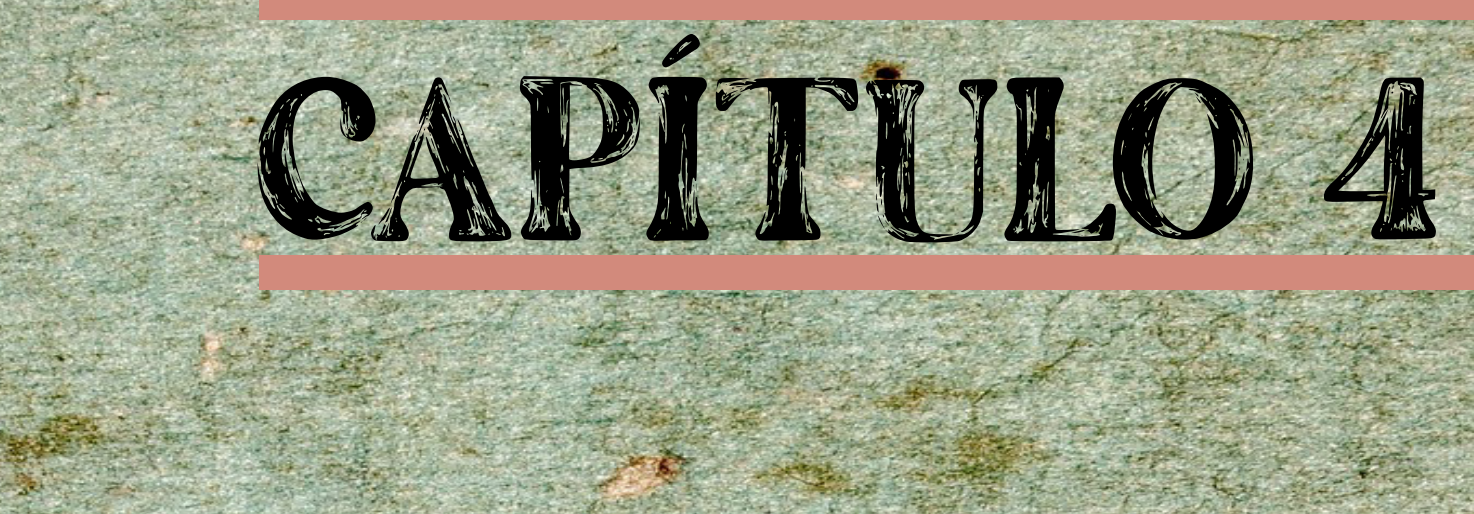

\section{SEGURANÇA \\ $\rightarrow$ ALIMENTAR E \\ QUALIDADE AMBIENTAL: UMA PROPOSTA DE UTILIZAÇÃO DA JACA VERDE COMO ALIMENTO}

Kathleen Hodgson Weintraub Camila Gonçalves de Oliveira Rodrigues Katia Cilene Tabai 


\section{INTRODUÇÃO}

A transformação do sistema alimentar em um modelo capaz de atender toda a população com alimentos saudáveis ${ }^{7}$, ao mesmo tempo que respeita a qualidade ambiental e os aspectos socioculturais dos territórios, é um desafio na sociedade contemporânea. Neste contexto, o debate sobre as alternativas de produção de alimentos que sejam mais sustentáveis, considerando as dimensões social, ambiental e econômica, vem sendo pautado por diferentes campos do conhecimento. Isso envolve, inclusive, pensar em alimentos que crescem naturalmente com abundância em uma determinada região e que são resilientes às alterações ambientais que acompanham as mudanças climáticas.

Este estudo visa explorar um exemplo deste tipo de alimento, a jaca, fruto da árvore jaqueira (Artocarpus heterophyllus Lam.), que cumpre esta função em vários ecossistemas no Brasil. A jaca é abundante em diferentes regiões do país, sobretudo em áreas do bioma Mata Atlântica. A fruta tem diferentes propriedades nutricionais e é utilizada de maneira variada na culinária. A árvore da jaqueira, por sua vez, tem uma resiliência às mudanças climáticas muito maior que cultivos de grande escala como trigo e milho. Ao mesmo tempo, a árvore jaqueira é uma espécie exótica no Brasil, considerada uma espécie com comportamento invasivo ou oportunista ${ }^{8}$, na Mata Atlântica, por profissionais conservacionistas e gestores de algumas áreas protegidas (MOURA, 2011; ABREU, 2008).

$7 \quad$ Para os fins desta pesquisa, utilizou-se o conceito de alimentação saudável contemplado no Guia Alimentar para a População Brasileira, a saber, a alimentação saudável baseia-se no consumo e preparação culinária principalmente de alimentos in natura ou minimamente processados, com variedade e predominantemente de origem vegetal (BRASIL, 2014). O guia alimentar enfatiza a utilização de alimentos produzidos pela agricultura familiar, de preferência orgânicos ou de base agroecológica e a necessidade de evitar o uso de alimentos ultraprocessados, aqueles prontos para o consumo, em detrimento da chamada comida de verdade (TABAI, 2018).

8 Segundo a Plataforma Intergovernamental sobre Biodiversidade e Serviços Ecossistêmicos (IPBES), uma espécie invasora tem uma tendência "a expandir e modificar os ecossistemas aos quais foi introduzido" (IPBES, 2020). Ao mesmo tempo, outras disciplinas têm sugerido a substituição da palavra invasora para o termo oportunista para categorizar espécies que se adaptam facilmente e crescem abundantemente em novos habitats devido a sua habilidade de dispersar por longas distâncias e reproduzir. 
O manejo da jaqueira em Unidades de Conservação (UC) (BRASIL, 2000) e respectivas zonas de amortecimento é uma prioridade e também um desafio para os gestores destas áreas. Planos atuais de controle geralmente se baseiam em eliminação ou redução da espécie através de anelamento e uso de herbicidas, frequentemente apresentando resultados inadequados e criando outros problemas ambientais (CABRAL, et al. 2020).

No entanto, este estudo visa explorar um manejo alternativo, baseado na comercialização da jaca verde como um alimento, buscando integrar a segurança alimentar e a conservação de florestas na Mata Atlântica. Tal comercialização visa transformar o desafio do controle da espécie da jaqueira em uma oportunidade de promover uma melhor alimentação na região e gerar renda para pequenos proprietários rurais. O manejo da jaqueira para fins alimentares pode funcionar em bases sustentáveis, a partir de um modelo com critérios ambientais claros e indicadores sociais e econômicos relevantes no contexto das políticas públicas intersetoriais de Segurança Alimentar e Nutricional ${ }^{9}$. Um manejo a partir da coleta dos seus frutos para processamento e comercialização poderia apresentar uma estratégia mais sustentável, que auxilie o objetivo dos gestores de diminuir a densidade de plântulas de jaqueira, diminuindo também sua densidade populacional, enquanto aproveita os benefícios alimentares da árvore.

A fim de contribuir para o desenvolvimento de um modelo de manejo da jaca que favoreça a sustentabilidade ambiental, social e econômica das pessoas e os ecossistemas que abrigam estas árvores, será necessária uma investigação da jaqueira, a partir de uma abordagem interdisciplinar, explorando a história, ecologia, nutrição e usos culinários desta planta subutilizada no Brasil.

9 De acordo com o artigo $4^{\circ}$. da Lei Orgânica de Segurança Alimentar e Nutricional LOSAN, a segurança alimentar pode ser definida como a garantia da qualidade biológica, sanitária, nutricional e tecnológica dos alimentos, bem como seu aproveitamento, estimulando práticas alimentares e estilos de vida saudáveis que respeitem a diversidade étnica e racial e cultural da população (BRASIL, 2006). 


\section{JAQUEIRAS NA MATA ATLÂNTICA: UM OLHAR SOCIOECOLÓGICO PARA UMA ESPÉCIE EXÓTICA}

A jaqueira (Artocarpus heterophyllus Lam.) é uma árvore frutífera que pode ser encontrada em muitas regiões do país, em áreas abertas e de florestas, em unidades de conservação, e principalmente nos grandes centros urbanos, parques, quintais e jardins (ABREU; RODRIGUES, 2005). Apesar da sua significativa presença no país, a jaqueira não é uma espécie nativa do Brasil. Ela é exótica, originalmente da Índia e da região do sudeste da Ásia. No estado do Rio de Janeiro, ela se apresenta em densidades elevadas em determinados ambientes, incluindo áreas protegidas. Esta densidade de jaqueiras em UC e suas zonas de amortecimento, tem preocupado profissionais conservacionistas e gestores destas áreas em virtude da correlação percebida entre alta densidade de jaqueiras e baixa biodiversidade da flora e fauna nacionais (RAMOS, 2011).

Uma espécie pode mostrar comportamento considerado invasivo num lugar e não em outros, como a jaqueira, a qual é somente chamada uma espécie invasora no Brasil, apesar do fato que cresce em muitos países da África, Ásia e América Latina (BASSO, 2017). Neste sentido, este estudo visa apresentar a jaqueira a partir de uma perspectiva que vai além da abordagem da biologia da conservação, mas que inclui também um olhar histórico, social, cultural e geográfico. Portanto, o tema da jaqueira no bioma Mata Atlântica será abordado a partir da perspectiva teórica-metodológica de sistemas socioecológicos (SSE), uma abordagem interdisciplinar, que reconhece a interconectividade entre sociedade e natureza, e busca compreender como esta inter-relação se manifesta em nossas paisagens. A perspectiva de SSE traz uma nova abordagem para a gestão dos bens comuns, afirmando que todos os recursos utilizados por humanos estão contemplados em sistemas socioecológicos (OSTROM, 2009). Especificamente, SSE são "unidades biogeofísicas e os atores sociais e instituições associadas, sendo inerentemente complexos e com capacidade adaptativa, delimitados por limites espaciais ou funcionais, envolvendo determinado ecossistema e seu contexto de problemas ou conflitos" (GLASER et al. 2012 citado por SOLÓRZANO 
et al., 2018, pg. 3). Segundo Solorzano et. al (2018), um SSE pode ser aplicado e entendido em várias escalas; no caso deste estudo, a perspectiva de SSE será utilizada para abordar a presença da jaqueira nas florestas remanescentes da Mata Atlântica no estado do Rio de Janeiro.

Aplicando o conceito de SSE para uma espécie exótica considerada invasora, busca-se indicar soluções mais integradas, aplicáveis e efetivas para o seu manejo em UC e suas zonas de amortecimento. Esta perspectiva interdisciplinar traz um novo olhar para uma espécie que foi considerada "vilã" no passado recente. Alguns pesquisadores, a partir da perspectiva dos SSE, questionam o uso da terminologia "invasora", preferindo o termo "oportunista" para caracterizar espécies que se adaptam facilmente e crescem abundantemente em novos habitats, devido a sua habilidade de dispersão por longas distâncias e fácil reprodução (SCIENCE JRANK, 2020). A partir desta perspectiva de SSE, a distribuição da jaqueira nas florestas do Rio de Janeiro passa a ser compreendida como sendo entrelaçada com a história de colonização e ocupação do Brasil, uma vez que sua presença está sempre associada à ambientes com clara evidência da presença humana, seja no passado como no presente. Começamos primeiro com esta história.

\section{UMA BREVE HISTÓRIA DA JAQUEIRA NO BRASIL E NO RIO DE JANEIRO}

A jaqueira pertence à Família Moraceae, Subfamília Artocarpoideae, Gênero Artocarpus e Espécie Artocarpus heterophyllus Lam. A palavra "Artocarpus" deriva do grego; Artos significa pão e carpos significa fruta (BASSO, 2017). Esta espécie nativa da Índia foi introduzida no Brasil como parte de um plano de experimentação agrícola dos portugueses, iniciado aproximadamente em 1680, no qual várias espécies asiáticas que tinham valor potencial de mercado para exportação à Europa foram levadas às colônias portuguesas (CABRAL, et al. 2016). A diminuição do preço do açúcar estava impactando a economia do Brasil e os colonos portugueses estavam em busca de alternativas de renda. Em 1683, 
portugueses enviaram do porto da cidade de Goa, na Índia, para Salvador, uma quantidade entre 35 e 40 mudas de jaqueira, que chegaram de barco, juntamente com instruções de plantio (SOLORZANO, et al. 2017). A espécie nunca virou um produto de exportação como foi originalmente imaginado pela Coroa Portuguesa; em vez disso, a espécie foi sendo disseminada pelo nordeste do Brasil e depois para outras regiões do país, como uma árvore ornamental para chácaras periurbanas - devido ao valor estético e sua utilização como quebra-vento. A madeira da jaqueira também é excelente para movelaria e construção civil, sendo empregada na construção naval. Acabou se tornando um importante alimento popularmente consumido por escravos e pessoas de baixa renda, e até consumida pelo gado devido ao seu baixo custo e abundância. (SOLORZANO et al. 2017).

Durante o século XVIII, a jaqueira se espalhou ao norte e ao sul do país. A espécie se adaptou aos ambientes com tanta facilidade, que no final do século a fruta foi considerada asiática e brasileira, com alguns botânicos a chamarem de Artocarpus brasiliensis. Segundo Solorzano et al. (2019) "a visão dominante dada por ambientalistas e conservacionistas da jaqueira ser exótica e invasora, é algo historicamente mais recente e que ganhou corpo apenas nas últimas décadas com estudos sobre a dinâmica populacional da espécie em uma floresta urbana do Rio de Janeiro"(p. 119). Historiadores estimam a chegada da jaqueira no Rio de Janeiro no ano 1780 , onde ela também se espalhou pela cidade e arredores como uma árvore ornamental e para uso alimentar (SOLORZANO, et al. 2017). Foram registradas citações da presença da jaqueira em chácaras e passeios públicos do Rio em vários documentos da época, como os relatos das cientistas Johann Baptist Von Spix e Carl Friedrich Philipp Von Martius e o livro de Monsignor José Pizarro (SPIX; MARTIUS, 1824, p. 174 citado por CABRAL, et al. 2016). Mudas de jaqueira que vieram da ilha de Mauritius, na África, também foram plantadas no Jardim Botânico do Rio de Janeiro em 1809 (CABRAL et al. 2016.

A jaqueira também era uma das espécies exóticas escolhidas para o reflorestamento do Parque da Tijuca em 1861 por Manuel Gomes Archer (SALES; GUEDES-BRUNI, 2018). 
Cabral et al (2016) concluem que Archer provavelmente notou a capacidade da jaqueira de tolerar solo degradado melhor que as espécies nativas; então além de seu valor como alimento e espécie ornamental, a jaqueira foi utilizada no projeto para criar as condições necessárias para outras espécies nativas crescerem.

A jaqueira é uma espécie muito comum no Parque Nacional da Tijuca, especialmente nas porções de borda da floresta e associada às antigas fazendas, chácaras e carvoarias (SOLORZANO et al., 2018). Solorzano et al. (2018) argumentam que a alta capacidade biológica de se reproduzir da jaqueira não é suficiente para explicar o número atual dos indivíduos no parque. Segundo os autores, a jaqueira já tinha chegado e se espalhado no maciço da tijuca antes do reflorestamento através do consumo da fruta da jaca nas carvoarias e fazendas de café que ocupavam a região; os humanos que transitavam a área que é atualmente o Parque Nacional da Tijuca comiam e jogavam sementes depois de comer a polpa da fruta (SOLORZANO et al., 2018).

Este estudo sugere que a situação atual de uma alta densidade de jaqueiras na floresta é resultado de anos de intervenções humanas, não só de uma introdução inicial de poucos indivíduos da espécie. Para Solorzano (2019), a floresta da Tijuca é uma Sistema Socioecológico (SSE), em que as condições de expansão da espécie da jaqueira foram criadas pelas ações humanas dentro da floresta. "Em vez de invadir a floresta pristina, a jaqueira ocupa os espaços abertos pelas atividades humanas, particularmente pelas populações que dependiam da floresta para obter sustento e moradia" (SOLORZANO, 2019, p. 117).

Os pesquisadores também sugerem que estas atividades antrópicas nas florestas urbanas do Rio de Janeiro produzem ecossistemas diferentes dos encontrados nos padrões do bioma Mata Atlântica, os quais podem ser chamados ecossistemas emergentes. Ecossistemas emergentes - ou neoecossistemas - apresentam "padrões de dominância (composição e abundância relativa) não vistos anteriormente em dados biomas, sendo resultado da ação antrópica, porém que não depende do humano para perpetuar tais padrões" (HOBBS et 
al., 2006 citado por LOUREIRO, [2018]). Solórzano et al. (2019) propõe que a floresta urbana Parque Nacional da Tijuca, com uma alta densidade de jaqueiras, é um exemplo de um neoecossistema, em qual existe uma alteração em sua funcionalidade ecológica, estrutura e composição. A introdução de espécies exóticas é uma forma de gerar ecossistemas emergentes, juntamente das formas tradicionais de transformação da paisagem (HOBBS et al., 2006). A interação da sociedade moderna através destes usos e atividades pretéritas na floresta produziu ecossistemas diferentes dos encontrados nos padrões da Mata Atlântica, apresentando alteração em sua funcionalidade ecológica, estrutura e composição, originando os ecossistemas emergentes. Para Solorzano et al. (2019), as florestas do Rio de Janeiro se apresentam como ecossistemas emergentes, com a densidade de jaqueiras um sinal claro desta transformação. Ecossistemas emergentes apresentam um desafio para gestores de áreas protegidas, devido ao fato que existem barreiras significativas para devolver eles ao seu estado histórico (HOBBS, et al. 2013).

A jaqueira adaptou-se aos vários biomas do país, sendo encontrada nos estados de Amazonas, Bahia, Espírito Santo, Paraíba, Paraná, Pernambuco, Piauí, Rio de Janeiro, Rio Grande do Norte, Santa Catarina, São Paulo e o Distrito Federal (INSTITUTO HORUS, 2020). A espécie especificamente floresceu na Mata Atlântica no estado do Rio de Janeiro. Em 2015, foi publicado o Inventário da cobertura arbórea da cidade do Rio de Janeiro, e a jaqueira é uma das cinco espécies mais comuns na cidade, com base na abundância, tamanho e distribuição (RIO DE JANEIRO, 2015). Em algumas unidades de conservação no estado carioca também existe uma alta densidade de jaqueiras, por exemplo: no Parque Natural Municipal da Mendanha, numa pesquisa sobre densidade de jaqueiras, nas parcelas avaliadas se observou uma dominância da jaqueira com 30-40\% dos indivíduos registrados (MAGALHÃES, et al., 2015).

Olhando as florestas do Rio de Janeiro como Sistemas Sócio-ecológicos, argumentamos que esta abundância da jaqueira é um resultado de uma interação complexa e histórica entre as ações dos humanos e a natureza. 


\section{JACA COMO ALIMENTO PARA SEGURANÇA ALIMENTAR E NUTRICIONAL}

Existe um reconhecimento crescente, no nível global, de políticas para o desenvolvimento sustentável, que evidenciam o papel das unidades de conservação e demais áreas de florestas na geração de benefícios e serviços ecossistêmicos para a sociedade. Nas diretrizes da Avaliação do Ecossistema do Milênio (MEA), se estabelece como os serviços ecossistêmicos contribuem para vários aspectos de bem-estar humano, incluindo saúde e segurança alimentar (MEA, 2005). Nas suas recomendações, inclui-se o fato de que "existe um grande potencial para o melhoramento e maior utilização de espécies negligenciadas e subutilizadas," como elas crescem naturalmente e são chamadas "selvagens" (MEA, 2005, p. 211). A jaqueira, no contexto do Brasil, exemplifica tais espécies, sendo que seus benefícios alimentares são pouco reconhecidos e, portanto, subaproveitados no país. O MEA também enfatiza a importância da produção de alimentos locais para diminuir impactos ambientais do sistema alimentar e tornar mais resilientes às mudanças climáticas (MEA, 2005).

A jaca (Figuras 1 e 2) é a maior fruta comestível do mundo, pesando entre 2 a $20 \mathrm{~kg}$ e há casos de frutas pesando até $56 \mathrm{~kg}$ (RANASIGNHE et al., 2018). Essas frutas podem ter um cumprimento entre 22 e 90 centímetros, e um diâmetro entre 13 e 50 centímetros. Uma árvore pode produzir até 100 frutas em um ano. A jaca é extremamente nutritiva com várias propriedades medicinais.

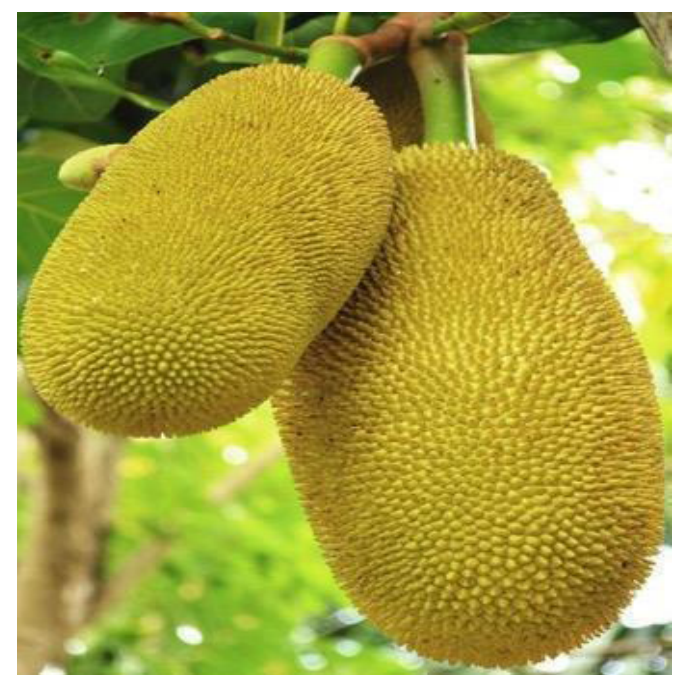

Fonte: CHA'S ORGANICS, [2019]

Figura 1: $O$ fruto da jaca

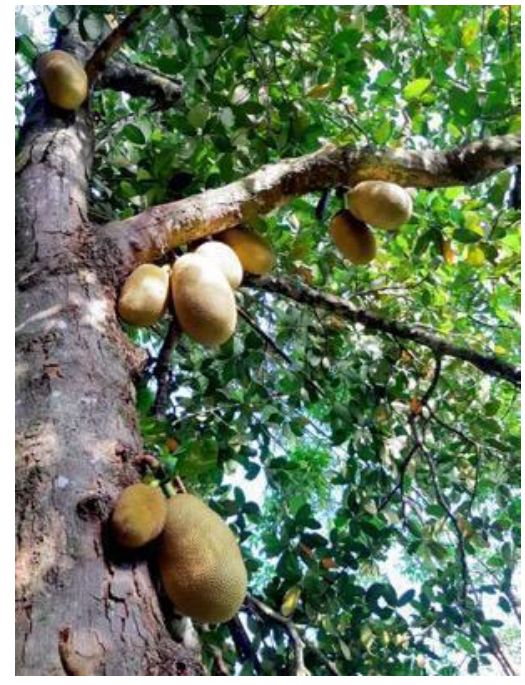

Figura 2: A árvore da jaqueira 
Uma porção de 100 gramas de jaca, dependendo da maturidade da fruta, contém entre 50 e 400 calorias (em média 96 calorias), entre 1.2 e 2.6 gramas de proteína, 1.5 e 3.6 de fibras e 9 e 25 gramas de carboidratos (RANASINGHE et al., 2018). Em comparação com outras frutas tropicais, a jaca contém substancialmente mais proteína, cálcio e ferro. A jaca também é conhecida por seus altos níveis de potássio, magnésio e fósforo e quase inexistentes níveis de sódio e colesterol. É rica em vitamina $\mathrm{C}$ e é uma das poucas frutas ricas no grupo de vitaminas do complexo $\mathrm{B}$ como $\mathrm{B} 6$, niacina, riboflavina e ácido fólico. $\mathrm{A}$ fruta também contém vários fitonutrientes que podem atuar como antioxidantes ${ }^{10}$. Estas propriedades fazem a jaca ser conhecida por suas atividades antibacteriana, antifúngica, antidiabética, anti-inflamatória e antioxidante. Ela contém compostos funcionais com capacidade para reduzir várias doenças, como doenças cardíacas, pressão alta, derrames e perda óssea. Jaca especificamente no estágio verde tem outros benefícios para a saúde. Segundo James Joseph, diretor indiano de Jackfruit 365, "Quando fizemos uma análise, encontramos que jaca [verde] como uma refeição é melhor que arroz e roti (pão indiano) para uma pessoa que quer controlar seu nível de açúcar" (ALJAZEERA, 2020).

Além das propriedades nutricionais já apresentadas, a jaca também tem sido destacada em virtude das possibilidades de utilização na culinária, sendo utilizada em uma variedade de receitas. Especificamente, a jaca verde é utilizada como uma alternativa para pessoas que não consomem proteína animal como carne vermelha ou frango, por exemplo. Ela tem um sabor neutro e adaptável aos temperos utilizados e uma textura facilmente modificável que tem capacidade de gerar a sensação da textura de vários tipos de carne. Dependendo da parte da jaca verde, é possível ter uma textura similar ao do frango, do camarão, do hambúrguer e de outros produtos animais. A jaca verde também pode substituir carboidratos como milho e trigo.

A jaca verde tem sido usada na culinária na Índia, no Sri Lanka e em outros países do Sudeste Asiático, por centenas, senão milhares de anos (STEPHEN-

10 Os antioxidantes são importantes pois combatem os radicais livres que podem levar as pessoas a desenvolverem doenças como o câncer (STANFORD, 2020). 
SON, 2016). Na Índia, especificamente, onde $40 \%$ da população é vegetariana, utiliza-se a jaca verde como um substituto para carne em vários pratos como curries, stir-fries e sopas. A palavra Jaca em bengali, um dos idiomas daquele país, se traduz como "a carne que cresce em uma árvore" (STEPHENSON, 2016). Na última década, mais de 75 festivais de jaca aconteceram nas províncias de Kerala e Karnataka, áreas de alta produção de jaca. O Vietnã está cultivando jaca em plantações há 17 anos, com mais de 50,000 hectares de cultivo, e é considerado um líder no mercado de produtos de jaca com valor agregado (SUCHITRA, 2018). Países como Filipinas, Camboja e Sri Lanka também estão ampliando sua produção e promoção da jaca no mercado (SUCHITRA, 2018).

Apesar do uso histórico da jaca na Índia, o país de origem, a fruta ainda é subutilizada, com quase $70 \%$ da produção sendo desperdiçados (SUCHITRA, 2018). Segundo o jornalista Shree Padre, especialista no mercado da jaca na Índia, a jaca como um alimento é subutilizado no país porque falta infraestrutura para o processamento da fruta numa escala maior, além de um preconceito da jaca como um "alimento dos pobres" (SUCHITRA, 2018). Nos últimos três ou quatro anos, muitas unidades pequenas surgiram para criação de produtos com valor agregado, mas a primeira empresa de processamento industrializado do país foi estabelecida somente em maio de 2018, em Kerala (SUCHITRA, 2018). $A$ jaqueira cresce em quase todo o país, mas o único cultivo em grande escala para comercialização acontece em Panruti na região de Tamil Nadu, principalmente como uma monocultura. O empresário James Joseph, previamente um diretor da Microsoft, viu este potencial inexplorado da fruta e fundou a Jackfruit 365 , empresa que fabrica e fornece jaca todos dias do ano através de várias formas de processamento como trituração para farinha, pasteurização e liofilização para conservar a jaca sem freezers, entre outras formas (PAL, 2016).

Além do consumo interno, a Índia passou a exportar jaca para o mercado internacional. Nos Estados Unidos e na Europa, o alimento tem crescido em popularidade nos últimos anos, virando uma moda no mercado vegano e vegetariano. Segundo especialistas no mercado, as vendas de jaca nos Estados Unidos 
aumentaram entre $50 \%$ e $75 \%$ nos últimos quatro anos (BURFIELD, 2017). Por muito tempo, a jaca era um alimento raro que somente podia ser encontrado em supermercados de especialidades orientais. Agora, várias empresas estão comercializando jaca verde para vender aos restaurantes e diretamente aos consumidores, com preços até $\$ 20.00$ (vinte dólares) por kilo. O Jack Fruit Company e Upton's Naturals tomam liderança no mercado, vendendo jaca verde já processada e temperada com sabores como churrasco ou curry.

É interessante que, ao se pesquisar a palavra-chave "jackfruit" no google trends - ferramenta que mostra a popularidade de uma palavra pesquisada no Google - observa-se o aumento de interesse pela Jaca entre 2014 e 2019 no mundo (Figura 3):

Figura 3: Número de vezes jaca foi pesquisada no Google

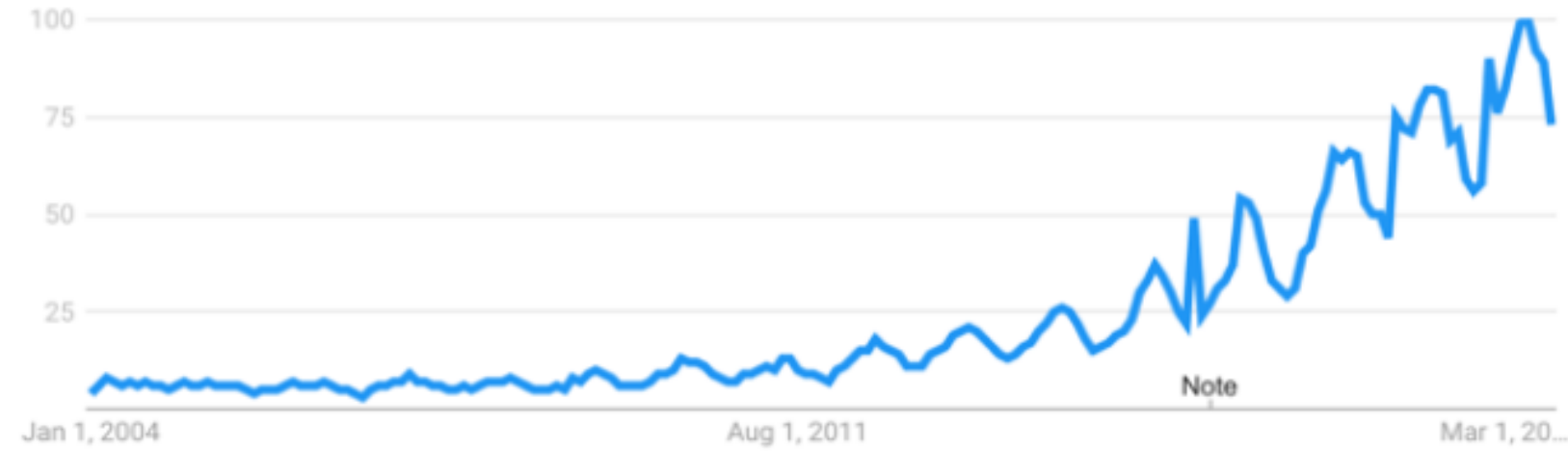

Fonte: Google trends, 2019

No Brasil, a popularidade da jaca verde também está crescendo; mas dada a abundância da jaqueira no país, sua utilização na dieta brasileira é ainda rudimentar, segundo empreendedores brasileiros que trabalham com a jaca. Pode-se encontrar jaca verde em alguns restaurantes, geralmente vegetarianos, 
principalmente como recheio da "coxinha" (um salgado típico do Brasil), imitando o frango desfiado. A coxinha de jaca "foi desenvolvida durante a industrialização de São Paulo, para ser comercializada como um substituto mais barato e mais durável às tradicionais coxas de galinha que eram vendidas nas portas de fábricas" (SILVEIRA et al., 2019). A região da Chapada Diamantina, na Bahia, é conhecida pelo pastel de "palmito" de jaca. Em Recife, Pernambuco, além das 180 toneladas de jaca madura que são comercializadas no CEASA, a jaca verde está sendo cultivada e vendida por agricultores como Luiz Amadeu, do Sítio Sete Estrelas, que fornece para restaurantes e lojas de produtos naturais, com uma produção de até $100 \mathrm{~kg}$ por semana durante a safra (TIAGO, [2018]). A eco-chef reconhecida no Brasil, Tati Lund, do Rio de Janeiro, promove a utilização da jaca verde em receitas como moqueca de jaca, tacos, bolinhos e chips de jaca verde (BARBOSA, 2019).

Um modelo de comercialização da jaca no estado do Rio de Janeiro que vale destacar, é o do Vale Encantado. O Vale Encantado, no Alto da Boa Vista, uma comunidade na zona de amortecimento do Parque Nacional da Tijuca, é conhecido por seu aproveitamento da jaca verde para uso culinário, servindo pratos no seu restaurante de ecoturismo e vendendo jaca processada para restaurantes no Rio. Os 140 moradores da comunidade são descendentes dos trabalhadores das fazendas de café do século XIX que ocuparam as encostas da área que hoje é o Parque da Tijuca (BARROS; MELO, 2011). Depois da proibição do plantio do café para o reflorestamento de Dom Pedro, a comunidade se sustentou com agricultura familiar, depois floricultura, e finalmente mineração. Quando a mineração foi proibida na década de 1990, as poucas famílias que permaneceram no local enfrentaram dificuldades para gerar renda (BARROS; MELO, 2011). Em 2005, o presidente da Associação de Moradores foi apoiado por uma ONG francesa, ABAQUAR/PARIS, e juntos fundaram uma cooperativa de ecoturismo sustentável em que ele se tornou Presidente. Promovendo trilhas e outras experiências na floresta, a cooperativa também criou um restaurante para visitantes que serve pratos que utilizam ingredientes locais, incluindo a jaca, cuja colheita já existe na 
cultura do extrativismo na comunidade. Seus pratos de "jacalhau" (inspirado no bacalhau) e empadinhas de jaca têm ganhado fama (NIDUMOLU, 2015). Recentemente, esta cooperativa começou a vender jaca verde processada a alguns restaurantes no Rio de Janeiro. Segundo a entrevista com o Presidente da Cooperativa, em 2019 a cooperativa processou 600 jacas no total, cada jaca entre 7 e 15 quilos, extraídas de 30 árvores. Com base nestes números, a cooperativa comercializou aproximadamente 6 toneladas de jaca no ano passado.

Embora o interesse na jaca verde esteja crescendo, em comparação com a quantidade da jaca que é produzida no país, a comercialização e consumo são ainda mínimos (SILVEIRA et al., 2019). É importante destacar que ao longo deste estudo foram registrados poucos estudos sobre a utilização da fruta de forma verde no país, sendo interpretado aqui como uma subutilização. Adicionalmente, pesquisas acadêmicas que expliquem porque esta fruta tão abundante, é tão subutilizada no Brasil, ainda são incipientes.

Existe um preconceito cultural em relação à jaca em vários lugares do Brasil. Oliveira (2009) salienta que, parte deste preconceito está relacionado ao cheiro forte da jaca quando está apodrecendo no chão - um cheiro que muitos brasileiros, especialmente no nordeste e sudoeste do país, reconhecem e associam negativamente. "Uma das hipóteses levantadas para entender o baixo consumo deste fruto, é seu aroma característico muito acentuado, o que leva de imediato a apreciação ou a rejeição" (OLIVEIRA, 2009, p.7).

De forma geral, a população conhece apenas a possibilidade do consumo da jaca madura, que é limitada geralmente à preparação de sobremesas. Por outro lado, a jaca verde tem uma gama de possibilidades muito maior que a madura, mas a maioria da população ainda não conhece suas utilizações na culinária. Finalmente, para o uso adequado da jaca verde na gastronomia, é necessário processá-la. Contudo, este processo pode ser trabalhoso uma vez que a casca do fruto é dura e produz uma goma pegajosa (SILVEIRA et al., 2019). É possível que esta dificuldade associada à falta de conhecimento de como processar o fruto, representam fatores que desestimulam o consumo da jaca verde. 


\section{JACA: UMA POSSÍVEL ALTERNATIVA PARA SEGURANÇA ALIMENTAR NO CONTEXTO DE MUDANÇA CLIMÁtica E CRISE}

Devido à abundância, ao alto nível de nutrição e à capacidade de reprodução em diferentes condições climáticas, a jaca está sendo chamada de "miracle crop" (cultivo milagroso) por pesquisadores no campo de segurança alimentar e está sendo vista como um alimento com grande potencial para os desafios de agricultura que estão surgindo com as mudanças climáticas (GOLDENBERG, 2014). O solo está se deteriorando entre 10 e 100 vezes mais rápido que está sendo formado no mundo, ameaçando a fertilidade de terras para cultivo de alimentos (FLAVELLE, 2019). Concentrações mais altas de dióxido de carbono na atmosfera também reduzirão a qualidade nutricional dos alimentos, ao mesmo tempo que o aumento da temperatura reduz o rendimento das colheitas e prejudica o gado (FLAVELLE, 2019). As mudanças climáticas podem gerar escassez na produção de alimentos em países em desenvolvimento, impactando mais os agricultores pequenos e as populações mais vulneráveis. O Brasil é um país dependente da exportação destes cash crops que estão sendo ameaçados pela mudança climática, e da produção do pequeno agricultor para o consumo interno do país. Há uma necessidade crescente mundial de aproveitar os alimentos produzidos localmente, que crescem naturalmente e de forma abundante e que são resilientes às mudanças ambientais resultantes da crise climática. No Brasil, a jaca demonstra potencial de ser um destes alimentos. Suas qualidades resilientes, em conjunto com sua abundância de produção, faz da jaca uma alternativa promissora para culturas mais frágeis no clima global em rápida mudança.

Danielle Nierenberg, presidente da organização internacional Food Tank, um instituto de pesquisa e ação para transformação do sistema alimentar global, afirma que essa futura escassez poderia ser parcialmente aliviada com o melhor aproveitamento de frutas locais, especificamente mencionando a jaca. Segundo ela, "a jaca cresce facilmente. Sobrevive a pragas, a doenças e a altas temperaturas. É resistente à seca. Ela alcança o que os agricultores precisam 
na produção de alimentos quando enfrentam muitos desafios sob as mudanças climáticas" (TFNET, 2014). Pesquisadores indianos também têm reconhecido o grande potencial da fruta para confrontar a fome mundial, enfatizando a densidade calórica e nutricional da fruta. Segundo Shyamala Reddy, da Universidade de Agricultura e Ciências em Bangalore, na India, "É um milagre que possa fornecer tanto nutrientes, como calorias, tudo; Se você comer apenas 10 ou 12 gomos desta fruta, vocên não precisará de alimento para outra metade do dia" (TFNET, 2014).

Esta densidade calórica e nutricional, combinada com a resistência e abundância da planta, faz da jaca um alimento propício para contribuir para a segurança alimentar no contexto de mudanças climáticas e crises ambientais e econômicas. De fato, a importância de acesso aos alimentos locais, abundantes e resilientes como a jaca, tem sido destacada no novo contexto de COVID-19 no mundo. A pandemia está impactando o sistema alimentar global, especialmente pelas restrições de movimento entre e dentro de países, que interrompem cadeias de fornecimento de alimentos inteiros, serviços de logística, e trabalhadores da agricultura, afetando a disponibilidade de comida. A crise pandêmica e econômica está ocasionando uma diminuição de renda, o aumento da taxa de desemprego e inclusive a redução do trabalho informal, colocando a população mais vulnerável e de baixo poder aquisitivo em risco de agravamento da insegurança alimentar (FAO, 2020).

A jaca já está sendo utilizada como solução neste contexto, como visto na Índia, onde a demanda da jaca disparou desde o lockdown, no final de março: "O coronavírus causou medo do frango e as pessoas mudaram para jaca. Em Kerala, o bloqueio causou um aumento na demanda por jaca verde e sementes devido à escassez de vegetais com as restrições nas fronteiras" (BOSE, 2020). No contexto do COVID no Brasil, onde agora "dezenas de milhões de pessoas que vivem na pobreza estão novamente enfrentando a fome", a jaca também poderia funcionar como uma possibilidade para combater a insegurança alimentar nesta crise (CIRAD, 2020). 
Além disso, algumas mudanças na produção e no consumo de alimentos sugerem que a indústria de carne será impactada pela pandemia. Especialistas de instituições como a Organização Mundial de Saúde (OMS) e do Centro de Controle e Prevenção de Doenças dos Estados Unidos (CDCP), alertam há anos que a maioria das doenças infecciosas vêm de animais - selvagens e domesticados - e que as práticas agrícolas industrializadas estão colocando a sociedade em risco com a propagação de viroses e bactérias que podem virar pandemias. Segundo Michael Greger, autor do "Bird Flu: A Virus of Our Own Hatching":

Quando sobrecarregamos galpões no tamanho de campos de futebol com milhares de animais apertados focinho a focinho ou bico com bico, estressamos seus sistemas imunológicos, queimamos seus pulmões com amônia advinda da decomposição de suas fezes além de expormos a uma baixíssima quantidade de luz solar e ar fresco - junte todos esses fatores e você tem a 'Tempestade Perfeita' para criação e desenvolvimento de uma nova doença. (GREGER citado por SAMUEL, 2020. Tradução própria).

Existem evidências que comprovam o aumento drástico das gripes aviárias na década de 1990, na Ásia, como resultado da adoção do modelo de factory farming no continente (SAMUEL, 2020). Além disso, o uso copioso de antibióticos nos animais em factory farms cria uma situação ideal para a criação de formas altamente resistentes a drogas de patógenos bacterianos" (SAMUEL, 2020). Finalmente, a degradação dos ecossistemas naturais- frequentemente causado pelo sistema alimentar - também põe humanos em contato direto com animais selvagens que carregam patógenos perigosos (RAYGORODETSKY, 2020). "Há razões para pensar que a pandemia gerará ainda mais interesse [nestes produtos], tanto porque a cadeia tradicional de suprimentos de carne está agora sob alguma pressão, quanto devido à crescente conscientização de que a agricultura industrial é um risco de pandemia." (SAMUEL, 2020).

Nos Estados Unidos, a produção de carne já está sendo impactada devido, principalmente, aos outbreaks desproporcionais da COVID que estão acontecendo nas fábricas de meat-packing. Segundo o economista lan Shepardson, "a indústria de carne dos EUA é a fonte da maioria dos novos pontos ativos da COVID no país," devido às temperaturas frias, condições de aglomeração, e longos 
períodos de trabalho dos funcionários (GIBSON, 2020). Fábricas na Austrália, Espanha, Brasil e Canadá também estão mostrando altas taxas de infecção, demonstrando que estes outbreaks são um fenômeno global (MOLTENI, 2020). Fábricas da Tyson e Smithfield foram fechadas devido a estes outbreaks, e o preço da carne (beef) nos Estados Unidos é o mais alto em duas décadas.

Estes riscos, que o sistema atual de agricultura industrializada apresenta neste contexto de pandemias, também gera uma possibilidade para uma transição mais rápida aos produtos baseados em plantas.

\section{CONSIDERAÇÕES FINAIS}

As áreas urbanas e periurbanas do estado do Rio de Janeiro estão repletas de jaqueiras, e estas poderiam propiciar uma alimentação saudável e de baixo custo para a população nas comunidades periféricas, que enfrentam dificuldades no abastecimento de alimentos.

O modelo do Vale Encantado, na área de abrangência do Parque Nacional da Tijuca, é uma experiência de manejo da jaqueira em áreas protegidas que aproveita a jaca como alimento e promove a geração de renda para os moradores na zona de amortecimento de uma unidade de conservação. Este caso pode servir como um modelo inspirador para outras iniciativas de comercialização da jaca que geram impacto socioambiental positivo próximo às áreas protegidas.

A jaca verde é um destes alimentos que vai continuar ganhando interesse no mundo, com possibilidades de promover uma alimentação segura e saudável neste novo contexto de pandemias e mudanças climáticas. Sua nutrição, variabilidade culinária, e resiliência às mudanças climáticas, além de sua abundância no país, fazem da jaca um alimento com grande potencial.

É importante destacar que ao longo deste estudo foram registradas poucas pesquisas sobre a utilização da fruta de forma verde no país, sendo interpretado aqui como uma subutilização. Adicionalmente, são escassas pesquisas acadêmicas que expliquem os motivos pelos quais esta fruta tão abundante, é tão subutilizada no Brasil. 
É ainda necessário frisar que iniciativas como essas, apontadas neste estudo, reforçam o desafio de se alcançar sistemas alimentares saudáveis e sustentáveis em prol da soberania e segurança alimentar, em especial de populações mais vulneráveis como a brasileira.

\section{REFERÊNCIAS}

ABREU, R. Dinâmica de populações da espécie exótica invasora Artocarpus heterophyllus L. (Moraceae) no Parque Nacional da Tijuca - Rio de Janeiro. 2008. Dissertação (Programa de Pós-Graduação em Botânica) - Escola Nacional de Botânica Tropical do Instituto de Pesquisas Jardim Botânico do Rio de Janeiro.

ABREU, R; RODRIGUES, P. Estrutura de populações de jaqueiras, subsídios para manejo e conservação da Mata Atlântica. In: I Simpósio Brasileiro sobre Espécies Exóticas Invasoras. Brasília. 2005.

ALJAZEERA. India's superfood jackfruit coes global. 2020. Disponível em: https://www.aljazeera.com/features/2020/5/19/indias-superfood-jackfruit-goesglobal. Acesso em: 13 de jun. 2020.

BARROS, O; MELO, M. Do mito à realidade : a experiência de turismo sustentável na comunidade Do Vale Encantado, Floresta de Tijuca, Rio de Janeiro, Brasil. Field Actions Science Reports, Open Edition Journals, 2011. Disponivel em: https://journals.openedition.org/factsreports/1154?lang=fr. Acesso em: 5 abr. 2020.

BARBOSA, C. A jaca é a nova queridinha dos adeptos da alimentação vegetariana. Veja Rio, 4 de maio, 2019. Disponível em: https://vejario.abril.com.br/comer-e-beber/jaca-vegetarianos-veganos/. Acesso em: 4 nov. 2020.

BOSE, M. Amid COVID-19 outbreak, demand for jackfruit soars in Maharashtra. Deccan Herald, 2020. Disponivel em: https://www.deccanherald.com/ national/west/amid-covid-19-outbreak-demand-for-jackfruit-soars-in-maharashtra-814468.html. Acesso em: 9 abr. 2020

BRASIL. Lei $\mathbf{n}^{\circ}$ 9.985, de 18 de julho de 2000. Regulamenta o art. 225, § 10, incisos I, II, III e VII da Constituição Federal, institui o Sistema Nacional de Unidades de Conservação da Natureza e dá outras providências. Brasília: Presidência da República, 2000. Disponível em: http://www.planalto.gov.br/ccivil_03/leis/ 19985.htm. Acesso em: 3 ago. 2018 
BURFIELD, T. From jackfruit to passion fruit, Melissa's talks specialties. The Packer, 2017. Disponivel em:

https://www.thepacker.com/article/jackfruit-passion-fruit-melissas-talks-specialties. Acesso em: 18 maio 2020.

CABRAL, D; SOLÓRZANO, A; DE OLIVEIRA, R. Urbanising rainforests: emergent socioecologies in Rio de Janeiro, Brazil. Landscape History, v. 37, n. 2, p. 57-78, 2016.

CIRAD. Covid-19 and food security: In Brazil, will emergency aid be enough to guarantee access to food for the country's poor? 2020. Disponivel em:

https://www.cirad.fr/en/news/all-news-items/articles/2020/science/covid-19-and-food-security-brazil. Acesso em: 24 de jun. 2020.

\section{FAO. Joint Statement on COVID-19 Impacts on Food Security and Nutrition.} Rome, 2020. Disponível em: http://www.fao.org/news/story/en/item/1272058/icode/. Acesso em: 15 jun. 2020.

FLAVELLE, C. Climate change threatens the world's food supply, united nations warns. New York Times, 2019. Disponível em: https://www.nytimes. com/2019/08/08/climate/climate-change-food-supply.html. Acesso em: 20 de março 2020.

GIBSON, K. U.S. meat industry seen as source of most new COVID-19 hotspots. CBS News, 2020. Disponível em: https://www.cbsnews.com/news/u-s-meat-industry-a-top-source-of-new-covid-19-hotspots/. Acesso em: 28 jun. 2020.

GOLDENBERG, S. Jackfruit heralded as 'miracle crop.' The Guardian, 2014. Disponível em: https://www.theguardian.com/environment/2014/apr/23/jackfruit-miracle-crop-climate-change-food-security. Acesso em: 17 abr. 2020.

IPBES. Plataforma Intergovernamental sobre Biodiversidade e Serviços Ecossistêmicos. 2020. Disponível em: https://ipbes.net/glossary/invasive-alien-species.

INSTITUTO HORUS. Localidades de Ocorrência. Inter-American Biodiversity Information Network. [2020]. Disponível em: http://bd.institutohorus.org.br/ www/?p=MDw1ajhjOH96biRzI3I4JHFkD1QKSVpYX0wORhUWEUxPSF83NT5jPGk\%2FPg\%3D\%3D. Acesso em: 3 de jun. 2020 
MAGALHÃES, L; KIFFER, W; RESENDE, A; PINHEIRO, M; GOMES E. De Provedora a Invasora - Como a jaqueira foi transformada em um grave problema ambiental para as Unidades de Conservação da cidade do Rio de Janeiro, Rio de Janeiro, p. 308 - 306, In: PONTAS, J. A. L. (Org.). Biodiversidade carioca: segredos revelados. Rio de Janeiro: Technical books, 2015.

MEA. MILLENIUM ECOSYSTEM ASSESSMENT. Ecosystems and Human Well-being: Current State and Trends. Washington DC: Island Press, 2005.

MOLTENI, M. Why Meatpacking Plants Have Become Covid-19 Hot Spots. Wired, 2020. Disponível em: https://www.wired.com/story/why-meatpacking-plants-have-become-covid-19-hot-spots/. Acesso em: 24 jul. 2020.

MOURA, C. Estrutura populacional e avaliação de métodos de controle da espécie exótica invasora Artocarpus heterophyllus Lamk. (Moraceae) no Parque Estadual da Ilha Grande, Angra do Reis, RJ. 2011. Dissertação (Programa de Pós-graduação em Ecologia e Evolução) - Universidade do Estado do Rio de Janeiro. Disponivel em: http://bdtd.ibict.br/vufind/Record/UERJ_f1c148dbb4e5904abd0167cb250a1e10

NIDUMOLU, A. Vale Encantado: Um Exemplo Emergente para Comunidades Sustentáveis. RioOnWatch, 2015. Disponivel em: https://rioonwatch.org. br/?p=14216. Acesso em: 23 abr. 2020.

OLIVEIRA, L, F. Efeito dos Parâmetros do Processo de Desidratação de Jaca (Artocarpus heterophyllus, Lam.) Sobre as Propriedades Químicas, Físico-químicas e Aceitação Sensorial. 121 p. Tese (doutorado). Universidade Federal Rural do Rio de Janeiro. Instituto de Tecnologia de Alimentos. Programa de Pós-Graduação em Ciência e Tecnologia de Alimentos. 2009.

PAL, S. This Ex-Microsoft Director Returned to India to Put Jackfruit on the Superfood Map. The Better India, 2016. Disponivel em: https://www.thebetterindia. com/59942/james-joseph-jackfruit-365-superfood-india/. Acesso em: 2 de maio, 2020.

RAMOS, L. Espécies invasoras ameaçam a biodiversidade do Estado. FAPERJ, 2011. Disponivel em: http://www.faperj.br/?id=1895.2.0. Accesso em: 28 jun. 2020. 
RAYGORODETSKY, G. Reimagining the Post-Pandemic "Normal": Learning from Indigenous Peoples about Reconciling Culture and Nature. Cultural Survival, 2020. Disponível em: https://www.culturalsurvival.org/news/reimagining-post-pandemic-normal-learning-indigenous-peoples-about-reconciling-culture=-and?fbclidIwAR0_bgulau6-KyNW0gOHSvLe_paSjB78AjR2tM04Uor6pDqSEWtVXohbNkQ. Acesso em: 14 mar. 2020

RAMOS, L. Espécies invasoras ameaçam a biodiversidade do Estado. FAPERJ, 2011. Disponivel em: http://www.faperj.br/?id=1895.2.0. Accesso em: 28 jun. 2020.

RANASINGHE, R; MADUW ANTHI, S; MARAP ANA, R. Nutritional and Health Benefits of Jackfruit (Artocarpus heterophyllus Lam.): A Review. International Journal of Food Science, 2018. Disponivel em: https://www.hindawi.com/journals/ijfs/2019/4327183/tab1/. Acesso em: 20 de Set, 2019.

RIO DE JANEIRO. Secretaria Municipal de Meio Ambiente. Inventário da cobertura arbórea da cidade do Rio de Janeiro. Rio de Janeiro: Prefeitura da Cidade do Rio de Janeiro, 2015. 232p. Vol. 1

SALES, G; GUEDES-BRUNI, R. Um Quebra-Cabeça Verde: 'Montando as Peças' do Reflorestamento Empreendido na Floresta da Tijuca. Fronteiras: Sociedade, Tecnologia e Meio Ambiente, v. 7, n. 3, p. 58-77, 2018

SAMUEL, S. The meat we eat is a pandemic risk, too. VOX, 2020.

Disponível em: https://www.vox.com/future-perfect/2020/4/22/21228158/coronavirus-pandemic-risk-factory-farming-meat. Acesso em: 20 de ago 2020.

SCIENCE JRANK. Opportunistic species. [2020]. Disponível em: https://science.jrank.org/pages/4867/Opportunistic-Species.html. Acesso em: 08 de maio, 2020.

SILVEIRA, A; SOLER, N; RIBEIRO, S; ANDRADE, P; BANDEIRA, S. Coxinha Recheada com "carne" de jaca: Produção e análise sensorial. Instituto Federal de Educação, Ciência e Tecnologia: Triângulo Mineiro. 2019.

SOLÓRZANO, A; DA SILVA SALES, G; NUNES, R. O Legado Humano na Paisagem do Parque Nacional da Tijuca: Uso, Ocupação e Introdução de Espécies Exóticas. Fronteiras: Journal of Social, Technological and Environmental Science, v. 7, n. 3, p. 43-57, 2018. 
SOLÓRZANO, A; CABRAL, D. C.; OLIVEIRA, R. R. Revealing Hidden Forest Dialogs: Species Introduction, Charcoal Production and the Environmental History of Rio de Janeiro's Urban Forests. In: JOANAZ DE MELO, C; VAZ, E; COSTA PINTO, L. (Orgs.). Environmental History in the Making. Cham: Springer International Publishing, 2017, v. 7, p. 219-237. Disponível em: <http://link.springer. com/10.1007/978-3-319-41139-2_13>. Acesso em: 31 ago. 2019.

SOLÓRZANO, A. Novas perspectivas sobre o debate da dicotomia sociedade $x$ natureza a partir da ecologia histórica: introdução e domesticação de uma espécie exótica na mata atlântica. Revista Desigualdade \& Diversidade, n.17, p. 107-127, 2019.

STANFORD. Antioxidants as part of your cancer diet. Stanford healthcare: 2020. Disponivel em: https://stanfordhealthcare.org/medical-clinics/cancer-nutrition-services/reducing-cancer- risk/antioxidants.html. Acesso em: 10 de out. 2019.

STEPHENSON, E. Behind Jackfruit's Rise from South Asian Staple to Vegan Trend. 2016. Disponível em: https://www.eater.com/2016/5/17/11683930/jackfruit-vegan-pulled-pork. Acesso em: 10 de set. 2019.

SUCHITRA, M. The jackfruit will definitely become the most sought-after fruit in the coming years in India. Downtoearth, 2018. Disponivel em:

https://www.downtoearth.org.in/interviews/food/-the-jackfruit-will-definitely-become-the-most-sought-after-fruit-in-the-coming-years-in-india--50450. Acesso em: 3 jun. 2020.

TABAI, K. C. Políticas de segurança alimentar e saúde pública. In: SARTORIO, Lucia Aparecida Valadares. (Org.). Sustentabilidade: qualidade de vida, economia solidária e educação. 1ed. Nova Iguaçu: Editora Entorno, 2018, v.1, p. 137-156.

TFNET. Jackfruit heralded as miracle crop. International Tropical Foods Network, 2014. Disponivel em: https://www.itfnet.org/v1/2014/04/jackfruit-heralded-as-miracle-food-crop/. Acesso em: 14 dez. 2019.

TIAGO, R. Jaca: de fruto exótico das Índias a "carne" da moda. Curiosamente, 2018. Disponivel em:

https://curiosamente.diariodepernambuco.com.br/project/jaca-de-fruto-exotico-das-indias-a-carne-da-moda/. Acesso em: 19 de jun. 2020. 
do $10.48209 / 978-65-89949-32-5$

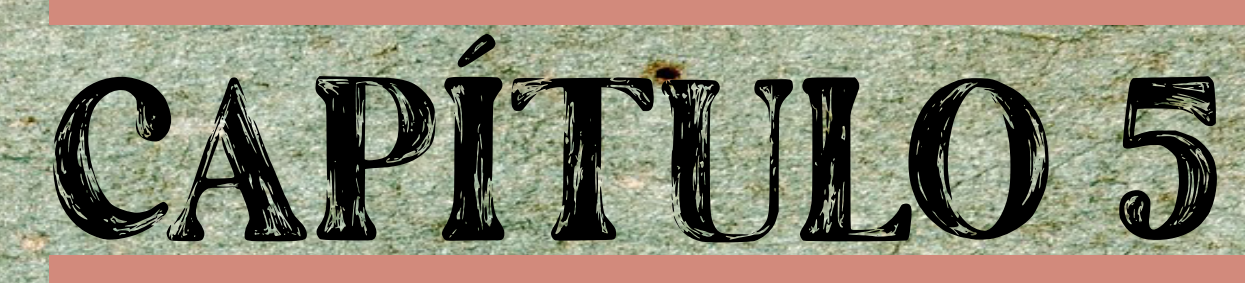

SEGURANÇA

-X ALIMENTAR

E NUTRICIONAL.

E ALTERAÇÕES NO

CONSUMO DE ALIMENTOS

DURANTE A PANDEMIA

DO CORONAVIRUS

Dayane de Castro Morais Elizangela da Silva Miguel

Carina Aparecida Pinto Silvia Eloiza Priore 


\section{INTRODUÇÃO}

A segurança alimentar e nutricional tem como primícias o acesso regular e permanente a uma alimentação de qualidade e em quantidade suficiente para garantir a saúde dos indivíduos ou grupos populacionais (BRASIL, 2006; MORAIS; LOPES; PRIORE, 2020). O termo qualidade relaciona-se ao Direito Humano a Alimentação Adequada (DHAA) abarcando aspectos mais amplos do que a qualidade nutricional, como também a qualidade sanitária e química dos alimentos, estando estes livres de contaminantes, como os agrotóxicos; o respeito e valorização da cultura alimentar; o acesso à informação sobre os alimentos consumidos; a diversidade alimentar; o acesso a recursos naturais, como a água; bem como o não comprometimento dos outros direitos (ABRANDH, 2007; MACHADO; SPERANDIO, 2020).

O acesso a alimentação é um direito humano conquistado pela população brasileira após a Ementa Constitucional em 2010, que incluiu no Artigo $6^{\circ}$ da Constituição Federal a alimentação, juntamente com outros direitos sociais como educação, saúde e lazer (ABRANDH, 2007; BRASIL, 2010). Assim, o Estado passa a ter o dever de prover ações e políticas que garantam o acesso à alimentação pela população.

Porém, mesmo sendo um direito adquirido, milhões de brasileiros não tem acesso ao alimento de forma estável, sofrendo privações em termos de qualidade e quantidade (IBGE, 2020; Rede PENSSAN, 2021).

Estudos realizados no país demonstram a relação existente entre a insegurança alimentar (e nutricional) e o consumo alimentar inadequado com menor consumo de carnes, ovos, leite e derivados; frutas e hortaliças; menor variedade da dieta e maior consumo de café, açúcar e óleo (PANIGASSI et al., 2008; ANTUNES et al., 2010; MORAIS, 2014; MORAIS et al., 2014; ALMEIDA et al., 2017; MORAIS; ANDRÉ, 2020). Esta relação será mais aprofundada ao longo deste capítulo. 
A população brasileira vivenciava aumento da prevalência de insegurança alimentar em seus diferentes níveis, inclusive no mais grave no qual há presença de fome, mesmo antes da pandemia do Coronavírus. Ao analisarmos as prevalências de insegurança alimentar, pela Escala Brasileira de Insegurança Alimentar (EBIA), nas duas últimas décadas verificamos, em um primeiro momento (2004 a 2013), aumento da segurança alimentar, contraponto à redução da insegurança alimentar em seus diferentes níveis (leve, moderada e grave). Estas prevalências foram apresentadas pela Pesquisa Nacional de Amostra de Domicílios (PNAD) nas edições de 2004, 2009 e 2013, que indicam a evolução da segurança alimentar de $65,1 \%$ para $77,4 \%$ dos domicílios brasileiros neste período. Já no período entre 2013 a 2017/2018, verifica-se um retrocesso marcado pela redução da segurança alimentar e aumento da insegurança leve (de $14,8 \%$ para $24,0 \%$ ), moderada (de $4,6 \%$ para $8,1 \%$ ) e grave (de $3,2 \%$ para 4,6\%), como indicam a PNAD de 2013 e a Pesquisa de Orçamentos Familiares (POF) na edição 2017/2018 (IBGE, 2020).

Com a pandemia da Covid-19 a população viu sua renda familiar reduzir, em função do crescente desemprego, do isolamento social e do aumento do preço de alimentos e outros serviços essenciais como o gás de cozinha. Assim, a renda ficou comprometida e a dificuldade em arcar com as diferentes contas fez com que o brasileiro priorizasse algumas despesas como aluguel, transporte, água, luz, entre outras, e modificasse o seu padrão alimentar, em quantidade e qualidade, conforme o orçamento. Estas questões serão discutidas mais detalhadamente na próxima seção deste capítulo.

\section{CONSUMO ALIMENTAR VERSUS SEGURANÇA ALIMENTAR E NUTRICIONAL}

O consumo alimentar é influenciado por fatores sociais, nutricionais, econômicos e culturais (CARVALHO et al., 2011; SILVA et al., 2012), o que impacta diretamente na segurança alimentar e nutricional, uma vez que esta 
perpassa por estes determinantes que influenciam na alimentação (PEREIRA et al., 2006; KEPPLE, SEGALL- CORRÊA, 2011; MALUF; REIS, 2013).

Assim, para avaliação do consumo alimentar, é preciso considerar as várias dimensões do sistema alimentar que determinam o processo de segurança ou insegurança alimentar. A Organização das Nações Unidas para Agricultura e Alimentação (FAO) define quatro dimensões da segurança alimentar e nutricional (FAO, 2014), como apresentado na figura 1.

Figura 1 - Dimensões da segurança alimentar e nutricional.

\begin{tabular}{|c|c|c|c|}
\hline DISPONIBILIDADE & ACESSO & UTILIZAÇÃO & ESTABILIDADE \\
\hline $\begin{array}{l}\text { Oferta adequada } \\
\text { de alimentos para } \\
\text { atender toda } \\
\text { população, tendo } \\
\text { como referência o } \\
\text { nível de consumo } \\
\text { adequado. }\end{array}$ & $\begin{array}{l}\text { Capacidade de } \\
\text { obter alimentos } \\
\text { de forma } \\
\text { socialmente } \\
\text { aceitável, por } \\
\text { exemplo, por meio } \\
\text { da produção, } \\
\text { compra, caça } \\
\text { ou troca. }\end{array}$ & $\begin{array}{c}\text { Utilização } \\
\text { biológica, podendo } \\
\text { ser influenciada } \\
\text { pelas condições de } \\
\text { saneamento básico } \\
\text { e saúde das } \\
\text { pessoas e a } \\
\text { segurança } \\
\text { microbiológica e } \\
\text { química dos } \\
\text { alimentos, além do } \\
\text { conhecimento } \\
\text { nutricional e } \\
\text { escolhas e hábitos } \\
\text { alimentares. }\end{array}$ & $\begin{array}{c}\text { Necessidade de } \\
\text { garantir a } \\
\text { disponibilidade, } \\
\text { o acesso regular } \\
\text { e contínuo aos } \\
\text { alimentos e a sua } \\
\text { utilização. }\end{array}$ \\
\hline
\end{tabular}

Fonte: Elaborado pelas autoras. Adaptado de FAO (2014).

A partir destas dimensões observa-se que o Brasil, mesmo tendo produção de alimentos suficiente para alimentar toda a população, enfrenta altas prevalências de insegurança alimentar e nutricional. Muitos agricultores familiares produzem determinados alimentos, como frutas e hortaliças, mas estes não são 
consumidos pelo seu núcleo, ao passo que adquirem rotineiramente no mercado outros alimentos como doces e ultraprocessados (MIGUEL, 2018).

Diante disso, nota-se a importância da retomada da segurança alimentar e nutricional como agenda política (CARVALHO; VIOLA; SPERANDIO, 2021) e do incentivo à criação de políticas voltadas para a qualidade da alimentação, tanto no meio urbano quanto rural.

\section{SITUAÇÃO DE INSEGURANÇA ALIMENTAR DURANTE A PANDEMIA}

Com a pandemia do coronavírus a insegurança alimentar (e nutricional) se propagou. O relatório "Estado de segurança alimentar e nutricional no mundo" aponta que 690 milhões de pessoas passaram fome em 2019, demonstrando um aumento de 10 milhões em relação a 2018 e quase 60 milhões em cinco anos, nas diferentes regiões do mundo. No material é destacado que, com a extensão da pandemia, o número de indivíduos com fome no mundo pode sofrer um acréscimo de 83 a 132 milhões de pessoas, conforme projeções estatísticas (FAO, 2020; 2021).

Considerando o Brasil, esta situação se agravou ainda mais, sendo que as prevalências de insegurança alimentar passaram de 36,7\%, em 2017/2018 (IBGE, 2020) para 55,2\%, em 2020 (Rede PENSSAN, 2021). Destaca-se que a insegurança alimentar leve, moderada e grave atingiram 34,7\%, 11,5\% e $9,0 \%$, respectivamente, dos domicílios brasileiros durante o primeiro ano da pandemia. Estas porcentagens indicam que 116,8 milhões de brasileiros sofrem de insegurança alimentar, sendo que 19 milhões destes estão em insegurança alimentar grave, ou seja, passam fome (Rede PENSSAN, 2021).

Ressalta-se que as maiores prevalências de insegurança alimentar estão presentes nas macrorregiões Norte, Nordeste e zona rural do país, inclusive a grave (Rede PENSSAN, 2021). 
Segundo dados da FAO a situação de insegurança alimentar e nutricional é agravada ao considerarmos que o preço de uma alimentação saudável, com quantidade e qualidade de alimentos adequados para uma boa nutrição, é superior àquela rica em carboidratos. Ainda, aponta que leite e derivados, frutas e hortaliças são os grupos de alimentos mais caros, e que pelo menos três bilhões de pessoas no mundo não tem recursos financeiros para adquirir e consumir uma alimentação saudável. Assim, o acesso à alimentação adequada fica comprometido, deixando a população mais vulnerável à insegurança alimentar e nutricional (FAO, 2020; 2021).

Neste contexto, observa-se que as dimensões da segurança alimentar e nutricional de acesso, disponibilidade, utilização biológica e estabilidade têm seu descumprimento intensificado durante a pandemia da Covid-19, gerando situação de insegurança alarmada para o momento atual e com projeções de agravamento nos próximos anos.

\section{FATORES RELACIONADOS Às ALTERAÇÕES NO CONSUMO ALIMENTAR DURANTE A PANDEMIA}

Apandemia da Covid-19 impactou principalmente no orçamento das famílias, levando a alterações no consumo alimentar em decorrência da crise sanitária global, contribuindo para o agravamento da situação de insegurança alimentar e nutricional no Brasil. O aumento do desemprego, somado ao isolamento social, à inflação e à menor renda levaram à população ao menor acesso a alimentos saudáveis, contrapondo ao maior consumo de alimentos ultraprocessados. Esses fatores estão apresentados no esquema a seguir (Figura 2). 
Figura 2 - Fatores relacionados ao aumento da insegurança alimentar e nutricional durante a pandemia da Covid-19.

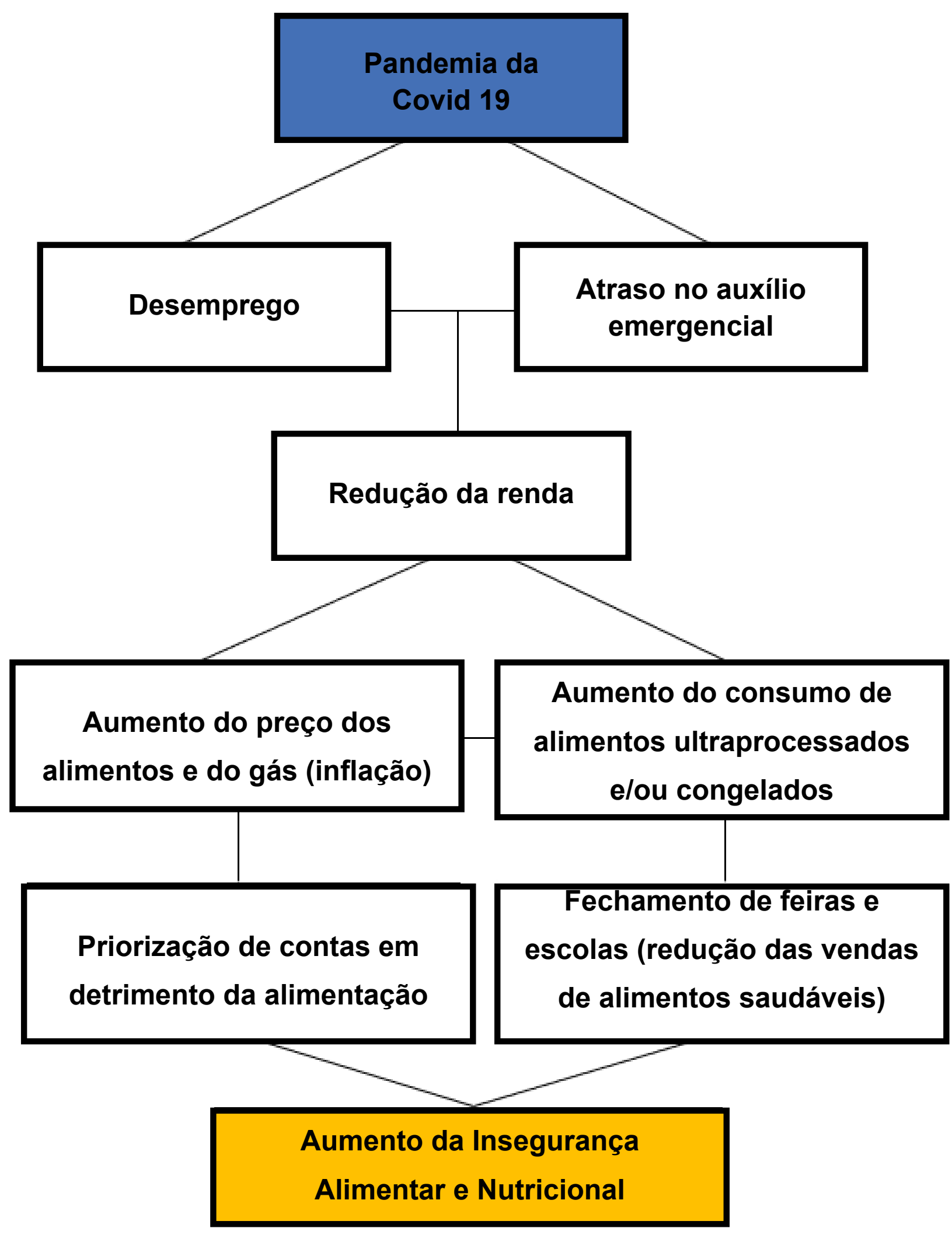

Fonte: Elaborado pelas autoras. 


\section{CONSUMO ALIMENTAR DURANTE A PANDEMIA}

Durante a pandemia tem havido aumento do consumo de ultraprocessados pela população (MALTA et al., 2020; BONACCIO et al., 2021). Este aumento devese ao preço dos mesmos, facilidade de preparo e consumo, além da saciedade que esses proporcionam por serem altamente calóricos. Somado a isto, houve maior divulgação destes produtos na mídia (inclusive com propagandas em lives, pela televisão e internet) e aumento das promoções e vendas casadas de produtos ultraprocessados. Ressalta-se que estes produtos geralmente são ricos em açúcar, gordura e sódio, tornando-os mais palatáveis e mais aceitáveis, e com maior procura, inclusive em situações de privação alimentar e ansiedade.

Estudos demonstraram uma alteração do padrão alimentar, durante a pandemia, com redução do consumo regular de hortaliças, legumes, frutas, carnes e queijo; e aumento do consumo de doces, alimentos congelados, embutidos, ovos, salgadinhos, chocolates, biscoitos doces e torta (MALTA et al., 2020; GALINDO et al., 2021; JAFRI et al., 2021).

A redução no consumo de hortaliças, legumes e frutas deve-se ao menor poder de compra da população que acaba por não priorizar estes alimentos em função dos mesmos gerarem menos saciedade (PANIGASSI et al., 2008; MORAIS et al., 2014). Além disso, o isolamento social e o fechamento de alguns estabelecimentos como feiras dificultou o acesso a estes alimentos, que por serem mais perecíveis precisam ser adquiridos com menor periodicidade.

Já a redução do consumo de carne e queijos deve-se ao aumento do preço destes alimentos, que podem ser explicados pelo aumento da inflação do país, bem como pela maior exportação destes alimentos, principalmente a carne bovina. Essa redução leva à maior procura por carnes de menor qualidade (com mais gordura), inclusive de embutidos.

A redução da variedade de alimentos, bem como da quantidade consumida também foi relatada em estudo realizado em diferentes países, durante a pandemia. Além da redução do tamanho das porções consumidas, observou- 
se diminuição do número de refeições realizadas ao longo do dia (JAFRI et al., 2021). Destaca-se que a redução da variedade de alimentos consumidos pode ter sofrido influência direta do aumento no preço de alimentos básicos, como arroz, feijão e carnes; bem como da dificuldade de acesso a alimentos perecíveis durante os períodos de distanciamento social. Ainda, essa menor variedade de alimentos no prato do brasileiro pode ser reflexo do aumento do preço do gás de cozinha, que levou à redução de preparações no fogão tradicional para economizar gás ou então à utilização de fogareiros improvisados, por muitas famílias brasileiras em situação de vulnerabilidade social.

Ressalta-se que a redução no consumo de alimentos saudáveis (como frutas, hortaliças, carnes, leite, leguminosas e cereais) foi maior nos moradores de domicílios em situação de insegurança alimentar, pela EBIA, quando comparados àqueles em segurança alimentar. Enquanto nos domicílios em insegurança alimentar esta redução chegou a até $85 \%$, naqueles em segurança ficou entre 7 a $15 \%$ (GALINDO et al., 2021).

O aumento do consumo de ovos, durante a pandemia, pode ser reflexo da redução do consumo de carnes, já que este apresenta preço mais acessível quando comparado às carnes bovina, suína e de frango. Destaca-se que os ovos são considerados alimentos saudáveis e esta substituição não é negativa. Porém, estes alimentos não apresentam os mesmos micronutrientes que a carne, como ferro heme e vitamina B12.

Os doces e guloseimas (como biscoitos doces e chocolate) apresentaram aumento de consumo e este pode estar relacionado à maior saciedade, além da necessidade de prazer e alegria, associados a momentos de medo, ansiedade e angústia. Este grupo de alimentos foi o que sofreu maior aumento de consumo durante a pandemia (GALINDO et al., 2021).

Segundo Jansen et al. (2021), o isolamento social culminou em maior ansiedade e medo, em relação à doença e suas implicações, com consequente aumento do consumo de doces e lanches prontos, levando ao possível desenvolvimento ou agravamento de distúrbios alimentares. 
O isolamento social causado pela pandemia de Covid-19 culminou ainda no fechamento de restaurantes e necessidade de maior consumo de alimentos nos domicílios. Diante dessa necessidade de preparo do próprio alimento, a pesquisa realizada pelo Instituto Brasileiro de Defesa do Consumidor (Idec) demonstrou o aumento no consumo de alimentos ultraprocessados pela população brasileira (Idec, 2020). Os ultraprocessados, assim como os alimentos congelados ou prontos, são práticos para preparo e consumo, e muitas vezes os consumidores que não têm o hábito ou não sabem cozinhar e querem ganhar tempo dão preferência a estes tipos de alimentos.

Ainda, durante a pandemia e distanciamento social, houve a suspensão da oferta de alimentação no ambiente escolar. Com isso, algumas entidades executoras (municipais ou estaduais) do Programa Nacional de Alimentação Escolar (PNAE) passaram a ofertar kits de alimentos ou até cartões de repasse financeiro visando o acesso ao alimento pelos alunos da rede pública, para o cumprimento das diretrizes do programa e da legislação vigente. Porém, muitas entidades executoras não conseguiram oferecer alimentação adequada e suficiente, segundo as recomendações do PNAE, durante todos os dias letivos de cada ano, tanto em 2020 como em 2021. Ademais, essa alimentação não chegou a todos os matriculados na rede pública, sendo que em muitos municípios houve recorte de renda para a oferta, descumprindo a diretriz de universalidade do programa. Somado a isso, tem-se o fato de que a alimentação ofertada foi muitas vezes diluída entre os membros da família, em função da privação de alimentos no domicílio, não atendendo, portanto, as necessidades nutricionais dos estudantes que receberam a alimentação (SPERANDIO, MORAIS, 2021).

Dessa forma, população brasileira segue na contramão do Guia Alimentar para a População Brasileira (BRASIL, 2014), que recomenda a preferência por alimentos in natura e minimamente processados, bem como evitar o consumo dos ultraprocessados, uma vez que estes não devem fazer parte de uma alimentação adequada e saudável. 


\section{IMPACTO DAS MUDANÇAS DO CONSUMO ALIMENTAR NA SEGURANÇA ALIMENTAR E NUTRICIONAL}

\section{Deficiência de micronutrientes}

De acordo com o relatório da FAO sobre o "Estado da Segurança Alimentar e Nutrição no Mundo", entre 720 e 811 milhões de pessoas em todos os continentes passaram fome no ano de 2020, desse total, mais de 118 milhões começaram a passar fome em função da pandemia (FAO, 2021).

O relatório evidenciou que 14 milhões de pessoas que começaram a passar fome vivem na América Latina e Caribe. Na África e na Ásia este número aumentou em 46 milhões e 57 milhões de pessoas nestas regiões, respectivamente, em relação ao observado no relatório do ano de 2019 (FAO, 2021).

O número de pessoas subalimentadas está aumentando. O progresso atingido em relação ao atraso do crescimento infantil diminuiu e as prevalências de sobrepeso e obesidade aumentaram na população adulta, tanto dos países ricos como dos países pobres (FAO, 2021).

Segundo o relatório da FAO de 2021, os efeitos da pandemia de COVID-19 ainda não podem ser totalmente quantificados. No entanto, estima-se que 149,2 milhões de crianças menores de 5 anos tenham sido afetadas pela baixa estatura, 45,4 milhões pelo baixo peso e 38,9 milhões pelo excesso de peso. Entre os adultos, a obesidade continua a aumentar, sem sinais de mudança de tendência regional ou global. De acordo com este relatório, o esforço empenhado para erradicar a desnutrição em todas as suas formas foi prejudicado, principalmente pelos efeitos negativos dos hábitos alimentares durante a pandemia (FAO, 2021).

Como apresentado anteriormente, no Brasil, os domicílios tiveram uma redução drástica no consumo de alimentos saudáveis como carnes, frutas, hortaliças, legumes, leite e derivados durante a pandemia de COVID-19, conforme estudo conduzido pelos pesquisadores da Universidade Livre de Berlim, em parceira com pesquisadores da Universidade Federal de Minas Gerais e da Universidade de Brasília (GALINDO et al., 2021). 
A análise foi feita com base em dados de um questionário aplicado a 2004 pessoas, por meio de consulta telefônica, pelo Instituto Brasileiro de Pesquisa e Análise de Dados (IBPAD) no período de 21 de novembro a 19 de dezembro de 2020 e evidenciou que $44,0 \%$ dos domicílios brasileiros reduziram o consumo de carne durante a pandemia, $40,8 \%$ o de frutas, $40,4 \%$ o de queijos e $36,8 \%$ o consumo de hortaliças e legumes (GALINDO et al., 2021). A redução no consumo destes alimentos tem como impacto a ingestão insuficiente de vitaminas e minerais, tendo como consequência deficiência de ferro, vitamina $A$, vitamina B12, vitamina $\mathrm{C}$, entre outras, expondo a população à deficiência de micronutrientes $\mathrm{e}$ consequentemente à fome oculta e insegurança alimentar e nutricional.

Ressalta-se que os dados da POF 2017-2018 sobre análise do consumo alimentar demonstraram elevada prevalência de inadequação dos micronutrientes na população brasileira acima dos 10 anos de idade antes da pandemia, com destaque para os seguintes micronutrientes; cálcio, vitamina $A$, piridoxina e magnésio onde as prevalências de inadequação foram superiores a 50,0\%. No caso do cálcio a prevalência de inadequação chegou a 99,0\% entre os adolescentes do sexo feminino, vitamina A atingiu $89,3 \%$ entre os homens, piridoxina a $96,7 \%$ entre os idosos do sexo feminino e magnésio a $80,5 \%$ entre os idosos do sexo masculino (IBGE, 2020).

\section{Desnutrição x Obesidade}

Segundo o relatório da FAO, em 2019, entre um quarto e um terço das crianças com menos de cinco anos (191 milhões) tiveram atrasos no crescimento, baixo peso para a estatura e magreza excessiva. Outras 38 milhões estavam com sobrepeso. Já entre os adultos, a obesidade já se tornou uma pandemia (FAO, 2020).

Sobre o excesso de peso, este tem sido agravado pelas mudanças no padrão alimentar da população brasileira, com destaque para o aumento do consumo de alimentos ultraprocessados em substituição aos in natura e minimamente processados (BARCELOS et al., 2014, IBGE, 2019). 
Os ultraprocessados são considerados práticos, palatáveis, duráveis e atrativos para a população, além de muitas vezes serem de baixo custo. Contudo, apresentam alta densidade calórica e alto teor de sódio, são ricos em gorduras e açúcares livres, que comprometem a qualidade da alimentação e colocam em risco a saúde dos indivíduos, podendo levar ao surgimento de doenças crônicas não transmissíveis - DCNT (BIELEMANN et al., 2015; LOUZADA et al., 2015).

Logo, o aumento das prevalências de inadequação de nutrientes, fome oculta e excesso de peso, muitas vezes são determinados pelo consumo destes alimentos. Assim, os ultraprocessados podem ser responsáveis pela relação entre consumo de alimentos/escolhas alimentares e problemas de saúde na população, contribuindo para o aumento da prevalência de insegurança alimentar e nutricional, seja no meio urbano ou rural, como já mencionado anteriormente.

\section{CONCLUSÃO}

Além da crise sanitária, a pandemia da COVID-19 agravou o cenário da insegurança alimentar e nutricional no Brasil, com redução da qualidade e quantidade de alimentos consumidos pelas famílias brasileiras. Assim, faz-se necessário a criação de programas de transferência de renda e seguridade de emprego para garantir o acesso ao alimento aos grupos mais vulneráveis.

Porém, no período pós-pandemia é preciso a manutenção e ou a criação de políticas públicas específicas visando reverter a situação de fome, desemprego e insegurança alimentar (e nutricional) que o país se encontra e também tentar amenizar as repercussões desta situação para os próximos anos, principalmente em relação às implicações do consumo alimentar e isolamento imposto pela pandemia, que comprometem o estado de saúde da população, contribuindo para a desnutrição e/ou o excesso de peso, fome oculta, bem como o surgimento de doenças crônicas não transmissíveis.

Assim, as estratégias adotadas devem priorizar as políticas de acesso tendo como foco a alimentação adequada e saudável, de forma estável, visando à promoção da saúde da população. 


\section{REFERENCIAS}

ABRANDH. Associação Brasileira pela Nutrição e Direitos Humanos. 2007. Curso de Formação em Direito Humano e Alimentação Adequada - Módulo I: Segurança Alimentar e Nutricional (SAN) e o Direito Humano à Alimentação Adequada. Disponível em: www. direitohumanoalimentacao.org. Acesso em: 06 set. 2021.

ALMEIDA, J. A. et al. Fatores associados ao risco de Insegurança Alimentar e Nutricional em famílias de assentamentos rurais. Ciência e Saúde Coletiva, Rio de Janeiro, v.22, n.2, p. 479-488, 2017.

ANTUNES, M. M.; SICHERI, R.; SALLES-COSTA, R. Consumo alimentar d crianças menores de três anos residentes em área de alta prevalência de insegurança alimentar domiciliar. Cadernos de Saúde Pública, Rio de Janeiro, v. 23, n. 4, p. 785-793, 2010.

BARCELOS, G. T.; RAUBER, F.; VITOLO, M. R.. Produtos processados e ultraprocessados e ingestão de nutrientes em crianças. Revista Ciência e Saúde, Porto Alegre, v. 7, n. 3, p. 155-161, 2014.

BIELEMANN, R. M. et al. Consumo de alimentos ultraprocessados e impacto na dieta de adultos jovens. Revista de Saúde Pública, São Paulo, v. 49, n. 28, p. 1-10, 2015.

BONACCIO, M. et al. Changes in ultra-processed food consumption during the first ItallA lockdown following the COVID-19 pandemic and major correlates: Results from two population-based cohorts. Public Health Nutrition, v. 24, n.12, p. 3905-3915, 2021.

BRASIL. Lei $n^{\circ} 11.346$, de 15 de setembro de 2006. Cria o Sistema Nacional de Segurança Alimentar e Nutricional - SISAN com vistas em assegurar o direito humano à alimentação adequada e dá outras providências. Diário Oficial [da] República Federativa do Brasil, Brasília, DF, set. 2006.

BRASIL. Constituição (2010). Emenda Constitucional n 64 , de 4 de fevereiro de 2010. Altera o art. $6^{\circ}$ da Constituição Federal, para introduzir a alimentação como direito social. Diário Oficial [da] República Federativa do Brasil, Brasília, DF, fev. 2010.

BRASIL. Ministério da Saúde. Secretaria de Atenção à Saúde. Departamento de Atenção Básica. Guia alimentar para a população brasileira. 2. ed. Brasília, 2014. 
CARVALHO, E. O.; ROCHA, E. F. Consumo alimentar de população adulta residente em área rural da cidade de Ibatiba (ES, Brasil). Ciência e Saúde Coletiva, Rio de Janeiro, v. 16, n. 1, p. 179-185, 2011.

CARVALHO, C. A.; VIOLA, P. C. F.; SPERANDIP, N. How is Brazil facing the crisis of Food and Nutrition Security during the COVID-19 pandemic? Public Health Nutrition. v. 24, n. 3, p. 561-564, 2021.

FAO. Organização das Nações Unidas Para Alimentação e a Agricultura. O estado da Segurança Alimentar e Nutricional no Brasil: um retrato multidimensional. Relatório 2014, 90p. Disponível em: http://www.fao.org.br/download/SOFI_p.pdf. Acesso em: 06 set. 2021.

FAO, IFAD, UNICEF, WFP and WHO. The State of Food Security and Nutrition in the World 2020. Transforming food systems for affordable healthy diets. Food and Agriculture Organization of the United Nations. Rome, FAO. 2020.

FAO, IFAD, UNICEF, WFP and WHO. The State of Food Security and Nutrition in the World 2021. Transforming food systems for food security, improved nutrition and affordable healthy diets for all. Rome, FAO. 2021

GALINDO, E. et al. "Efeitos da pandemia na alimentação e na situação da segurança alimentar no Brasil." Food for Justice Working Paper Series, no. 4. Berlin: Food for Justice: Power, Politics, and Food Inequalities in a Bioeconomy. 56p. 2021.

INSTITUTO BRASILEIRO DE GEOGRAFIA E ESTATÍTICA-IBGE. Pesquisa de Orçamentos Familiares - POF 2017-2018: Primeiros Resultados. Rio de Janeiro, 2019. Disponível em: https://biblioteca.ibge.gov.br/visualizacao/livros/liv101670. pdf. Acesso em: 02 set. 2021.

INSTITUTO BRASILEIRO DE GEOGRAFIA E ESTATÍTICA-IBGE. Pesquisa de orçamentos familiares 2017-2018: análise da segurança alimentar no Brasil. Rio de Janeiro, 2020. Disponível em: https://biblioteca.ibge.gov.br/visualizacao/ livros/liv101749.pdf. Acesso em: 06 set. 2021.

INSTITUTO BRASILEIRO DE DEFESA DO CONSUMIDOR (Idec). Período de pandemia registra aumento do consumo de ultraprocessados no Brasil. 2020. Disponível em: https://idec.org.br/release/periodo-de-pandemia-registra-aumento-do-consumo-de-ultraprocessados-no-brasil. Acesso em: 02 de set. 2021. 
JAFRI, A. et al. Food availability, accessibility and dietary practices during the COVID-19 pandemic: A multi-country survey. Public Health Nutrition, v. 24, n. 7, p. 1798-1805, 2021.

JANSEN, E. et al. Parental stress, food parenting practices and child snack intake during the COVID-19 pandemic. Appetite, v. 161, p. 105119, 2021.

KEPPLE, A. W.; SEGALL-CORREAA, A. M. Conceituando e medindo segurança alimentar e nutricional. Ciência e Saúde Coletiva, Rio de Janeiro, v. 21, p.111122, 2011.

LOUZADA, M. L. C. et al. Alimentos ultraprocessados e perfil nutricional da dieta no Brasil. Revista Saúde Pública, São Paulo, v. 49, n. 38, p. 1-11, 2015.

MACHADO, J.C.; SPERANDIO, N. Introdução à Segurança Alimentar e Nutricional. In: MORAIS, D.C.; SPERANDIO, N.; PRIORE, S.E. Atualizações e debates sobre segurança alimentar e nutricional. FACEV. 2020.

MALUF, R. S; REIS, M. C. Conceitos e Princípios de Segurança Alimentar e Nutricional. In: Segurança Alimentar e Nutricional: perspectivas, aprendizados e desafios para as políticas públicas. Rio de Janeiro: Editora Fiocruz. 2013.

MALTA, D. C. et al. A pandemia da COVID-19 e as mudanças no estilo de vida dos brasileiros adultos: um estudo transversal, 2020. Epidemiologia e serviços de Saúde, Brasília, v. 29, n. 4, p. 1-13, 2020.

MIGUEL, E. S. Uso de agrotóxicos na produção de alimentos e condições de saúde e nutrição de agricultores familiares. Orientadora: Silvia Eloiza Priore. 2018. 161 f. Dissertação (Mestrado em Agroecologia). Universidade Federal de Viçosa, Viçosa, 2018.

MORAIS. D. C. (In)Segurança Alimentar e Nutricional e relação com indicadores sociais, econômicos e nutricionais de famílias residentes de zona rural. Orientadora: Silvia Eloiza Priore. 2014. 158 f. Dissertação (Mestrado em Ciência da Nutrição). Universidade Federal de Viçosa, Viçosa, 2014.

MORAIS, D. C. et al. Insegurança alimentar e indicadores antropométricos, dietéticos e sociais em estudos brasileiros: uma revisão sistemática. Ciência e Saúde Coletiva, Rio de Janeiro, v. 19, n. 5, p. 1475-88, 2014.

MORAIS, D. C.; ANDRÉ, H. O. Indicadores sociais e nutricionais da Insegurança Alimentar e Nutricional. In: MORAIS, D. C.; SPERANDIO, N.; PRIORE, S. E. Atualizações e debates sobre segurança alimentar e nutricional. p. 93-115. FACEV. 2020. 
PANIGASSI, G. et al. Insegurança alimentar intrafamiliar e perfil de consumo de alimentos. Revista de Nutrição, Campinas, v. 21, p. 135-144, 2008.

PEREIRA, D. A. et al. Insegurança Alimentar em Região de Alta Vulnerabilidade Social da Cidade de São Paulo. Revista Segurança Alimentar e Nutricional, Campinas, v.13, n. 2, p.34-42, 2006.

REDE BRASILEIRA DE PESQUISA EM SOBERANIA E SEGURANÇA ALIMENTAR - Rede PENSSAN. Inquérito Nacional sobre Insegurança Alimentar no Contexto da Pandemia da Covid-19 no Brasil (VIGISAN). 2021. Disponível em: http://olheparaafome.com.br/VIGISAN_Inseguranca_alimentar.pdf. Acesso em: 31 ago. 2021.

SILVA, C. C. S. et al. Associação entre consumo alimentar e (in)segurança alimentar e nutricional em São José dos Ramos - PB. Brazilian Journal of Food Technology, Campinas, v. 15, p. 23-30, 2012.

SPERANDIO, N.; MORAIS, D. C. Alimentação escolar no contexto de pandemia: a ressignificação e o protagonismo do Programa Nacional de Alimentação Escolar. Revista Segurança Alimentar e Nutricional, Campinas, v. 28, p. 1-11. 2021. 
de $10.48209 / 978-65-89949-32-6$

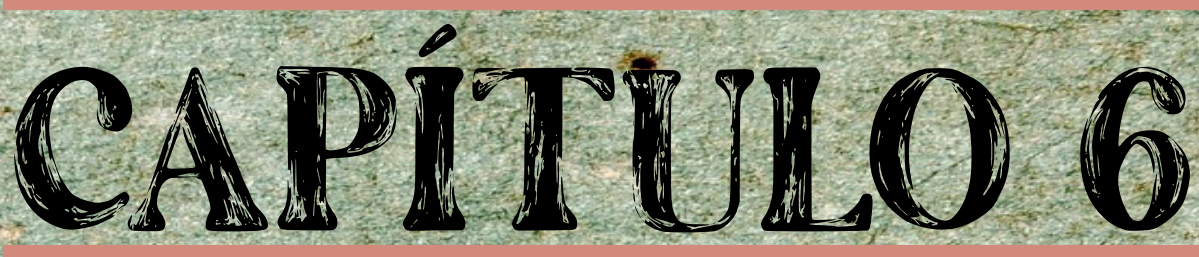

CONSUMO DE ARROZ

$+\infty$

E FEIJ ÃO POR

JOVENS ADULTOS:

MUDANÇAS GERADAS

PELA PANDEMIA

DA COVID-19

Victória Teixeira Xavier Cilene da Silva Gomes Ribeiro 


\section{INTRODUÇÃO}

A alimentação e nutrição se constituem em um dos fatores condicionantes e determinantes de saúde e bem-estar do ser-humano (BRASIL, 1990). Além de sua função básica para sobrevivência humana e determinante de saúde, a alimentação carrega a influência de fatores históricos, ecológicos, culturais, sociais, econômicos e políticos (MACIEL, 2005).

Os hábitos alimentares vão além do consumo do alimento, que nutre o corpo humano ajudando-o em suas questões fisiológicas. Deve-se levar em consideração como esse alimento se torna comida ou seja, como se transforma em hábito alimentar e cultura: se foi manuseado e sofreu mudanças, se sofreu adição de temperos ou sobre ele foi utilizada alguma técnica culinária, levando às preparações e aos alimentos questões culturais (BARBOSA, 2006). Por isso, a investigação das práticas alimentares não se limita aos alimentos ingeridos per se, pois compreende tanto fatores objetivos e subjetivos sobre o que se come e o como se come (CANESQUI, 2005).

A alimentação é criada através de tradições e histórias vividas pela sociedade. No Brasil, podemos dizer que a culinária sofreu diversas influências dos povos que já estavam aqui, juntamente com os que chegaram devido as Grandes Navegações (MACIEL, 2004) oriundos da Europa, África e Ásia (RIBEIRO, 2014).

A vinda dos portugueses, a exemplo, integrou alimentos e práticas de preparo e consumo aos povos nativos, bem como reconfigurou os mesmos. Muitas foram as miscigenações alimentares ocorridas do além-mar, trazidas e levadas, que passaram a configurar novos padrões e hábitos alimentares mundo afora. O feijão é um exemplo típico de um alimento amplamente difundido pelos portugueses, a partir de tal miscigenação cultural. Apesar de algumas espécies desta leguminosa já existirem nas Américas e entre os povos africanos, tal alimentos só passou a ser amplamente consumido a partir de tal integração entre os povos (MACIEL, 2004). 
O uso e consumo de feijão se potencializou na época dos bandeirantes, pois estes não nativos da terra, caminhavam dentro do Brasil em busca de novas riquezas e precisavam se alimentar com produtos que fossem de fácil transporte, plantio e preparo, tendo sido o feijão um alimento que atendia a tais necessidades (LEME, 2015). Mas, apesar de muitas espécies serem nativas, e outras terem sido trazidas pelos povos que colonizaram o Brasil, o feijão apenas se consolidou como base alimentar brasileira no século XIX, se tornando, muitas vezes, a única fonte proteica da alimentação da população com menor poder aquisitivo (MACIEL, 2004).

A consolidação de uma identidade alimentar nacional veio apenas no modernismo, movimento artístico-cultural que buscou ideias de valorização do cotidiano e da cultura, aproximação com a linguagem popular e simplificação do discurso. Neste momento, no início do século $X X$, em que houve uma crescente onda de nacionalismo, procurou-se criar uma identidade do que é ser brasileiro (AMARAL,2012), onde o incentivo ao consumo de feijão passou a ser amplamente disseminado por alguns autores da época, como Monteiro Lobato, Mario de Andrade, entre outros (LEME, 2015).

Mas, foi a partir do século XVIII que a tradicional combinação de arroz com feijão se tornou base alimentar no Brasil (MACIEL,2004). Nesse período, a plantação de arroz foi consolidada, pois surgiu a primeira plantação empresarial, na cidade de Pelotas, que possuía irrigação acionadas pelas máquinas de vapor que auxiliavam na inundação das lavouras. Até aquele momento, as plantações eram de pequenos produtores e feita de maneira colonial (CONAB, 2015).

A farinha que antes era consumida com o feijão, deu lugar ao arroz em muitos espaços geográficos brasileiros. Mas, o costume de consumir, de forma constante, arroz, feijão e farinha, de maneira combinada não se perdeu ao longo do tempo (MACIEL, 2004), sendo até hoje evidenciada em praticamente todo território nacional.

Mas, apesar do consumo de arroz e feijão ser base alimentar da maior parte dos brasileiros (MACIEL,2004), tem sido evidenciado um decréscimo no consu- 
mo desta combinação nos últimos 10 anos. De acordo com dados publicados pelas Pesquisas de Orçamentos Familiares (POF) de 2008-2009 e de 2017-2018, evidencia-se diminuição de $12.8 \%$ no consumo de feijão, apesar do aumento de 9\% nas preparações a base de feijão, o que, em âmbito geral, caracteriza diminuição de 3.8\% no seu consumo (IBGE, 2020). O arroz, por sua vez, teve seu consumo reduzido em $7.9 \%$ quando puro e aumento de $1.4 \%$ em preparações que possuem como base o arroz, caracterizando uma redução de $6.5 \%$ no consumo geral deste alimento (IBGE, 2020).

Em janeiro de 2020, a Organização Mundial da Saúde (OMS) declarou que o SARs-Cov-2, vírus da doença Covid-19, tornou-se uma emergência sanitária global. O vírus que teve seu epicentro na China (VELEVAN; MEYER, 2020), fez com que o mundo se tornasse off-line (PEREIRA,2020), exigido drásticas alterações nos hábitos de vida da população, devido à necessidade de isolamento social para reduzir a disseminação da doença (BRASIL, 2020a; OLIVEIRA et al., 2020) uma vez que é altamente contagiosa (ZHAl et al., 2020). Neste novo contexto, tem-se evidenciado inúmeras mudanças nas rotinas familiares e empresariais, que influenciaram diretamente nas escolhas, acesso e consumo dos alimentos.

Sem dúvidas, realizando isolamento social, mudanças nos hábitos alimentares ocorreram, impactando na saúde da população. Segundo Oliveira, Silva e Lemos (2020), em estudo realizado com a população brasileira, entre maio e setembro de $2020,70,9 \%$ dos participantes da pesquisa assumiram preferir alimentos ultra processados em suas dietas (OLIVEIRA, SILVA, LEMOS, 2020). Malta et al (2020) reforçam que já existem estudos capazes de mostrar como a pandemia vem afetando o cotidiano das pessoas, em que se mostram pioras na qualidade de vida dos indivíduos devido ao aumento do consumo de ultra processados e bebidas alcoólicas, e também na diminuição de atividades físicas (MALTA, et al, 2020). Além da piora na qualidade de vida, tem sido evidenciado grave redução no poder médio de compra dos brasileiros, concomitantemente ao 
aumento significativo dos valores financeiros de alimentos que compõem a cesta básica, estando entre eles o arroz e feijão (SCHENEIDER, et al. 2020), fato também gerador das mudanças nas escolhas alimentares da população.

Durante os meses que se passaram entre a pandemia, foi possível notar aumento do valor de aquisição de alimentos como arroz com feijão, devido a diversos fatores produtivos e comerciais (BACCARIN, OLIVEIRA,2021), o que pode ter agravado os cenários já mostrados pela POF, com diminuição gradual do consumo de arroz e feijão.

A partir destas análises, este estudo objetivou avaliar possíveis alterações no acesso, preparo e consumo de arroz e feijão entre jovens adultos, durante a pandemia, analisando quais foram as mudanças ocorridas no cotidiano alimentar dos mesmos.

\section{DESENVOLVIMENTO}

A partir de pesquisa online realizada entre 262 jovens adultos, todos brasileiros, em que $75,6 \%$ se autodeclararam do sexo feminino e $24,4 \%$ do sexo masculino, 59,5\% alegaram que as preparações que consomem no ambiente doméstico são preparadas por suas mães, pais, avós ou pelo cônjuge e 40,5\% referenciaram preparar seus próprios alimentos, neste caso tendo liberdade em escolher o que vão e como vão comer os alimentos, levando em consideração valores pessoais.

Nos resultados desta pesquisa foi possível evidenciar que a cozinha ainda é considerada um território feminino, fato este já referenciado por diversos autores (GUIMARÃES, DAOU, 2021; BEVOUIR, 2004).

Dos 262 participantes da pesquisa, 9,5\% (25) referiram morar sozinhos, $17,6 \%$ (46) moram apenas com mais um indivíduo, 31,7\% (83) alegam morar com mais duas pessoas e $41,2 \%$ declaram morar com 4 ou mais pessoas em seus domicílios. 
No que se refere ao consumo de arroz pelos pesquisados, $96,4 \%$ inferiram consumir arroz antes da pandemia da Covid-19, que $76,3 \%$ consumiam tal alimento diariamente e $13,7 \%$ o faziam até duas vezes por dia. E, 8,8\% faziam consumo de arroz, pelo menos uma vez por semana. Dos participantes da pesquisa apenas 6,8\% $(n=18)$ declararam não terem percebido alterações em relação ao consumo de arroz durante a pandemia. Mas, $55 \%(n=155)$ relataram ter aumentado o consumo deste tipo de alimento, 13\% $(n=34)$ declararam ter diminuído o consumo e $25,2 \%(n=66)$ reforçou não ter sofrido nenhum tipo de alteração no consumo alimentar de arroz durante a pandemia.

Dos motivos que levaram os participantes a aumentarem seu consumo de arroz, 37,6\% reforçaram que passaram a cozinhar mais em suas casas, $28 \%$ passaram a comer mais no ambiente doméstico, 14\% citaram que o consumo aumentado se deu em virtude de terem retornado à casa dos pais, 4,3\% passaram a comer mais marmitas ou comida comprada pronta e 16,1\% alegou ter aumentado o consumo de arroz em virtude do aumento dos preços de outros alimentos.

Em contrapartida, dentro os motivos que levaram à redução no consumo de arroz durante a pandemia da Covid-19 estão o aumento dos preços de aquisição deste alimento (31,5\%), a inserção de alimentos diferentes em suas dietas $(24,1 \%)$, o aumento no consumo de fast food $(11,11 \%)$, passar a cozinhar e consumir mais alimentos em casa $(12,2 \%)$, passar a consumir mais alimentos prontos $(5,6 \%)$, não ter tempo para preparar esses alimentos $(5,6 \%)$, por ter tempo de preparo demorado $(3,7 \%)$, ter voltado para a casa dos pais $(1,9 \%)$, por passar a preferir alimentos ultraprocessados e por não ter tempo para realizar a compra desse tipo de alimento $(1,9 \%)$.

Sem dúvidas, o aumento de preço do arroz no mercado nacional brasileiro tem aumentado de forma muito significativa desde o início da pandemia. Segundo o IBGE o valor deste produto em 2020 aumentou 70,6\% em comparação ao ano anterior (IBGE,2020).

Já no que se refere aos indicadores de consumo de feijão antes e durante a pandemia, evidenciou-se que $98,1 \%$ alegaram consumir feijão antes da pande- 
mia, sendo que $53,5 \%$ o faziam diariamente, $11,5 \%$ o faziam duas vezes por dia e $28,5 \%$ pelo menos uma vez por semana.

Dos participantes que sinalizaram consumir feijão com frequência antes da pandemia, 56,1\% referiram não ter gerado nenhuma alteração no mesmo durante o isolamento da Covid-19, 21,4\% comentaram ter aumentado o consumo deste alimento, e 13,7\% reforçaram ter diminuído o consumo durante este período. Os motivos declarados para o aumento do consumo foram: passar a cozinhar mais no ambiente doméstico (35,1\%), passar a comer mais em casa $(29,7 \%)$, ter retornado para casa dos pais $(17,6 \%)$, aumento no preço dos produtos $(12,2 \%) \mathrm{e}$ passar a comer mais marmitas prontas $(5,4 \%)$.

Os motivos citados para justificar a redução no consumo de feijão durante a pandemia da Covid-19 foram: o aumento do preço de aquisição deste alimento $(18,5 \%)$, ter passado a cozinhar e comer no ambiente doméstico $(18,6 \%)$, ausência de tempo para preparar o alimento $(14,7 \%)$, ter ampliado a variedade de alimentos consumidos que anteriormente não faziam parte da rotina alimentar $(13 \%)$, pelo fato de acharem o preparo demorado (13\%), em virtude do aumento de consumo de fast food $(9,3 \%)$, por achar seu preparo difícil de ser executado $(7,4 \%)$, por desconhecer a forma de preparo do alimento $(1,9 \%)$, por passar a consumir marmitas ou preparações prontas $(1,9 \%)$ e por passarem a consumir tais alimentos apenas na casa dos pais $(1,9 \%)$.

Constatou-se que entre os 264 participantes, 28,4\% alegaram ter de 18 a 20 anos, 36,6\% ter de 21 a 23 anos, $14,9 \%$ ter de 24 a 26 anos e 6,6\% alegaram ter 27 ou 28 anos de idade, segundo o Instituto Brasileiro de Geografia e Estatística (IBGE) apenas 7,3\% do total de brasileiros se encontra nestas faixas etárias, e segundo estatísticas do próprio IBGE este número diminuiu 3,5\% entre os anos de 2012 e 2019 (IBGE,2019).

Comparando os resultados encontrados, referentes à renda declarada pelos participantes, com os dados obtidos através do Instituto Brasileiro de Planejamento e Tributação (IBPT), percebe-se uma diferenciação entre os pesquisados 
e o cenário nacional já que 41,6\% declararam ter de 3 a 5 salários-mínimos como renda familiar, enquanto apenas $12,65 \%$ dos brasileiros possuem essa renda familiar, além disso, 17,6\% declaram receber 1 a 2 salários-mínimos, em contra partida, no Brasil, essa é a renda mensal que mais possui brasileiros, no total de $79,02 \%$; e $37,8 \%$ dos pesquisados alegam contar com 6 ou mais salários-mínimos mensais, nacionalmente, este número é menor, sendo de $33,56 \%$ dos brasileiros (IBPT,2021).

O consumo de arroz e feijão foram diretamente afetados por questões relacionadas aos processos de cocção, ao tempo disponível para o preparo, a quem se direcionava a tarefa de preparar tais alimentos, aos diferentes tipos de acesso a estas preparações nos espaços familiares. Mesmo que boa parte dos entrevistados tenha alegado que manteve o consumo destes alimentos, é notório que sua produção e consumo estão atrelados aos hábitos e referências familiares.

\section{CONCLUSÃO}

Identificou-se que a população pesquisada manteve, dentro do praticável, uma alimentação regular apesar do cenário pandêmico, além disso percebeu-se que há uma independência e autonomia culinária quando pensado sobre $o$ ato de cozinhar, mas também é visível que o papel de mães e avós ainda é forte nas relações de cuidado alimentar e nos processos de produção deste binômio tão brasileiro, o arroz com feijão.

\section{REFERENCIAS}

AMARAL, Aracy. O modernismo brasileiro e o contexto cultural dos anos 20. Revista Usp, n. 94, p. 9-18, 2012. Disponível em:< https://www.revistas.usp.br/revusp/article/view/45021/48633> Acesso em 03 set. 2021

BARBOSA, K. Significados e experiências de pessoas em situação de rua acometidas por tuberculose. 2018. $121 \mathrm{f}$. Tese (Doutorado em Enfermagem) - Centro de Ciências da Saúde, Universidade Federal da Paraíba, João Pessoa, 2018. 
BARBOSA, Lívia. Feijão com arroz e arroz com feijão: o Brasil no prato dos brasileiros.Horizontes Antropológicos, Porto Alegre -RS, v.13, n.28, jul/ dez.2007. Disponível em <https://www.scielo.br/scielo.php?pid=S010471832007000200005\&script=sci_arttext> Acesso em: 13abr.2021

BEZERRA, Anselmo César Vasconcelos et al. Fatores associados ao comportamento da população durante o isolamento social na pandemia de COVID-19. Ciência \& Saúde Coletiva, v. 25, p. 2411-2421, 2020. Disponível em < https://www. scielosp.org/pdf/csc/2020.v25suppl1/2411-2421/pt > Acesso em 07 set 2021

BONETT, L. P., BAUMGARTNER, M. S. T., KLEIN, A. C., SILVA, L. I. Compostos nutricionais e fatores antinutricionais do feijão comum (Phaseolus Vulgaris L.). Arq. Ciênc. Saúde Unipar, Umuarama, v. 11, n. 3, p. 235-246, set/dez. 2007. Disponível em: < file:///C:/Users/Acer\%20A315/Downloads/2044-7439-1-PB\%20 (1).pdf >. Acesso em: 26 abr.2021

BRASIL. LEI N 8.080, DE 19 DE SETEMBRO DE 1990. Dispõe sobre as condições para a promoção, proteção e recuperação da saúde, a organização e o funcionamento dos serviços correspondentes e dá outras providências. 1990

CANESQUI, A. M. Mudanças e Permanências da Prática Alimentar Cotidiana de Famílias de Trabalhadores. In: CANESQUI, A. M., GARCIA, R. W. D., (Org.). Antropologia e nutrição: um diálogo possível. Rio de Janeiro: Editora FIOCRUZ, 2005.

CONAB. Companhia Nacional de Abastecimentos - Estoques. Disponível em: <https://www.conab.gov.br/estoques>. Acesso em: 09 set. 2021.

COSTA, Simone da Silva. Pandemia e desemprego no Brasil. Revista de Administração Pública, Rio de Janeiro, v.54, n.4, jul.2020. Disponível em $<$ https://www.scielo.br/scielo.php?pid=S0034-76122020000400969\&script=sci_ arttext> Acesso em 28 abr.2021

DE BEAUVOIR, Simone. 0 segundo sexo. $2^{\mathrm{a}}$ ed. Rio de Janeiro: Nova Fronteira, 2009.

DE OLIVEIRA, Mariana Fernandes Brito. Autonomia culinária: desenvolvimento de um novo conceito. 2018. Tese de Doutorado. PhD Thesis. 552 State University of Rio de Janeiro (UERJ). Disponível em < https://www.researchgate. net/profile/Mariana-Oliveira-33/publication/344956039_Tese_Autonomia_culinaria_2018/links/5f9b127c458515b7cfa94b16/Tese-Autonomia-culinaria-2018.pdf > Acesso em 03 set 2021 
GUIMARÃES, Sandra Suely Moreira Lurine; DAOU, Saada Zouhair. DIVISÃO SEXUAL TRABALHO, TRABALHO REPRODUTIVO E AS ASSIMETRIAS DE GÊNERO NA PANDEMIA DA COVID-19. Revista Direito e Sexualidade, v. 2, n. 1, 2021. Disponível em < https://periodicos.ufba.br/index.php/revdirsex/article/ view/42979/24774 > Acesso em 03 set 2021

IBGE - Instituto Brasileiro de Geografia e Estatística. Brasil,2021. Disponível em < https://educa.ibge.gov.br/jovens/conheca-o-brasil/populacao/18318-piramide-etaria.html> Acesso em 08 set 2021

IBGE - Instituto Brasileiro de Geografia e Estatística. Brasil,2021. Disponível em $<$ https://educa.ibge.gov.br/jovens/conheca-o-brasil/populacao/18320-quantidade-de-homens-e-mulheres.html> Acesso em 05 set 2021

IBGE - Instituto Brasileiro de Geografia e Estatística. Brasil,2021. Disponível em < https://www.ibge.gov.br/estatisticas/economicas/precos-e-custos/9256-indice-nacional-de-precos-ao--consumidor-amplo.html?=\&t=destaques $>$ Acesso em 08 set 2021

IBPT - Instituo Brasileiro de Planejamento e Tributação, Brasil 2021. Disponível em < https://ibpt.com.br/populacao-que-recebe-ate-tres-salarios-minimos-e-a-que-mais-gera-arrecadacao-de-tributos-no-pais/> Acesso em 06 set 2021

LEME, Adriana Salay. Feijão, dono das tradições: representação identitária e consumo efetivo no Brasil (1973-2009). Nome da revista em negrito, São Paulo, may 2015. Disponível em: < https://www.teses.usp.br/teses/disponiveis/8/8138/ tde-26052015-122424/publico/2014_AdrianaSalayLeme_VCorr.pdf >. Acesso em: 22 may. 2021.

MACIEL, M. E. Identidade Cultural e Alimentação. In: CANESQUI, A. M., GARCIA, R. W. D., (Org.). Antropologia e nutrição: um diálogo possível. Rio de Janeiro: Editora FIOCRUZ, 2005.

MACIEL, Maria Eunice. Uma cozinha à brasileira. Revista Estudos Históricos, Rio de Janeiro, v.1, n.33, p.25-39, jan/jun.2004. Disponível em <http://bibliotecadigital.fgv.br/ojs/index.php/reh/article/view/2217/1356>Acesso em : $13 a b r .2021$

MALTA, Deborah Carvalho. et al. A pandemia da COVID-19 e as mudanças no estilo de vida dos brasileiros adultos: um estudo transversal, 2020. Rev.Epidemiologia e Serviços de Saúde, Brasília, v.29, n.4, set.2020. Disponível em: <http://scielo.iec. gov.br/scielo.php?script=sci_arttext\&pid=S1679-49742020000400025> Acesso em: 27 abr.2021 
NAVES, Maria Margareth Veloso, características químicas e nutricionais do arroz. B.CEPPA, Curitiba, v. 25, n. 1, p. 51-60, jan./jun. 2007. Disponivel em: < https:// core.ac.uk/download/pdf/328054375.pdf > Acesso em: 26 abr.2021

NICOLA, ET AL . As Implicações Socioeconômicas a Pandemia De Coronavírus (Covid-19): Uma Revisão. INT J SURG. Londres, junho 2020. Disponível em < https://www.ncbi.nlm.nih.gov/pmc/articles/PMC7162753/ > Acesso em 09abr.2021

OLIVEIRA, Nadja Thomé de; SILVA, llane Karine Martins Mendes da. Isolamento social durante a pandemia de COVID-19 e a influência dos hábitos alimentares dos brasileiros. UNIT-AL_BIO, Disponivel em: < https://openrit.grupotiradentes. com/xmlui/bitstream/handle/set/3644/Banca\%20Tcc\%20-\%20N\%c3\%a1\%20 e\%20llane\%20\%283\%29.pdf?sequence=1 > Acesso em: 26 abr.2021

ORSINE, Joice Vinhal Costa et al. Práticas de alimentação e nutrição na prevenção e enfrentamento à Covid-19. 2021. Instituto Federal de Educação, Ciência e Tecnologia Goiano - IF Goiano. Disponível em < https://repositorio. ifgoiano.edu.br/bitstream/prefix/1898/1/Praticas_de_alimentacao_e_Nutri\%C3\%A7\%C3\%A3o_no_enfrentamento_\%C3\%A0_COVID-19.pdf > Acesso em : 03 set 2021

PEREIRA, André Filipe Serrano. Mundo desconectado, mas online Análise de como o Covid-19 afetou o comportamento do consumidor em compras online durante o período de confinamento. Repositório Científico do Instituto Politécnico de Viseu, Viseu, Disponível em <https://repositorio.ipv.pt/bitstream/10400.19/6534/1/ Andre_Pereira_Dissertacao.pdf> Acesso em: 10abr.2021

Pesquisa de Orçamentos Familiares. IBGE - Instituto Brasileiro de Geografia e Estatística. Brasil,2021. Disponível em < https://biblioteca.ibge.gov.br/visualizacao/livros/liv101742.pdf > Acesso em 05 set 2021

RIBEIRO, Darcy. O Povo Brasileiro: A formação e o sentido Brasil. $1^{\text {a }}$ edição digital. São Paulo. Global Editora. 2014,138 e 162 p.

SANTOS, Taíse Gama dos, SILVEIRA, Jonas Augusto Cardoso da., LONGOSILVA, Giovana. RAMIRES, Elyssia Karine Nunes Mendonça. MENEZES, Risia Cristina Egito de. Tendência e fatores associados à insegurança alimentar no Brasil: Pesquisa Nacional por Amostra de Domicílios. Cadernos de Saúde Pública, Rio de Janeiro, v.34, n.4, 29març.2018. Disponível em <https://doi.org/10.1590/0102311X00066917> Acesso 20 abr.2021 
SCHNEIDER, Sergio et al. Os efeitos da pandemia da Covid-19 sobre o agronegócio e a alimentação. Estudos Avançados, v. 34, p. 167-188, 2020. Disponível em < https://www.scielo.br/j/ea/a/kQdC7V3FxM8WXzvmY5rR3SP/?format=pdf\&lang=pt $>$ Acesso em 07 set 2021

VELAVAN, Thirumalaisamy P. e MEYER, Christian G.. A epidemia de COVID-19. Trop Med Int Health, , v.25, n.3, p,278-280, 16fev.2020. Disponível em: <https:// www.ncbi.nlm.nih.gov/pmc/articles/PMC7169770/> Acesso em: 27 abr.2021 


\section{SOBRE AS ORGANIZADORAS}

\section{LIZIANY MŮㄴLLER}

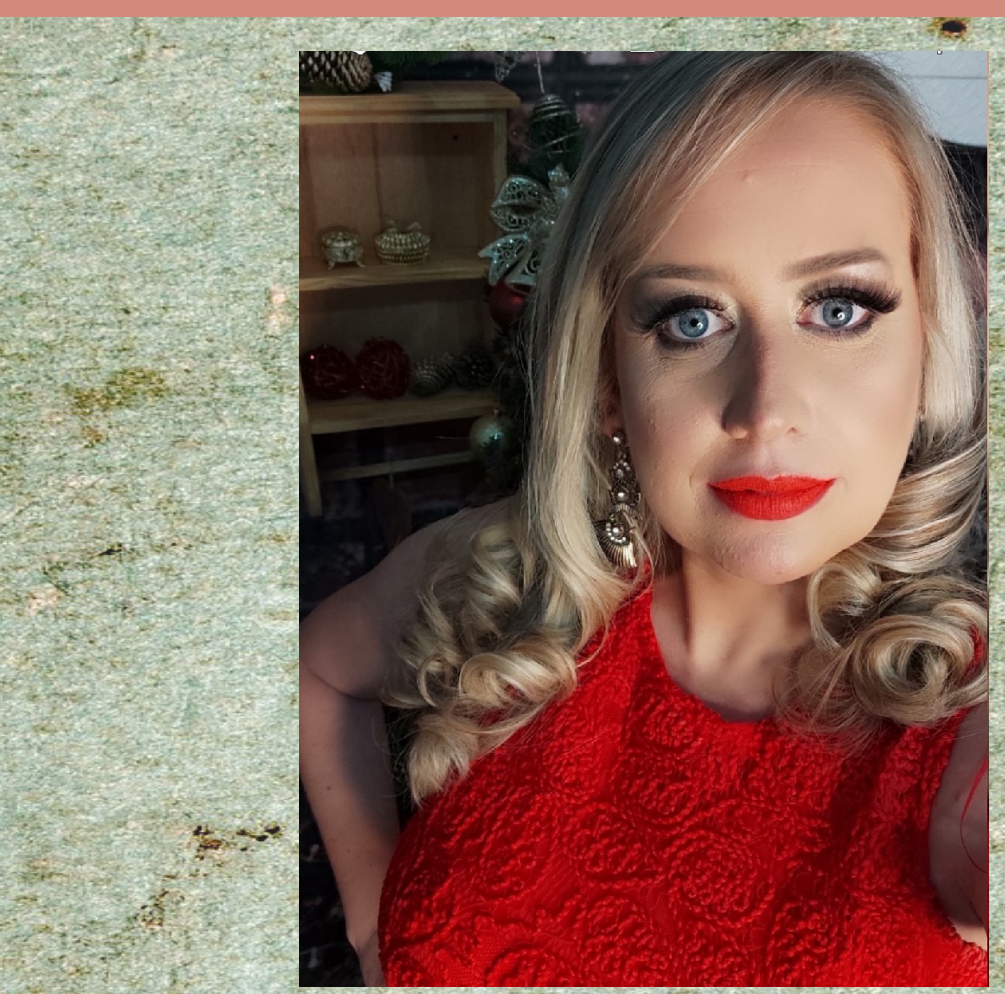

Possui Bacharelado em Zootecnia (2004) e Licenciatura pelo Programa Especial de Graduação de Formação de Professores para a Educação Profissional (2011) ambas pela Universidade Federal de Santa Maria, Mestrado (2006) e Doutorado (2009) pelo Programa de Pós Graduação em Agronomia na Universidade Federal de Santa Maria, Pós-doutorado em Zootecnia no Programa de Pós Graduação em Zootecnia na Universidade Federal de Santa Maria (2011). Já atuou como: Professora e Orientadora do Curso de Especialização em Tecnologia de Informação e Comunicação da Universidade Aberta do Brasil/UFSM; Professora do Curso de Especialização em Agricultura Familiar Camponesa e Educação do campo-Residência Agrária; Professora e Orientadora do PPGTER - Programa de Pós-Graduação em Tecnologias Educacionais em Rede nivel Mestrado da Universidade Federal de Santa Maria. Atualmente é professora Associada II, responsável pelo Laboratório Mediações Sociais e Culturais - Departamento de Educação Agrícola e Extensão Rural - Centro de Ciências Rurais - Universidade Federal de Santa Maria; Professora e Coordenadora do Curso de Licenciatura em Educação do Campo da Universidade Aberta do Brasil/UFSM; Professora Permanente no Programa de Pós-Graduação em Extensão Rural. Também coordena a ação de Extensão-Fiex/CCR/UFSM "Programa de Capacitações Temas Emergentes e Ensino Híbrido para Educação Básica? e o grupo de pesquisa registrado no CNPq "Girassol? Grupo de Pesquisa em Agroecologia, Educação e Inovações Sociais”. 


\section{ALESSANDRA REGINA MŨLLER GERMANI}

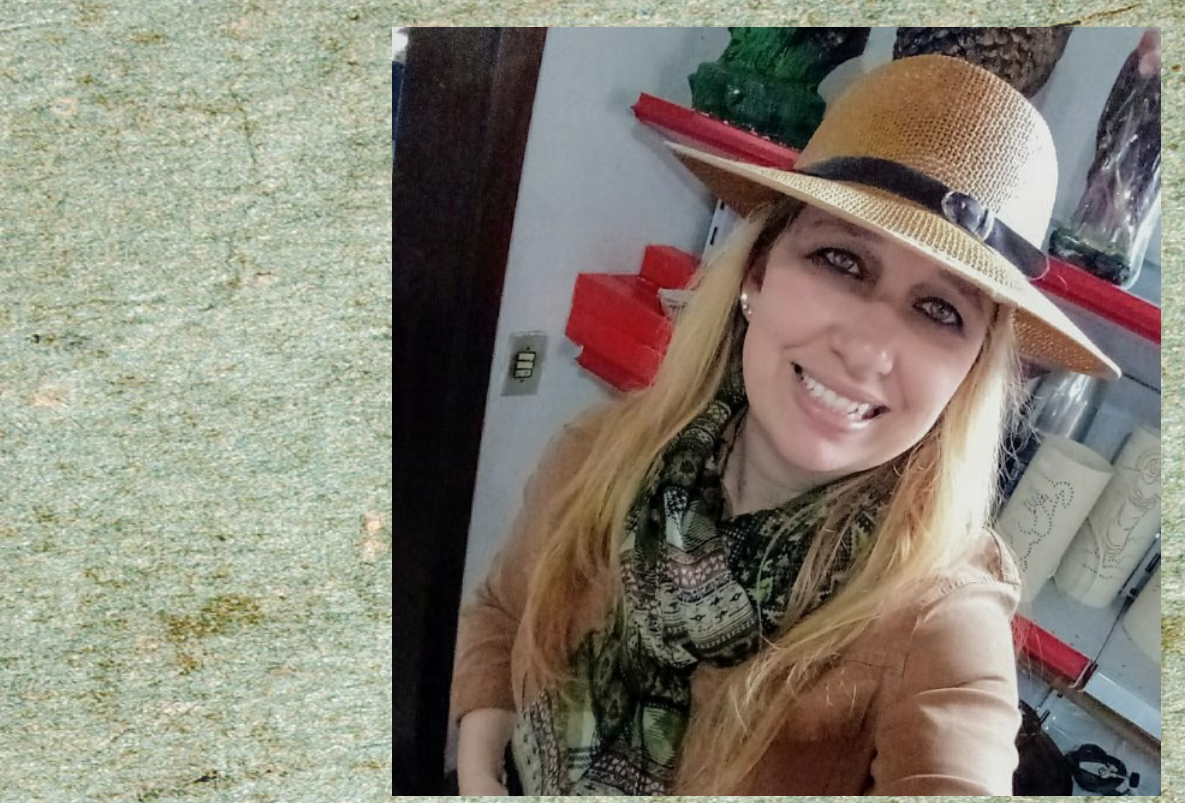

Graduação em Enfermagem pela Universidade Federal de Santa Maria - UFSM (19951999), Especialização em Docência na Saúde pela Universidade Federal do Rio Grande do Sul-UFRGS (2014-2015), Mestrado em Enfermagem - Area de Concentração Saúde, Sociedade e Filosofia pelo Programa de Pós-Graduação em Enfermagem da Universidade Federat de Santa Catarina - UFSC (2000-2002), Doutorado em Extensão Rural - Area de Concentração Extensão Rural e Desenvolvimento pelo Programa de Pós-Graduação em Extensão Rural (PPGExR), da Universidade Federal de Santa Maria-UFSM (2015 - 2019).Atuei como Diretora das Ações em Saúde no município de Restinga Sêca/RS (1999) e Diretora de Saúde Coletiva no município de Santa Maria/RS (2001-2002). Na docência atuei como Professora Substituta no Curso de Enfermagem, na Universidade Federal de Santa Maria - UFSM (1999-2001); Professora do Curso de Gräduação em Enfermagem, na Universidade Regional Integrada do Alto Uruguai e das Missões - Campus de Santiago/RS (2002-2004) e Campus de Frederico Westphalen/ RS (2002 - 2010), Professora Colaboradora no Curso de Pós-graduação-Especialização em Saúde Coletiva, no Centro Universitário Franciscano - UNIFRA/RS (20072010); Professora do Curso de Graduação em Enfermagem na Universidade Federal da Fronteira Sul - UFFS Campus Chapecó/SC (2010-2013). Atualmente atuo como Professora do Curso de Graduação em Medicina na Universidade Federal da Fronteira Sul - UFFS Campus Passo Fundo/RS (2013 em diante); Professora do Programa de Residência Multiprofissional em Saúde na Universidade Federal da Fronteira Sul UFFS Campus Passo Fundo/RS (2018 em diante); Professora formadora no Curso de Licenciatura em Educação do Campo - EAD, do Centro de Ciências Rurais - CCR, da Universidade Federal de Santa Maria - UFSM (2019 em diante). Pesquisadora do Grupo de Pesquisa Inovação em Saúde Coletiva: políticas, saberes e práticas de promoção da saúde - UFFS Campus Passo Fundo/RS, nas linhas de pesquisa: Políticas e práticas de gestão na saúde e Práticas de educação e formação na saúde (2014 em diante). Vice-líder e Pesquisadora do Girassol - Grupo de Pesquisa em Agroecologia, Educação do Campo e Inovações Sociais - UFSM Campus Santa Maria/RS, na linha de pesquisa Agroecologia e Desenvolvimento Sustentável. (2020 em diante).Tenho experiências de gestão, ensino, pesquisa, extensão e pós-graduação voltadas à saúde coletiva e estudos rurais; atuando em diversos Conselhos, Comissões e Comitês. 


\section{GISELE MARTINS GUIMARÃES}

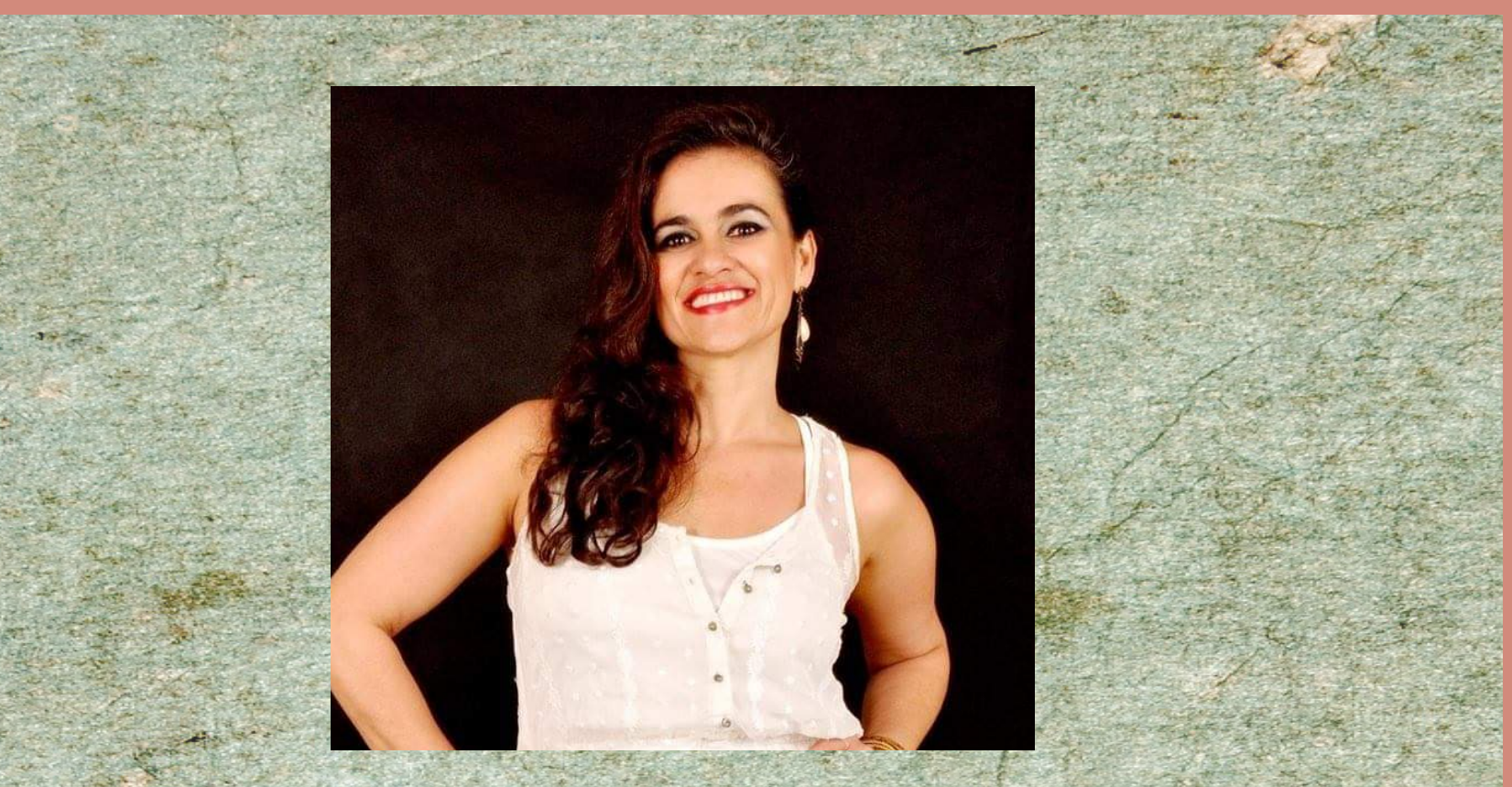

De formação multidisciplinar, é graduada em Zootecnia pela Universidade Federal de Santa Maria-UFSM, Mestre em Extensão Rural pela mesma instituição e Doutora em Desenvolvimento Rural (PGDR), pela Universidade Federal do Rio Grande do Sul - UFRGS. É Professora-Adjunta na Universidade Federal de Santa Maria no Departamento de Educação Agrícola e Extensão Rural e no Programa de Pós Graduação em Extensão Rural (PPGExR-UFSM). Atua como pesquisadora e consultora técnica nos seguintes eixos temáticos: Desenvolvimento Rural, Extensão e Comunicação Rural, Agroeocologia, Agricultura Familiar, Agroindústrias Familiares, Educação e Soberania Alimentar e Economia Solidária. É integrante do Grupo de Pesquisa em Extensão Rural Aplicada - UFSM. É também cantora, intérprete e compositora. Possui disco autoral gravado e é atuante como intérprete nos Festivais do Rio Grande do Sul com participação em vários registros fonográficos. É produtora e apresentadora do quadro "Com a Palavra: o Artista" do Podcast PONTO DE CULTURA, realização do segmento da Cultura Viva do Rio Grande do Sul. 


\section{TATIANA APARECIDA BALEM}

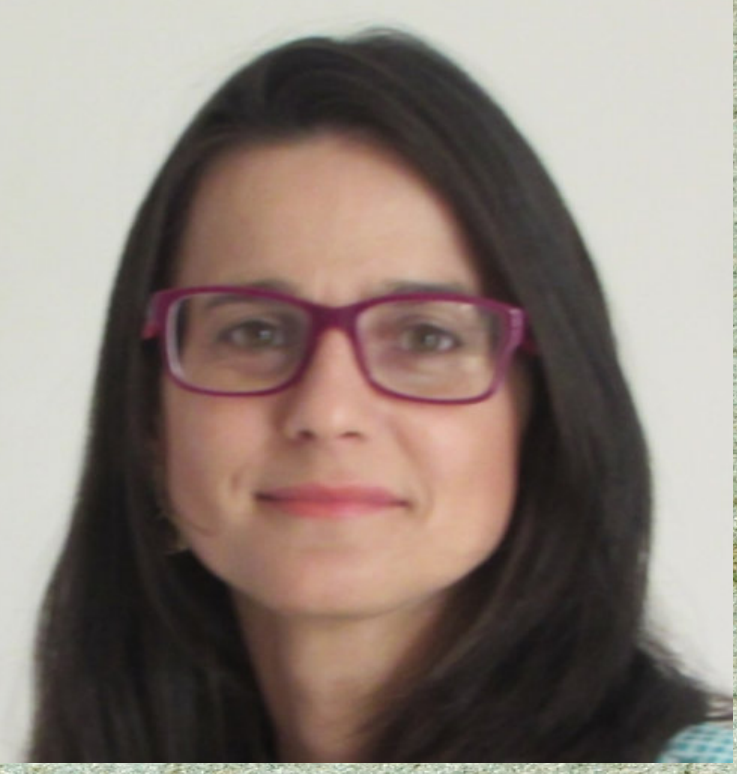

Tatiana Aparecida Balem é Doutora (2015) e mestre em Extensão Rural (2004) pela Universidade Federal de Santa Maria (UFSM), é graduada em Agronomia (2001) e possui curso de Formação de Professores para a Educação Profissional pelo Programa Especial de Graduação (PEG) (2011) também da UFSM. Atuou como assessora de Desenvolvimento Rural na Prefeitura Municipal de Santa Maria de janeiro de 2001 a janeiro de 2002. De fevereiro de 2002 a fevereiro de 2008, atuou como Extensionista Rural de Nivel Superior da Emater/RS/Ascar nos municípios de Tupanciretã e Quevedos. Desde fevereiro de 2008, atua como professora de Educação Básica, Técnica e Tecnológica no Instituto Federal Farroupilha, campus Júlio de Castilhos. Sua área de atuação é desenvolvimento rural, extensão rural, agroecologia, gestão ambiental, políticas públicas, Agricultura Familiar, sociologia rural e sociologia da alimentação. Atualmente é Coordenadora do Núcleo de Estudos em Agroecologia- NEA JC. 


\section{SOBRE AS AUTORAS E OS AUTORES}

\section{Abel Perinazzo Cassol}

Doutor em Sociologia (UFRGS). Professor do Departamento de Sociologia e Antropologia da Universidade Federal do Maranhão (UFMA).

E-mail:abelcassol@hotmail.com

\section{Carmen Viana Ramos}

Nutricionista. Doutora. Docente do Mestrado em Saúde da Familia do Centro Universitário Uninovafapi.

\section{Carina Aparecida Pinto}

Nutricionista, Mestra e Doutoranda em Ciência da Nutrição pela Universidade Federal de Viçosa.

Email: carinapinto2001@yahoo.com.br

\section{Cilene da Silva Gomes Ribeiro}

Nutricionista, Douttora em História e Mestre em Engenharia de Produção. Professora Titular da Pontifícia Universidade Católica do Paraná.

E-mail: Cilene.silva@pucpr.br

\section{Camila Gonçalves de Oliveira Rodrigues}

Professora Associada da Universidade Federal Rural do Rio de Janeiro. Líder do grupo Observatório de Parcerias em Áreas Protegidas.

E-mail: camila.rodrigues.ufrij@gmail.com

\section{Dayane de Castro Morais}

Nutricionista, Mestra e Doutora em Ciência da Nutrição. Pós-doutoranda no Departamento de Nutrição da Universidade Federal de Viçosa.

E-mail: dayanecm@yahoo.com.br

\section{Elizangela da Silva Miguel}

Nutricionista, Mestra em Agroecologia e Doutoranda em Ciência da Nutrição pela Universidade Federal de Viçosa.

E-mail: elizangela.miguel@ufv.br 


\section{Jersica Martins Bittencourt}

Nutricionista, Mestranda em Agroecologia pela Universídade Federal de Viçosa.

E-mail: jersicamartinsbittencourt@gmail.com

\section{Katharina Eduarda Rocha Lima}

Academicas do Curso de Nutrição do Centro Universitário Uninovafapi.

\section{Kathleen Hodgson Weintraub}

Mestre em Práticas em Desenvolvimento Sustentável - Universidade Federal Rural de Rio de Janeiro. Brasil. Email: khweintraub@gmail.com

\section{Katia Cilene Tabai}

Professora Titular. Universidade Federal Rural do Rio de Janeiro - UFRRJ. Líder do Grupo de Pesquisa de Segurança Alimentar e Nutricional (SAN) do CNPq. Email: ktabai@ufrrj.br

\section{Letícia Paludo Vargas}

Doutora em Extensão Rural (UFSM). Docente do Programa de Mestrado e Doutorado em Desenvolvimento Regional da Universidade do Contestado (UnC).

E-mail: leticia.vargas@professor.unc.br

\section{Lya Raquel Mendes da Rocha}

Academicas do Curso de Nutrição do Centro Universitário Uninovafapi.

\section{Letícia Mazza Malta}

Academicas do Curso de Nutrição do Centro Universitário Uninovafapi.

\section{Mario Duarte Canever}

Doutor em Administração, ênfase em Agronegócio (Wageningen University). Docente do Programa de Pós-Graduação em Desenvolvimento Territorial e Sistemas Agroindustriais da UFPel.

E-mail: caneverm@gmail.com.

\section{Patrícia Martins da Silva}

Doutorado em Agronomia (UFPel). Professora do Departamento DCSA/FAEMI UFPel. Email: patrícia.silva@ufpel.edu.br 


\section{Sílvia Oliveira Lopes}

Nutricionista, Mestra em Agroecologia e Doutoranda em Ciência da Nutrição pela Universidade Federal de Viçosa (UFV).

Email: silvia.lopes.nut@hotmail.com

\section{Suzana Maria Rebêlo Sampaio da Paz}

Nutricionista. Doutora em Saúde Pública - USP.

\section{Silvia Eloiza Priore}

Nutricionista, Mestra e Doutora em Nutrição pela Universidade Federal de São Paulo/Escola Paulista de Medicina. Prof a Titular do Departamento de Nutrição e Saúde e Coordenadora do Programa de Pós-graduação em Agroecologia da UFV. Email: sepriore@gmail.com

\section{Theonas Gomes Pereira}

Nutricionista. Doutora. Docente do Curso de Nutrição do Centro Universitário Uninnovafapi.

\section{Victória Teixeira Xavier}

Graduanda do Curso de Nutrição da Pontifícia Universidade Católica do Paraná. E-mail: victoria.teixeira@pucpr.edu.br. 
$2=$

www.arcoeditores.com

contato@arcoeditores.com (Jarcoeditores ( larcoeditores - C (55)99723-4952
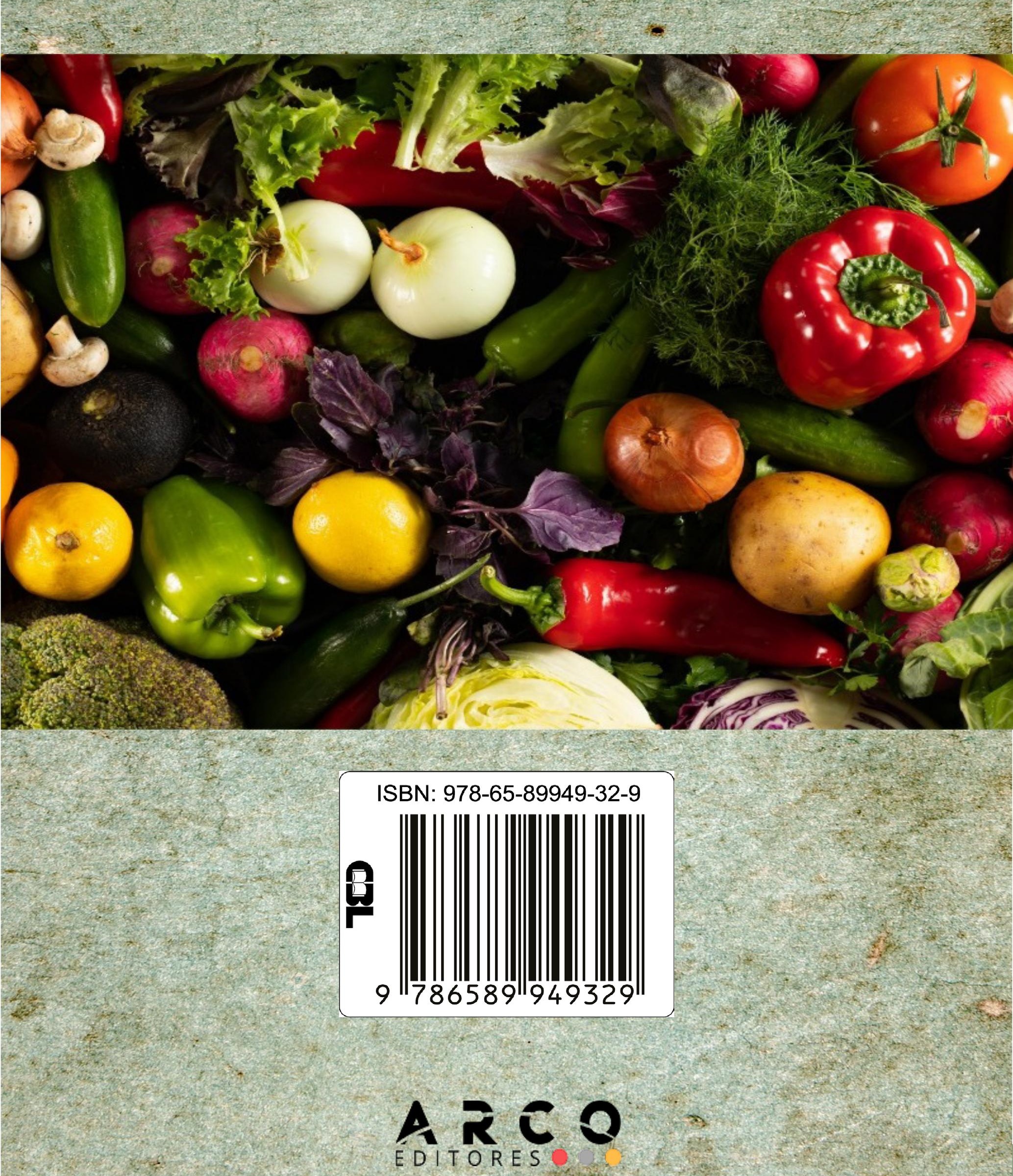